\title{
Third Annual Conference on Fire Research
}

Ileana M. Martinez, Editor

\author{
Center for Fire Research \\ National Engineering Laboratory \\ National Bureau of Standards \\ U.S. Department of Commerce \\ Washington, D.C. 20234
}

October 1979

Final Report

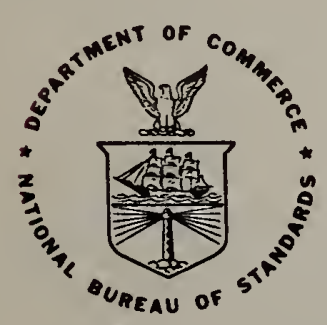

$Q C$

U.S. DEPARTMENT OF COMMERCE

NATIONAL BUREAU OF STANDARDS 

NBSIR 79-1916

$\because 4$

THIRD ANNUAL CONFERENCE ON FIRE RESEARCH

Ileana M. Martinez, Editor

Center for Fire Research

National Engineering Laboratory

National Bureau of Standards

U.S. Department of Commerce

Washington, D.C. 20234

October 1979

Final Report

U.S. DEPARTMENT OF COMMERCE, Juanita M. Kreps, Secretary Luther H. Hodges, Jr., Under Secretary Jordan J. Baruch, Assistant Secretary for Science and Technology NATIONAL BUREAU OF STANDARDS, Ernest Ambler, Director 

FOREWORD

When we began the Annual Conference on Fire Research two years ago, we did so in the belief that we were filling a need. It seemed that an effective research program requires some amount of direct interaction among its participants. Fire researchers are widely scattered and spring from many disciplines, so natural interaction is really not enough; for the moment it has to be fostered.

The 1979 Conference begins the second cycle of an approach which stresses fundamentals and the applied aspects of fire research in alternate years. This will be the first opportunity to build upon earlier conferences. We can check our progress as well as plot the future.

The Center staff believe it will be time well-spent. We hope the other Conference participants will share that view when the Conference is over. The real payoff, however, will be in the new ideas and shared perceptions that all of us take home.

August 22, 1979

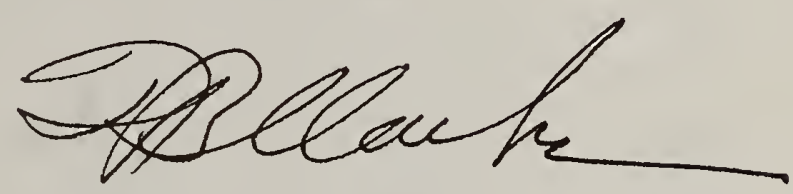

Frederic B. Clarke

Director

Center for Fire Research 


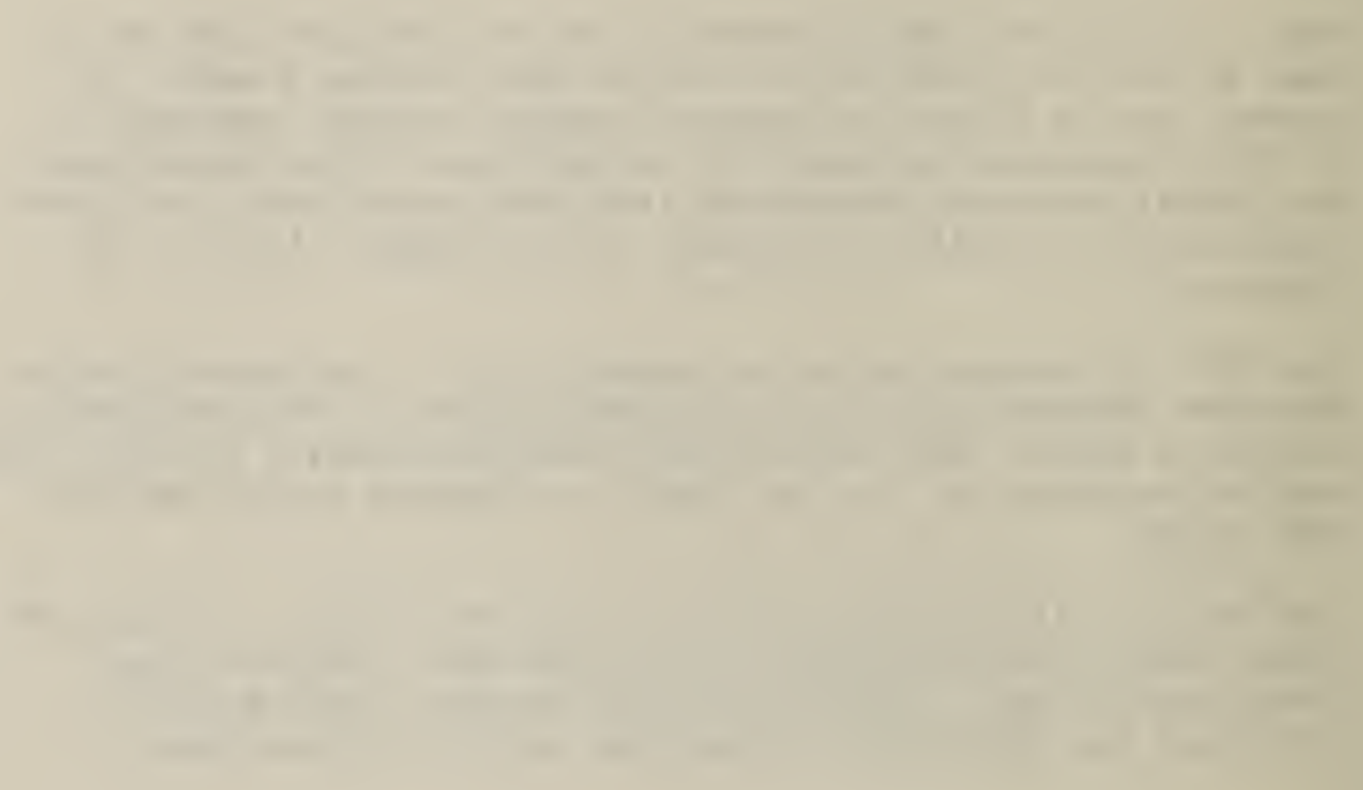




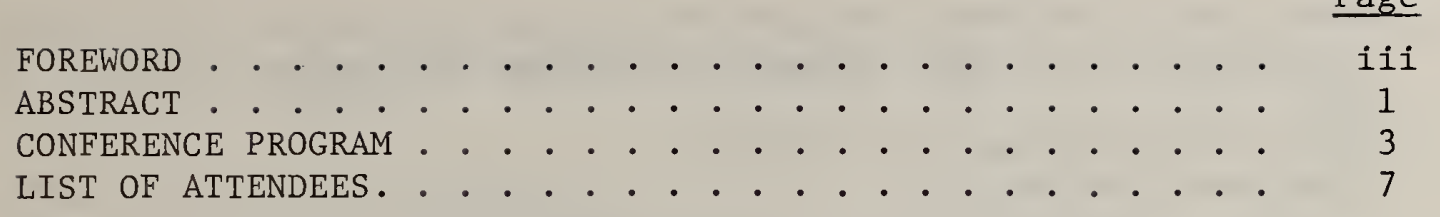

CENTER FOR FIRE RESEARCH PROGRAMS. . . . . . . . . . . . . 15

Hazard Analysis and Fire Information . . . . . . . . . 17

Fire Chemistry Research. . . . . . . . . . . . 20

Fire Physics Research. . . . . . . . . . . . . 24

Fire Toxicology Research . . . . . . . . . . . . 28

Product Flammability Research. . . . . . . . . . . 31

Furnishings Flammability Research. . . . . . . . . . . 33

Construction Fire Research . . . . . . . . . . . 37

Fire Protection Systems Research . . . . . . . . . . 42

Design Concepts Research . . . . . . . . . . . . 47

Ad Hoc Working Group on Mathematical Fire Modeling . . . . 52

Arson Control Project. . . . . . . . . . . . . 53

Large Scale Fire Research Facilities . . . . . . . . . 54

CONTRACTS AND GRANTS

Brown University

Flame Propagation and Extinction for Solid Fuels. . . 59

Brunswick Corporation

Experimental Studies on Pyrolytic Aerosols and

Fire Detectors. . . . . . . . . . . . . . .

California Institute of Technology

Experimental Study of Environment and Heat Transfer

in a Room Fire. . . . . . . . . . . . . . . 66

Clemson University

Antimony Oxide-Organohalogen-Polymer Substrate

Interactions in the Solid Phase . . . . . . . . . 
Factory Mutual Research Corporation

Determination of Fuel Parameters for Fire Modeling . . . .

Factory Mutual Research Corporation

The Home Fire Project. . . . . . . . . . . . . . . .

Georgia Institute of Technology

Investigation of Smoke Formation by Polymeric Matertials:

Smoke Reduction Methods and Chemical Characterization. . .

Harvard University

The Home Fire Project. . . . . . . . . . . . . . .

81

IIT Research Institute

Preflashover Room Fire Model: Parametric Sensitivity

Analysis and Development of a Submodel for Burning

Furniture Items. . . . . . . . . . . . . . . . .

The Johns Hopkins University

Evaluation of Toxicity of Combustion Products. . . . . .

The Johns Hopkins University

Fire Casualties Study . . . . . . . . . . . . . .

The Johns Hopkins University

Fire Problems Research and Synthesis, Combustion Research.

Lawrence Berkeley Laboratory

Fire Growth Experiments - Toward a Standard Room

Fire Test. . . . . . . . . . . . . . . . . .

Lawrence Berkeley Laboratory

Fire Modeling. . . . . . . . . . . . . . . . . . .

Lawrence Berkeley Laboratory

Polymer Combustion and Flame Chemistry . . . . . . . .

Lawrence Berkeley Laboratory

Thermal Radiation of Luminous Flames and Smoke . . . . .

Loyola University of Chicago

Behavioral Analysis of the Life Safety Code. . . . . .

National Electrical Manufacturers Association

NEMA Fluid Filled Transformer Flammability Study . . . .

National Fire Protection Association

Investigation and Analysis of Major Fires. . . . . . . 
North Carolina State University

Occupant Responses Variability in Escape from

Residential Fires. . . . . . . . . . . . . . . .

Pennsylvania State University

An Investigation of Fire Impingement on a Horizontal

Ceiling. . . . . . . . . . . . . . . . . . .

Princeton University

An Experimental Investigation of Flame Spread Over

Condensed Combustibles: Gas Phase Interactions. . . . .

Princeton University

Smoldering Combustion Studies. . . . . . . . . . . .

SRI Internationa1

The Effect of Fire Retardants on the Heat Release Rate of Building Materials . . . . . . . . . . . . . . .

SRI Internationa1

Continuation of Decision Analysis Studies in Fire

Hazard Analysis. . . . . . . . . . . . . . . . .

SRI International

Polymer Degradation During Combustion. . . . . . . . . 136

Underwriters Laboratories, Inc.

Measurement of Air Flow Around Doors Under Standardized

Fire Test Conditions . . . . . . . . . . . . . .

University of Arizona

Evaluation of the Combustion Toxicology of Several

Polymeric Materials. . . . . . . . . . . . . . 140

University of California (San Diego)

Studies of Flame Extinction in Relationship to Fire

Suppression. . . . . . . . . . . . . . . . . .

University of Florida

Network Models of Building Evacuation. . . . . . . . 151

University of Maryland

The Determination of Behavior Response Patterns in Fire

Situations, Project People II. . . . . . . . . . 153

University of Massachusetts

Flame Suppression by Chemical Inhibitors . . . . . . . . 158 
University of Massachusetts

Waking Effectiveness of Household Smoke and Fire Alert

Detector Devices . . . . . . . . . . . . 164

University of Montana

Ignition and Fire Spread of Cellulosic Materials . . . 168

University of North Carolina, Chapel Hill

The Psychology of Arson: Theoretical Analyses with

Suggestions for Application. . . . . . . . . . . 173

University of Notre Dame

Fire and Smoke Spread. . . . . . . . . . . . 175

University of Pittsburgh

Toxicity of Plastic Combustion Products. . . . . . . 177

University of Utah

Indepth Considerations of the Toxicological Effects of

Combustion Products. . . . . . . . . . . . . 182 
THIRD ANNUAL CONFERENCE ON FIRE RESEARCH

August 22-24, 1979

Ileana M. Martinez, Editor

\begin{abstract}
This report contains extended abstracts of grants and contracts for fire research sponsored by the Center for Fire Research, National Bureau of Standards, as well as descriptions of the internal programs of the Center for Fire Research.
\end{abstract}

Key words: Chemistry of fire; combustion products: fire hazards; fire modeling; fire research; human behavior in fires; physics of fire; toxicity of combustion products.

Note: The Annual Conference on Fire Research held August 22-24, 1979 marked the third time the Center for Fire Research sponsored such an event. This year, the Conference stressed the more fundamental aspects of fire research, in particular the chemistry and physics of fire. Topics discussed included smoldering combustion, smoke and radiation, ignition and inhibition, enclosure modeling and fire spread.

These basic aspects of fire research are only a part of all grants sponsored by the Center for Fire Research. The Conference is devoted in alternate years to the basic and applied aspects of fire research. For the sake of completeness however, this publication includes abstracts of all our internal and extramural activities in an attempt to give an overview of our work. 

ANNUAL CONFERENCE ON FIRE RESEARCH

Center for Fire Research

National Engineering Laboratory

National Bureau of Standards

August 22, 23, 24, 1979

Tuesday, August 21

7:00 p.m. Registration and Informal Reception

Sheraton Potomac Inn, Rockville, Maryland

Wednesday, August 22

8:15 a.m. Registration, Green Auditorium Lobby

9:00 a.m. Opening Session, Green Auditorium

Dr. C. Huggett - Deputy Director, Center for Fire Research

9:15 a.m. Smoldering Combustion - Dr. F. Rogers, Princeton University, Session Leader

Expository Talk: Smoldering Combustion - Dr. R. Gann, CFR/NBS

Effect of Some Additives on Smolder Characteristics of Loose-F111 Cellulosic Insulation - Dr. T. Ohlemiller, Princeton University

10:30 a.m. Coffee Break, Employee Lounge

11:00 a.m. Smoldering Combustion (cont'd)

Survey of Smolder and Flame Inhibition by Inorganic Powders-Mechanisms of Inhibition by Sulfur Dr. R. McCarter, CFR/NBS

Smoldering Combustion of Cellulosic Materials Professor F. Shafizadeh, University of Montana

An Investigation of the Mechanism of Smolder Resistance in Cellulose by Molecular Sulfur - Dr. W. Earl, CFR/NBS

12:00 noon Future Directions of Fire Research Dr. F. Clarke - Director, Center for Fire Research

12:30 p.m. Lunch, NBS Cafeteria 
Wednesday, August 21 (cont'd)

1:30 p.m. Smoke/Radiation - Dr. G. Mulholland, CFR/NBS, Session Leader

Expository Talk: Optical Techniques for Studying the Formation and Growth of Soot Particles Professor A. D'Alessio, University of Naples

The Role of Ions in Soot Formation - Dr. K. Smyth, CFR/NBS

Fire Modeling - Professor P. Pagni, University of California (Berkeley)

Soot Absorption and Scattering - Professor C. Tien, University of California (Berkeley)

3:20 p.m. Coffee Break, Employee Lounge

3:50 p.m. Smoke/Radiation (cont'd)

Study of Radiation from Flames and Smoke Layers -

Dr. A. Modak, Factory Mutual Research Corporation

Radiation from Pool Fires - Dr. A. Modak, Factory Mutual Research Corporation

Investigation of Smoke Formation of Polymeric Materials Professor B. Zinn and Professor R. Browner, Georgla Institute of Technology

Experimental Studies on Pyrolytic Aerosols and Fire Detectors - Dr. R. Chuan, Brunswick Corporation

Generation and Characterization of Carbonaceous Aerosols Dr. G. Mulholland, CFR/NBS

6:30 p.m. Wine and Cheese Party 
9:15 a.m. Ignition/Inhibition - Professor M. Drews, Clemson University, Session Leader

Flame Structure Measurement of Polymer Diffusion Flames W. Pitz, University of California (Berkeley)

Ignition and Low Pressure Flame Propagation of Polymers Dr. W. Berl, Johns Hopkins University/Applied Physics Laboratory

Antimony 0xide-Organohalogen-Polymer Substrate Interactions in the Solid Phase - Professor M. Drews, Clemson University

Fuel Parameters for Fire Modeling - Dr. A. Tewarson, Factory Mutual Research Corporation

10:40 a.m. Coffee Break, Employee Lounge

11:10 a.m. Ignition/Inhibition (cont'd)

Effect of Sample Orientation on Radiative Ignition Dr. T. Kashiwagi, CFR/NBS

Spontaneous Ignition of Coal - Dr. G. Mallard, CFR/NBS

Studies of Flame Extinction in Relationship to Fire Suppression - Professor A. Gordon, University of California (San Diego)

12:30 p.m. Lunch, NBS Cafeteria

1:30 p.m. Enclosure Modeling/Flame Spread - Dr. J. de Ris, Factory Mutual Research Corporation, Session Leader

Expository Talk: Enclosure Fire Modeling - Some Fundamentals and Some Applications - Dr. J. Quintiere, CFR/NBS

Flame Spread in Opposed Flow: Thermal and Kinetic Considerations - Dr. A. C. Fernandez-Pe1lo, Princeton University

Burning Rates and Extinction Limits: Measurements and Calculations - Professor M. Sibulkin, Brown University

Burning of Pool Fires in Vitiated Air - Dr. J. de Ris, Factory Mutual Research Corporation

3:20 p.m. Coffee Break, Employee Lounge 
Thursday, August 23 (cont'd)

3:50 p.m. Enclosure Modeling/Flame Spread (cont ${ }^{\circ} d$ )

Field Equation Modeling of Nonlinear Convection in Room Fires - Dr. R. Rehm, Center for Applied Math, NBS

Modeling of Smoke Dynamics - Dr. G. Mulholland, CFR/NBS

The Theory of Boundary Layer Burning with Radiation Jana Backovsky, Harvard University

Data for Fire Modeling, Professor H. Emmons - Harvard University

6:00 p.m. Volley Ball Game - Modelers vs Measurers followed by Barbecue at Smokey Glen Farm

Eriday, August 24

9:00 a.m. Continuation of Enclosure Modeling/Flame Spread - Dr. J. de Ris, Factory Mutual Research Corporation, Session Leader

An Investigation of Fire Impingement on A Horizontal Ceiling - Professor G. Faeth, Penn State University

Experimental Study of the Environment and Heat Transfer in a Room Fire - Professor T. Kubota, California Institute of Technology

Some Correlations for Room Fire - Dr. B. McCaffrey, CFR/NBS

Fire Induced Flows through Enclosure Openings - K. Steckel, Armstrong Cork/CFR

Modeling of Avallable Egress Time from Buildings - Dr. L. Cooper, CFR/NBS

10:4u a.m. Coffee Break, Employee Lounge

Il:10 a.m. Enclosure Modeling/Flame Spread (cont'd)

Development of a Burning Furniture Model - Dr. R. Pape, IIT Research Institute

Fire and Smoke Spread - Professor K. Yang, University of Notre Dame

12:00 noon Summary of Meeting - Dr. C. Huggett, CFR/NBS

12:30 p.m. Lunch, NBS Cafeteria

l:30 p.m. Visit NBS 
ANNUAL CONFERENCE ON FIRE RESEARCH

Center for Fire Reseach

National Engineering Laboratory

National Bureau of Standards

August 22, 23, 24, 1979

LIST OF ATTENDEES

ADORJAN, Alex, Pullman Kellogg, Three Greenway Plaza East, Houston, TX 77046

AFFENS, Dr. Wilbur A., Naval Research Laboratory, Code 6180, Washington, D.C. 20375

ALVARES, Norman J., Lawrence Livermore Laboratory, P.0. Box 5505, Livermore, CA 94550 ALTENKIRCH, Robert A., University of Kentucky, Dept of Mechanical Engineering, Lexington, KY 40506

AMBROSE, Jim, Virginia State Fire Marshal's Office, B1dg. 13, Suite 143, Koger Exec. Center, Norfolk, VA 23502

ANDERSEN, Donald, E. I. duPont de Nemours, Experimental Station, Wilmington, DE 19898 ANDERSON, Robert W., Diversified Insulation, Inc., P.O. Box 188, Hamel, MN 55340 BACKOVSKY, Jana, Harvard University, Engineering Sciences Lab, 40 Oxford St., Cambridge, MA 02138

BANKSTON, C. Perry, Jet Propulsion Laboratory, 4800 Oak Grove Dr., M.S. 67-201, Pasadena, CA 91103

BELLAN, Dr. J., Jet Propulsion Lab - Boeing, 4800 Oak Grove Drive, Mail Code 67-201, Pasadena, CA 91103

BENJAMIN, Irwin, Center for Fire Research, NBS

BERL, W. G., APL, Johns Hopkins University, Laurel, MD 20810

BIRKY, Merritt, Center for Fire Research, NBS

BLAIR, John A., DuPont Company, PP\&R - TSL, Chestnut Run, Wilmington, DE 19898

BOGNER, Chuck, DOT, Cambridge, MA 02142

BRIGHT, Richard, Center for Fire Research, NBS

BROWNER, Richard F., Georgia Institute of Technology, School of Chemistry, Atlanta, GA 30332 
BRYAN, Dr. John L., Fire Protection Engineering, University of Maryland, College Park, MD 20742

BUCHBINDER, Ben, Center for Fire Research, NBS

BUDNICK, Edward, Center for Fire Research, NBS

BURGESS, Bruce A., E.I. duPont de Nemours Co., Haskell Laboratory, E1kton Road, Newark, DE 19711

CAMME, Daniel, Brick Institute of America, 1750 01d Meadow Road, McLean, VA 22102

CHEN, Houston D., Brunswick Defense Division, Advanced Programs, 3333 Harbor Blvd., Costa Mesa, CA 92626

CHIPPETT, Simon, Union Carbide Corp, P.0. Box 8361, So. Charleston, WV 25303

CHRISTIAN, Wm. J., Underwriters Laboratories, Northbrook, IL 60062

CHUAN, Raymond L., Brunswick Corp, 3333 Harbor Blvd., Costa Mesa, CA 92626

CLARKE, Frederic, Center for Fire Research, NBS

COOPER, Leonard, Center for Fire Research, NBS

D'ALESSIO, Antonio, Laboratorio Ricerche Combustione, C.N.R., Universita di Napoli, 80125 Napoli, Italy

DANIHER, Dr. Frank A., Velsicol Chemical Corp, 1975 Green Road, Ann Arbor, MI 48105 DARR, William, Mobay Chemical Corp, Penn-Lincoln Parkway West, Pittsburgh, PA 15205

DATTA, A., U.S. Coast Guard R\&D Center, Avery Point, Groton, CT 06340

DAVIS, Sanford, Center for Fire Research, NBS

DE RIS, Dr. John, Factory Mutual Research Corporation, 1151 Boston-Providence Turnpike, Norwood, MA 02062

DREWS, Dr. Michael J., Textile Dept, Clemson University, Clemson, SC 29631

DUNLAP, Bill, Dow Chemical, P.0. Box 515, Granville, OH 43023

DYER, Dr. John H., The Ansul Company, One Stanton Street, Marinette, WI 54143

EARL, William, Center for Fire Research, NBS

EDELSON, Dr. David, Bell Laboratories, 600 Mountain Ave., Murray Hill, NJ 07974

EDWARDS, John C., U.S. Bureau of Mines, 4800 Forbes Ave., Pittsburgh, PA 15213

EICHER, W.J., Mobay Chemical Corp, Penn-Lincoln Parkway West, Pittsburgh, PA 15205 
EKLUND, Thor I., DOT/FAA/NAFEC, Tilton Rd., Atlantic City, NJ 08405

ELWING, David R., Veterans Administration, 810 Vermont Ave., NW, Washington, D.C. 20420 EMMONS, Howard W., Harvard University, Pierce Hall, Cambridge, MA 02138

ESCH,Victor H., M.D., Chief Surgeon, D.C. Fire Dept, C/o Police \& Fire Clinic, \#1 D.C. Village Lane, S.W., Washington, D.C. 20032

EVANS, Dave, Center for Fire Research, NBS

FAETH, G.M., Pennsylvania State University, 214 M.E. Bldg., University Park, PA 16802

FERNANDEZ-PELLO, A. Carlos, Princeton University, M.A.E. Dept, Engineering Quad., Princeton, NJ 08540

FISH, Doug, DuPont Company, 1007 Market St., Wilmington, DE 19898

FITCH, Wm. E., Owens Corning Fiberglas, Toledo, OH 43659

FRIEDMAN, Raymond, Factory Mutual Research, 1151 Boston-Providence Turnpike, Norwood, MA 02062

FU, Tim T., Navy, CEL/NCBC, Port Hueneme, CA 93043

FULMER, Glen, W.R. Grace \& Co., 7379 Rte. 32, Columbia, MD 21044

FUTRELL, Jean H., Flammability Research Center, 391 S. Chipeta Way, Suite E, University of Utah, Salt Lake City, UT 84112

GALlOWAY, John R., DuPont Company, 1007 Market St., Wilmington, DE 19898

GANN, Richard, Center for Fire Research, NBS

GLASSMAN, Irvin, Princeton University, Dept of Mechanical and Aeronautical Engr, Princeton, NJ 08540

GLOWINSKI, Robert W., National Forest Products, 1619 Mass Ave., N.W. Washington, D.C.20036

GOONAN, Thomas E., G.S.A., 18th \& F St., N.W., 非1014, Washington, D.C. 20405

GORDON, Alvin S., Professor, AMES Dept, UCSD, AMES, B-010, University of California San Diego, La Jolla, CA 92093

GRIMADO, P.B. (Phil), Bell Laboratories, North Road, Chester, NJ 07930

HANUSA, L. H., Mobay Chemical Corp, Penn-Lincoln Parkway West, Pittsburgh, PA 15205 
HARTZELL, Dr. Gordon E., Southwest Research Institute, 6220 Culebra Rd., P.0. Drawer 28510, San Antonio, TX 78284

HATHAWAY, William T., U.S. Dept of Transportation, Kendall Sq., Cambridge, MA 02142 HERTZBERG, Martin, Dept of Interior, Bureau of Mines, 4800 Forbes Ave., Pittsburgh, PA 15332

HESKESTAD, Gunnar, Factory Mutual Research, 1151 Boston-Providence Hwy, Norwood, MA 02062

HILLSTROM, Dr. W., U.S. Army Ballistic Research Laboratory, Aberdeen Proving Ground, MD 21005

HOKE, Charles, Uniroyal, Inc., $312 \mathrm{~N}$. Hill St., Mishawaka, IN 46544

HUGGETT, Clayton, Center for Fire Research, NBS

ISSEN, Lionel, Center for Fire Research, NBS

JACISIN, J. M., Bell Laboratories, North Road, Chester, NJ 07930

JARVIS, Dr. Chris, Clemson University, Dept of Textiles, Clemson, SC 29631

JONES, Everett B., US Navy, Naval Safety Center, NAS, Norfolk, VA 23511

KANAKIA, Mike, Southwest Research Institute, 6220 Culebra Rd, San Antonio, TX 78284

KASHIWAGI, Takashi, Center for Fire Research, NBS

KEHR, Clif, W. R. Grace \& Co., 7379 Rt 32, Columbia, MD 21044

KENNEDY, Thomas E., Defense Nuclear Agency, Washington, D.C. 20305

KENT, Ronald, Boise Cascade, Insulite Div., International Falls, MN

KERR, James W., FEMA, P.0. Box 4073, Falls Church, VA 22044

KRACKLAUER, Jack, Arapahoe Chemicals, Inc., 2075 N. 55th St., Boulder, C0 80301

KRAFTHEFER, Brian, Honeywell, Honeywell Plaza, Minneapolis, MN 55408

KUBOTA, Dr. Toshi, California Institute of Technology, Pasadena, CA 91125

LABES, Willis G., Professor Emeritus, Illinois Institute of Technology, RFD 非, Box 464, Charlottesville, VA 22901 
LAND, Richard, Harvard University, Engineering Sciences Laboratory, 40 Oxford St. Cambridge, MA 02138

LEE, James, Factory Mutual Research Corp, 1151 Boston-Providence Turnpike, Norwood, MA 02062

LEVIN, Bernard, Center for Fire Research, NBS

LEVINE, Robert, Center for Fire Research, NBS

LIE, T. T., National Research Council Canada, Montreal Rd., Ottawa, Ontario, Canada LIPSKA, Anne, Lawrence Livermore Laboratory, P.0. Box 5505, Livermore, CA 94550

LLOYD, John R., University of Notre Dame, Aerospace \& Mechanical Engr., Notre Dame, IN 46556

MAC DOUGALL, Ed, B.N.L., Bldg. 130, Upton, L.I., NY 11973

MC CAFFREY, Bernard, Center for Fire Research, NBS

MC CARTER, Robert, Center for Fire Research, NBS

MAGNUSSON, Sven E., Lund Institute of Technology, Division of Structural Mechanics, Fack 725, 22007 Lund 7, Sweden

MALLARD, Gary, Center for Fire Research, NBS

MARGEDANT, DuPont Company, 1007 Market St., Wilmington, DE 19898

MARTIN, Stan, SRI, 333 Ravenswood Ave., Menlo Park, CA 94025

MARTINEZ, Ileana, Center for Fire Research, NBS

MERTENS, John M., Illinois Institute of Technology, $10 \mathrm{~W}$. 32nd St., Chicago, IL 60616

MILKE, Jim, University of Maryland, Dept of Fire Protection Engineering, College Park, MD 20742

MITLER, Henri E., Harvard University, Engineering Sciences Laboratory, 40 Oxford St., Cambridge, MA 02138

MODAK, Ashok, Factory Mutual Research Corp., Norwood, MA 02062

MULHOLLAND, George, Center for Fire Research, NBS

MURCH, Robert, W.R. Grace \& Co., 7379 Rte 32, Columbia, MD 21044

NELSON, Harold (Bud), Center for Fire Research, NBS

OHLEMILLER, T.J., Princeton University, Guggenheim Lab, Forrestal, Princeton, NJ 08544 
OLSON, D.B., AeroChem Research Lab, P.0. Box 12, Princeton, NJ 08540

PAGNI, Prof. Patrick J., Mechanical Engineering Dept, University of California, Berkeley, CA 94720

PAPE, Ronald, IIT Research Institute, 10 W. 35th St., Chicago, IL 60616

PARKAN, Dr. C., The University of Calgary, Canada, Alberta T2N 1 44 Canada

PARKER, William, Center for Fire Research, NBS

PENKAVA, T.R., Mobay Chemical Corp, Penn-Lincoln Parkway West, Pittsburgh, PA 15205

PERKINS, Lowell R., E.I. duPont de Nemours, Inc., Dupont Experimental Station, Bldg. 353/202, Wilmington, DE 19898

PITZ, Bill, University of California, Berkeley, 65 Hesse Ct. Yd., Berkeley, CA 94720 PUNDERSON, Dr. John O., DuPont, P.0. Box 1217, Parkersburg, WV 26101

QUINTIERE, James, Center for Fire Research, NBS

REHM, Ronald G., Center for Applied Math, NBS

REUTHER, Prof. James J., Fuel Science Section, The Pennsylvania State University, 320 Steidle Bldg., University Park, PA 16802

ROBERTSON, Alex, Center for Fire Research, NBS

ROBINS, Robert F., Hardwood Plywood Mfgrs Assoc, 1825 Michael Faraday Drive, Reston, VA 22090

ROGERS, Frank, Princeton University, Guggenheim Labs, Princeton, NJ 08544

SCHEFFEY, Joe, Rolf Jensen \& Associates, Inc., 5803 Rolling Rd, Springfield, VA 22124

SCHWARCZ, Dr. Joseph M., N.L. Chemicals, P.O. Box 700, Hightstown, NJ 08520

SHAFIZADEH, Dr. Fred, University of Montana, Wood Chemistry Laboratory, University of Montana, Missoula, MT 59812

SIBULKIN, Merwin, Brown University, Division of Engineering, Providence, RI 02912

SIMONELLI, Richard A., General Electric Plastics Div., 1 Plastics Ave, Pittsfield, MA 01201

SINGER, Joseph M., Department of the Interior, Bureau of Mines, 4800 Forbes Avenue, Pittsburgh, PA 15213

SMYTH, Kermit, Center for Fire Research, NBS 
SPARKES, Charles J., Arapahoe Chemicals, Inc., 2075 N. 55th St., Boulder, C0 80301 STECKLER, Kenneth D., Armstrong Cork, Center for Fire Research, NBS

STROBRIDGE, Thomas R., National Bureau of Standards, Thermophysical Properties Division 736.1, 325 Broadway, Boulder, CO 80303

TEWARSON, Archibald, Factory Mutual Research Corp, 1151 Boston-Providence Turnpike Norwood, MA 02062

TIEN, Chang-Lin, University of California, Berkeley, CA 94720

TOVEY, U. S. Fire Administration, P.O. Box 19518, Washington, D.C. 20036

TROHA, Charles C., Fire Safety Consultant, 7100 Saunders Ct., Bethesda, MD 20034

TUFTS, Richard B., Maryland Casualty Co, P.O. Box 1228, Baltimore, MD 21203

ULLRICH, George W., Defense Nuclear Agency, Washington, D.C. 20305

VANPEE, Marcel, University of Massachusetts, Chemical Engineering Dept, Amherst, MA 01003

VICKERY, Gordon, U. S. Fire Administration, P.O. Box 19518, Washington, D.C. 20036

WALKER, Joseph, US Air Force Fire Protection Research \& Development, Hq AFESC/RDCF, Tyndall AFB, FL 32403

WASZECIAK, Paul, The Upjohn Company, 410 Sackett Point Road, North Haven, CT 06473

WATERMAN, Thomas E., IIT Research Institute, 10 W. 35th St., Chicago, IL 60616

WEAVER, Betsy, International Association of Fire Chiefs, 1329 18th St., NW Washington, D.C. 20036

WIDENOR, W. M., Naval Ship R\&D Center, Code 2843, NSRDC, Annapolis, MD 21402

WILKINS, Dr. Mark A., Attache (Technology) British Embassy, 3100 Massachusetts Ave., NW, Washington, D.C. 20008

WINGER, James, Center for Fire Research, NBS

WRIGHT, G. Todd, Owens-Corning Fiberglas, Granville Technical Center, B76, Granville, OH 43023

YANG, K.T., University of Notre Dame, Notre Dame, IN 46556

YEH, Kwar, University of Maryland, 3107 Turner Lab, College Park, MD 20742

ZINN, Ben T., Georgia Tech, Atlanta, GA 30332 

CENTER FOR FIRE RESEARCH PROGRAMS 

HAZARD ANALYSIS AND FIRE INFORMATION

FIRE SCIENCE DIVISION

CENTER FOR FIRE RESEARCH

\section{$\underline{\text { Professional Personnel }}$}

Benjamin Buchbinder, Head

Alan Gomberg, Fire Prevention Engineer

Susan Helzer, Mathematician

Nora Jason, Technical Information Specialist

Stefan Leigh, Operations Research Analyst

James Slater, Mathematician

\section{Program Objectives}

The work carried on in this program is based on two major objectives. The first is to characterize fire hazards by analytical means and to evaluate strategies for reducing fire losses on a cost/benefit basis, both to help establish research priorities and to guide the development of test methods for codes and standards. The second objective is to expand and maintain a technical fire literature collection, to provide technical information services for the Center for Fire Research (CFR) and for the fire community at large, and to provide access to fire loss data for CFR.

\section{Project Areas}

1. Decision Analysis

Decisions on the choice between strategic alternatives for reducing fire losses should be based on a systematic consideration of all benefits, risks and costs. However, because of the complexity of safety problems and the uncertainties inherent in the evaluation of strategies for reducing accidental losses, the choice among strategies is difficult. We have developed analytical techniques for assessing the risks and avoided damages associated with different fire safety alternatives, and the economic costs of these alternatives. Decision analysis provides the analytical framework for the combination of these loss and cost assessments in choosing the most cost effective strategy for addressing a particular fire problem. The initial decision analysis study of alternatives for the reduction of upholstered furniture fire losses served to establish the utility of this approach for fire hazard applications. A major decision analysis study is underway on the residential fire problem. Decision analysis is also being applied in other fire safety areas including transformer fluids and rail transportation. 


\section{Special Studies}

The growth of the National Fire Data Center at the U.S. Fire Administration has provided more and better data for fire hazard analysis. Using these data as a basis, we perform special studies related to the characterization of specific fire hazards. Current special study topics include the following:

-Identification of factors associated with high fire death rates in rural areas and certain geographical areas.

-Feasibility of linkage of fire incident report files with demographic data bases, to permit future analysis of fire incident data as a function of population characteristics.

- Improvement of fire incident data through quality control in editing and data processing.

\section{Plastics Hazard Analysis}

Because of the proliferation of plastic products in the market place, the absence of detailed fire incident data for evaluating the flammability hazards of these products, and the relative inadequacy of existing test methods, a study was conducted to attempt to identify and characterize the role of plastics in real fire incidents. We collected case history reports based on a detailed questionnaire form and performed laboratory testing of samples retrieved at the fire scene. The study is restricted to accidental residential fires in which an identifiable plastic product was significantly involved, and for which the sequence of events is partially reconstructible. To evaluate the role of the products in the context of the actual fire, information was collected on the building environment and the people involved as well as general information regarding extinguishment, fire growth, property damage, etc. Laboratory characterization of the materials included generic composition, ignition temperature, melting point, density, and smoke production. More than 135 data elements are coded and entered on a computer file for each fire incident; information on a total of 175 cases has been collected. This data base is being used in conjunction with other data for special studies to extend our knowledge of the role of plastics in residential fires.

4. Fire Research Information Services (FRIS)

CFR has one of the world's foremost collections of fire research documents, collected to serve the broad information needs of the Center and the fire community. In addition to continued augmentation and maintenance of the collection, FRIS provides a full 
range of technical information services to the Center staff.

These services include bibliographic searches, inter-library loan and book purchases, and maintenance of a periodical reference collection of 120 United States and foreign journals on fire research and related fields. We are currently studying the feasibility of developing an automated storage and retrieval system for bibliographic references to our own document collection. The long range plan is to link this system with other major fire related information systems, such as those at U.S. Fire Administration and the National Fire Protection Association (NFPA).

\section{Associated Contract}

SRI International, Fred L. Offensed - "Continuation of Decision Analysis Studies in Fire Hazard Analysis": 
FIRE CHEMISTRY RESEARCH

FIRE SCIENCE DIVISION

CENTER FOR FIRE RESEARCH

\section{Professional Personnel}

Richard G. Gann, Head

Dusan Bakos̄, Guest Worker

William H. Ear1, Postdoctoral Research Associate

W. Gary Mallard, Research Chemist

Gerald D. Mitche11, Research Chemist

Michael J. Manka, Chemist

John W. Rowen, Physical Scientist

Kermit C. Smyth, Research Chemist

Ivan Špilda, Guest Worker

\section{Affiliated}

John W. Hastie, Center for Materials Science, NBS

Program Objectives

The objectives in Fire Chemistry Research are:

(1) to provide understanding of the chemical processes which are important in the development and control of unwanted fires: kinetics and thermodynamics of combustion, fuel structure and additive effects on flammability, ignition, flame spread and structure, generation of soot and combustion products, and fire retardance and extinction;

(2) to transmit that knowledge to other fire research groups and to the technical community at large for use in developing fire resistant materials, standard test methods and building design codes.

\section{Project Areas}

\section{Spontaneous Ignition of Coal}

In many instances fires begin or propagate when materials are heated, smolder for a while, and then burst into flame or ignite some other substance. A similar problem exists with the ignition of low-grade coals long before they reach their eventual destination. Hence, studies on the self-heating of materials have a dual potential to reduce both fire loss and energy waste. It is our intent to develop a scientifically based susceptibility index for materials prone to spontaneous ignition and to demonstrate the validity of this index as a basis for ranking these materials for fire hazard. 
We are currently using a third generation adiabatic furnace in conjunction with simultaneous TGA/DSC determinations. Our current data on two coals suggests that as the coal is heated from ambient temperature, dehydration begins and is soon joined by a single surface oxidation sequence. As the temperature continues to rise, the water is expended and the endothermic volatilization reaction slows as the exothermic oxidation increases in rate. We are now testing this model, developing a mathematical formalism to relate it to actual self-heating, studying the kinetics and investigating the use of faster, more reliable, easier to perform tests for characterizing a coal's self heating tendency.

\section{Flammability of Dielectric Fluids}

In a recent action, the Environmental Protection Agency (EPA) banned the use of polychlorinated biphenyls, thus eliminating the existing "non-flammable" insulating fluids for transformers and capacitors. We are conducting a study to comprehensively delineate the fluid's properties which determine its fire potential in these uses. The work has included establishing patterns in device failures, determination of the similarity of the (gray body) nature of flame emissions from silicone and hydrocarbon fluids, construction of a model for the ignition of nearby fuels by flaming airborne droplets, evaluation of safety alternatives on a cost-plus-loss basis (with the Decision Analysis staff), evaluation of the effect of corona degradation on a fluid's fire point, and working with the consensus and industry standards groups to evolve technically sound fire safety criteria and test methods. A final report is in preparation.

\section{NMR Studies of Combustion of Solids}

Jointly with the NBS Center for Materials Science, we are developing a capability in magic angle spinning, high resolution nuclear magnetic resonance (NMR) of solids. Our intent is to follow the degradation of natural and synthetic polymers using the ${ }^{13} \mathrm{C}$ nuclide. Studies of both polyethylene and cellulose have shown that conformational differences can be observed between chemically similar samples. Preliminary spectra of wood and the difference crystalline forms of pure cellulose have been obtained as a prelude to detailed studies on wood decomposition and smoldering combustion.

\section{Sulfur Smoldering Retardance Mechanisms}

According to current statistics, at least one-fourth of all fire deaths result from scenarios which include a non-flaming step. As a result, test methods are being developed to evaluate the smoldering performance of materials, and the need for smoldering inhibitors has been accentuated. Experiments in Fire Physics Research have shown that elemental sulfur is an effective smoldering inhibitor, and we are now studying the modes in which it works. Experiments to date 
have shown that sulfur in cotton batting eases ignitability under radiant flux and decreases the smoldering propagation rate and the smoldering front temperature. In addition sulfur dramatically reduces the free radical density in the solid. We have established that $\mathrm{H}_{2} \mathrm{~S}$ and $\mathrm{SO}_{2}$ (and by analogy mercaptans and organosulfates) are not responsible. "Rather, it appears that the sulfur itself vaporizes and attaches to the radical sites, thus preventing further carbon chain oxidation. Confirming experiments are in progress.

\section{Mechanism of Fire Retardancy of Polypropylene}

This project involved our two Slovak Guest Workers and represented continuation of work began in Bratislava. The first effort involved isotastic polypropylene (IPP) treated with different levels of each of four halogenated fire retardants. Samples were slowly pyrolyzed in a thermogravimetric apparatus, rapidly pyrolyzed into a flame ionization detector, and burned in an oxygen index apparatus in both $\mathrm{N}_{2} \mathrm{O}$ and air. A draft report has been written, interpreting the results in light of the different retardant structures. In the second effort, the weight loss of pure and fire-retarded IPP samples were determined during pool combustion in a modified oxygen index apparatus. A report is due in the fall.

\section{Opto-Galvanic Spectroscopy of Flames}

A joint effort within NBS has devised this laser-excitation technique in which atomic and molecular absorptions are detected by changes in flame conductivity rather than by changes in light intensity. The current objective is to explore its application to flame and combustion product analyses. We now understand the opto-galvanic mechanism reasonably well and flame species temperature measurements are becoming

feasible. A first-principles model for the temperature measurements has been drafted. Simultaneous and stepwise two-photon processes have been studied, advancing the earlier single-photon work.

\section{Mechanisms of Soot Formation}

We are beginning a long-term study of the basic chemistry that determines the formation and character of soot. This effort will be carried out jointly with the NBS Center for Mechanical Engineering and Process Technology. Fundamental issues to be considered are the relative importance of free radical and ionic mechanisms, the dependence on fuel chemistry, and the nature of soot precursors. Present experiments are concerned with two aspects. In the first, metal atoms are being added sooting flames. A fraction of these are ionized in situ using the opto-galvanic effect, and the resulting changes in the soot formed are observed. The result will be an assessment of the discrete role of metal ions in soot chemistry. The second study involves a laser-induced fluorescence observed in a variety of flames. The excitation spectra are independent of the fuel for a number of gaseous and solid fuels as 
well as whether the flame is premixed or diffusion controlled. The broad, structureless emission suggests a large fused ring structure or mixture of structures or large poly-enes. While the fluorescence correlates with whether the flame is sooting or near-sooting, it is not clear that the species is (are) a soot precursor. Further work is planned to clarify this relationship and better identify the species.

\section{Associated Grants and Contracts}

1. Clemson University, Michael J. Drews - "Antimony Oxide-OrganohalogenPolymer Substrate Interactions in the Solid Phase"

2. University of California (Berkeley), Robert F. Sawyer and Nancy J. Brown - "Polymer Combustion and Flame Chemistry"

3. University of Montana, Fred Shafizadeh - "Ignition and Fire Spread of Cellulosic Materials"

4. Univeristy of Massachusetts, James Chien and Marcel Vanpee - "Flame Suppression by Chemical Inhibitors"

5. Johns Hopkins University, Applied Physics Lab, Robert Fristrom and Lawrence Hunter - "Polymer Flammability and Flame Inhibition"

6. SRI International, Fred offensend - "Decision Analysis Studies: Transformer Fire Hazard Analysis"

7. Georgia Institute of Technology, Ben T. Zinn and Richard F. Browner "Investigation of Smoke Formation by Polymeric Materials: Smoke Reduction Methods and Chemical Characterization of Particulates"

8. SRI International, Sharon K. Brauman - "Polymer Degradation During Combustion"

9. National Electrical Manufacturers Association, John H. Motherway "NEMA Fluid Filled Transformer Flammability Study" 


\section{FIRE PHYSICS RESEARCH \\ FIRE SCIENCE DIVISION \\ CENTER FOR FIRE RESEARCH}

$\underline{\text { Professional Personnel }}$

John A. Rockett, Head

Howard R. Baum, Research Physicist

Daniel Corley, Physicist

Margaret Harkleroad, Physicist

Taksahi Kashiwagi, Material Engineer

Thomas G. K. Lee, Fire Protection Engineer

Bernard J. McCaffrey, Mechanical Engineer

Robert J. McCarter, Chemical Engineer

George W. Mulholland, Research Chemist

James G. Quintiere, Mechanical Engineer

Ronald Rehm, Mathematician (Center for Applied Mathematics, NBS)

Keneth Steckler, Research Associate

\section{Program Objectives}

1. Growth and Spread of Room Fires: To predict the growth and spread of fire in a room or a set of simply interconnected rooms.

2. Mathematical Models: Develop advanced mathematical models for various flow phenomena in fires.

3. Ignition: To identify and quantify the phenomenon related to flaming ignition of solid and liquid fuels.

4. Smoke Characterization: To study smoke formation and to develop techniques for producing well characterized and reproducible aerosols.

5. Smoldering: To identify and quantify the phenomenon related to smoldering combustion of (porous) solid fuels and to devise means of quantifying the smolder tendency of materials.

Project Areas.

1. Growth and Spread of Fire

The objective of this project is to improve predictions of fire behavior in a room. A quasi steady state model which relates the potential for flashover in a room to its combustible contents and thermal and ventilation characteristics has been developed and compared to experimental data. Predictions are qualitatively good; quantitative predictions range from fair to quite good. Data obtained for wood and high density polyurethane foam cribs has been compared with the model 
after inclusions of the effect of radiation from the crib to its surroundings, of flow entrainment by the crib, and of the effect of the hot vitiated layer sinking below the top of the crib.

Experimental work begun by McCaffrey and Cox at the Fire Research Station, Borehamwood, England, on the near field entrainment of diffusion flame is being continued. Results show significant differences between the measured plume quantities near the base of the plume where combustion is occuring and predictions based on current (far field) models. Above the flame zone, far field models give good agreement with our data.

Full scale experiments carried out during the past year provide more detail for model evaluation especially a check on the overall flow prediction and secondary flows around the door. Very good mass balances for the room have been obtained but only after repositioning the flow measuring probes to a door location where the streamlines were truly horizontal.

\section{Mathematical Models}

The objective of this project is to improve the capability and accuracy of fire models through the application of the most efficient mathematical techniques.

Three relatively separate activities have been pursued.

a. In most fire situations the Reynolds (or Grashof) number is large. This suggests that, as is true in other areas of high Reynolds number fluid flow analysis, an inviscid flow approximation should prove useful. Since for strongly buoyant flows the equations are quite non-linear, numerical methods are called for. A careful examination of several numerical schemes has been pursued with numerous cross comparisons with analytic solution of test problems to determine the accuracy and stability of the techniques as applied to this set of equations. A satisfactory solution algorithm has been developed. The ability of the inviscid analysis to represent practical fire problems will now be studied.

b. Containership operations only allow below-deck storage of containers carrying no hazardous cargo. However, scheduling economics are strongly affected by the definition of hazardous. It has been proposed to the International Maritime Consulting Organization (IMCO) that the present limitations on below-deck storage could be relaxed if forced hold ventilation were provided.

To examine this, a procedure for calculating the in-hold flows and combustible vapor concentrations for various ventilation schemes and accident scenarios has been developed. Experimental data from a 1/12 scale model confirmed the qualitative features of the analysis. At sea ship hold measurements confirm the assumptions of the anlysis throughout most of a typical Gulf Coast to Europe run. 
c. Jointly with the smoke characterization project aerosol calculations have been developed. These follow changes in aerosol size and number distributions as smoke is transported from a fire to a detector. Extensions of this work will be incorporated in the inviscid room flow calculations.

\section{Ignition}

The purpose of this project is to identify and document the important phenomenon related to ignition. Work to date has concentrated on radiation assisted ignition - to flaming combustion - of solid and liquid fuels. Additional data on energy absorption by evolved gases in the convective plume above the igniton target has been obtained. The simplyfing concept of a material dependent characteristic surface temperature for ignition has been found to be satisfactory for PMMA (about $400^{\circ} \mathrm{C}$ ) but quite poor for red oak (variable from about 400 to $600^{\circ} \mathrm{C}$ ). Current work has concentrated on other important parameters such as surface orientation, size, type and location. High speed motion pictures have shown complex surface motions of liquid fuels between the beginning of irradiation and ignition.

An associated program has been started to study turbulent combustion.

4. Smoke Characterization

The objective of this project is to improve the accuracy and capability of smoke characterizing instruments and apply this to improving fire detection and fire analysis.

Techniques developed for generation of controlled, reproducible aerosols of known size distribution have been applied to smoke detector standardization and testing. A prototype portable tester suitable for evaluation of installed smoke detectors has been built and is being field tested. Aerosol generators have been designed and built for several other special applications related to environmental control.

An analytical model of smoke aging in the buoyant plume above a fire has been developed. This will form a part of a larger study of detector siting and sensitivity now in progress.

Future work will focus more strongly on the mechanisms of smoke formation and the role of aerosol and particulates in flame radiation.

5. Smoldering

The objective of this project is to identify and quantify the phenomena related to smoldering combustion of (porous) solid fuels and to devise means of quantifying the smolder tendency of materials. Much of the recent effort has been directed at applied problems. 
During the past year the emphasis of this program has shifted from upholstery materials to blown cellulose insulation. It was demonstrated that some flame retarded insulation would smolder readily and, in the presence of a slight draft, could ignite the timbers of a residential attic. A smoldering test for insulation was developed. It was found that the amount of inhibitor needed to pass the proposed smoldering and flaming tests was quite sensitive to the particular cellulose fiber and method of blending the inhibitor with the fiber. This process variability suggests the need for an inexpensive quality control test.

A search for satisfactory smolder inhibitors for cellulosics has turned up about 100 candidate slats. About two dozen of these combine four desirable characteristics: effectiveness as smolder inhibitors, flame inhibition or no interference with common flame inhibitors, low corrosion tendency for exposed metals, and low cost.

\section{Associated Grants \& Contracts}

Pennsylvania State University, G. M. Faeth - "An Investigation of Fire Impingement on a Horizontal Ceiling".

Lawrence Berkeley Laboratory, C. Tien - "Thermal Radiation of Luminous Flames and Smoke".

Georgia Institute of Technology, B. T. Zinn - "Investigation of Smoke Formation by Polymeric Materials: Smoke Reduction Methods and Chemical Characterization".

Brunswick Corporation, R. Chaun - "Experimental Studies on Pyrolysis Aerosols and Fire Detectors".

Princeton Univeristy, F. Dryer and R. Santoro - "An Experimental Investigation of Flame Spread Over Condensed Combustibles: Gas Phase Interactions".

Lawrence Berkeley Laboratory, P. Pagni - "Fire Modeling".

California Institute of Technology, E. E. Zukoski - "Experimental Study of Environmental and Heat Transfer in a Room Fire".

University of California (San Diego), F. J. Williams - "Studies of Flame Extinction in Relationship to Fire Suppression".

Harvard University/Factory Mutual Research Corporation, H.W. Emmons and R. Friedman - "The Home Fire Project".

Princeton University, I. Glassman - "Smoldering Combustion Studies".

Brown University, M. Sibulkin - "Flame Propagation and Extinction for Solid Fuels".

University of Notre Dame, K. T. Yang - "Fire and Smoke Spread". 
FIRE TOXICOLOGY RESEARCH

FIRE SCIENCE DIVISION

CENTER FOR FIRE RESEARCH

Professional Staff

Merritt M. Birky, Head

Maya Paabo, Research Chemist

Barbara C. Levin, Research Biologist

James E. Brown, Research Chemist

Susan E. Womble, Chemist

Dolores Malek, Guest Worker/JHU

Greg Smith, SPI Research Associate

Alan Stolte, Student

\section{Program Objective}

The objective of research in fire toxicology is to reduce human fire losses from inhalation of toxic combustion products by providing test methods and recommended practices for predicting and reducing the hazard.

\section{Project Areas}

1. The development of a toxicity test method.

2. The correlation of small scale toxicity test system with large scale fire experiments.

3. The identification of specific toxic products in thermal degradation products.

4. The development of a gas generator to calibrate portable "sniffers" to be used for arson investigations (Arson).

1. Development of Toxicity Test Method

An interlaboratory evaluation (ILE) has been initiated to evaluate the adequacy of a proposed toxicity test protocol. The ILE involves nine laboratories in which 12 materials will be evaluated. Each laboratory will test Douglas fir (the reference material) and 4 other materials. The nine laboratories are represented in an Ad-hoc committee established to critique the proposed combustion toxicity test method.

The test method is designed to identify those materials that produce "unusually" toxic and/or supertoxic combustion products. It is generally agreed within the ad-hoc toxicity group that a material that produces an 
atmosphere that is 100 times more toxic than Douglas fir should be classified as supertoxic. A definition of unusually toxic has not been agreed to at this time. Similarly, the use of incapacitation in the test method is still under discussion.

Plans are to finish the experimental work on the ILE in mid-July, 1980. Preliminary analytical and toxicological data from various laboratories are encouraging and suggest that the July milestone is reasonable although unforeseen difficulties could delay this.

Considerable amount of planning is going into relating the toxicity data obtained from the test method to a hazard assessment. That is, the potential hazard associated with the use of a given material is not limited or determined by the toxicity of the combustion products from this material. The hazard must take into account not only toxicity but such parameters as ignitability, flame spread, heat release, smoke, etc. Incorporation of these parameters into a hazard index is the desired goal.

\section{Correlation of Small Scale Toxicity Test System with Large} Scale Fire Experiments

A project has been initiated to carry out large scale (room size) experiments to determine if the products generated in the toxicity test system are representative of large scale fires. For this project, the principal scenarios that lead to loss of life have been selected for the initial experiments. Thus, self-smoldering of cotton and flexible polyurethane will be studied. Initially, this study will involve a chemical analysis of products from the self-smoldering of these materials in a large room. These results will be compared to the results from the small scale protocol system in which the samples are thermally degraded in a furnace. Later experiments will involve flaming combustion. Validation of the analytical results will be made with animal exposures.

\section{Identification of Specific Toxic Products}

The toxicity of thermal degradation products from materials containing chlorine in the structure, such as poly(vinylchloride) (PVC) is frequently attributed to compounds such as phosgene. For example, individuals in the fire services report unique toxicological problems that have been attributed to fires involving vinyls. As a result of these factors, a study was undertaken to determine if phosgene is produced during the thermal degradation of PVC.

Three types of experiments were performed to approximate scenarios in which PVC is involved. They are: 
1. thermal degradation of PVC in a furnace,

2. electrical over-loading of wire insulated with PVC, and

3. electrical arcing between wires coated with PVC.

linor concentrations (1ess than $10 \mathrm{ppm}$ ) of phosgene were identified in the first two scenarios. In the third scenario, concentrations in the order of $50 \mathrm{ppm}$ have been identified.

\section{Development of Gas Generator (Arson)}

Combustible gas detectors, frequently referred to as "sniffers" are often used in on-the-scene fire investigations as the first step to ascertain the presence of accelerants in cases where arson is suspected. At the present time, a standard technique does not exist for the calibration of such detectors. As a result, a gas generator is being developed to be used for the calibration of combustible gas detectors. The accelerant gas generator will be used to establish a performance standard for the evaluation of the sensitivity and selectivity of detectors.

Four organic compounds have been chosen as calibration gases. They are: hexane, isooctane, toluene and o-xylene. These four compounds were initially chosen as a result of their prevalance as components in gasoline and other accelerants. Vapor pressure was also an important consideration since the more volatile compounds are not likely to be present after a fire has occurred. Preliminary measurements are in progress using these four compounds, al though the generation system can be used for other compounds as desired.

Associated Grants

Johns Hopkins University - APL, W. Berl \& B. Halpin"Fire Casualty Study" University of Utah, J. Futrell \& D. Farrar-"Toxicological Evaluation of Material Combustion Products"

Johns Hopkins University, Z. Annau-"Evaluation of Toxicity of Combustion Products

University of Pittsburgh, Y. Alarie-"Toxicity of Plastic Combustion Products"

University of Arizona, W. Clayton-"Evaluation of the Combustion Toxicology of Several Polymeric Materials" 
PRODUCT FLAMMABILITY RESEARCH

FIRE SAFETY ENGINEERING DIVISION

CENTER FOR FIRE RESEARCH

\section{Professional Personnel}

James H. Winger, Head

Emil Braun, Physicist

John F. Krasny, Textile Technologist

Joseph J. Loftus, Research Chemist

David J. Mitchell, Mechanical Engineer

Richard D. Peacock, Chemical Engineer

Lee R. Smith, Physicist

Rita M. Perkins, Research Associate

\section{Program Objectives}

The program objective is to develop and apply technology to reduce fire losses associated with the use of products by working through regulatory agencies and voluntary standards and codes.

\section{$\underline{\text { Project Areas }}$}

\section{Mine Fire Safety}

The objective is to develop effective test methods, standards, and operating procedures to reduce fire losses in underground coal mines. The accident data have been reviewed and analyzed and fire scenarios developed for several products and systems. The existing fire tests for hydraulic fluids and conveyor belts have been reviewed, and appropriate tests are under development. Review of fire tests for explosion containment, fluid-filled electrical devices, and brattice cloth have started. Future items to be reviewed include hoses, intrinsic safety, electrical cables, etc. A recommended procedure and supporting documentation will be prepared for each product area and submitted to the Mine Safety and Health Administration.

\section{Fuelwood Fire Safety}

The objective is to develop methods and procedures to assure adequate fire safety when wood is used as a fuel in residences and small industries. The literature, model codes, and tests for the fire safety of wood-burning appliances have been reviewed, and a report has been published. An experimental program based on the review has been started. Recommended code changes and test procedures will be provided to the Department of Energy and the model code organizations. 


\section{Textiles}

The objective is to reduce fire losses due to the ignition and burning of textile products. A standard for cigarette ignition of upholstered furniture has been recommended to the Consumer Product Safety Commission (CPSC). Technical support is being provided to the CPSC staff as documentation is prepared to support a decision by the CPSC Commissioners.

A new standard for the flammability of general apparel has been recommended to the Consumer Product Safety Commission. Technical support is being provided to the CPSC staff.

A standard for the flammability of flight crew uniforms has been recommended to the Federal Aviation Administration (FAA). Technical support is being provided to the FAA as they prepare a proposed rule.

The capabilities for apparel fabrics to provide some protection from an existing fire is under investigation. Various test concepts and procedures are under evaluation as well as the performance of various fabrics in these procedures. 


\section{FURNISHINGS FLAMMABILITY RESEARCH \\ FIRE SAFETY ENGINEERING DIVISION \\ CENTER FOR FIRE RESEARCH}

\section{Professional Personnel}

Sanford Davis, Head

Vytenis Babrauskas, Fire Protection Engineer

David D. Evans, Mechanical Engineer

\section{Program Objectives}

The primary goals of the Furnishings Flammability Research are to assess the hazards of furnishings and building contents involved in fires and to provide the methodology for predicting these hazards based on smallscale laboratory tests and analytical models. A number of projects are in progress relating to interior furnishing products and their impact on the environment during a fire. (As a consequence of the floor covering work over the past years, a similar approach has been used for attic floor insulation, primarily used for retrofit applications. The people movers project relates to past transportation vehicle programs and their kinship to the room fire problems.)

\section{Project Areas}

\section{Institutional Mattress Fire Hazard Test Development}

Results of full-scale mattress burns were reported two years ago. Since then, a number of bench-scale tests were conducted to develop a procedure for predicting full-scale performance. A tentative test procedure has been developed containing two parts: a rate of heat release test using the new NBS calorimeter and a smoke specific extinction area test, based on measurements in the NBS smoke density chamber. For commercial laboratory usage, studies are under way to determine if an oxygen depletion measurement '? the Ohio State University calorimeter could be related to the NBS calorimeter values. It should be noted that the development addresses solely the problem of flaming mattress ignition in institutional environments; current Federal regulations for resistance to ignition from smoldering cigarettes are judged sufficient for residential applications.

\section{Burn Room Sensitivity Study}

Analysis of room burn test data and subsequent design use are often hampered by the lack of closed-form, approximate expressions for the effects of different variables. This problem is especially evident for the time-to-flashover, a most important hazard indicator, which currently cannot be estimated. A set of approximate functional relationships are needed that would enable time-to-flashover and other fire variables to be predicted, knowing fuel, room, and geometric 
conditions. To this end, a series of test burns and numerical simulations are being conducted using a simulated pool fire, which represents the simplest quantifiable fuel arrangement.

\section{Furniture Combustion Studies}

A number of related activities fall into the general area of characterizing the details of furniture combustion. A series of various pieces of furniture were burned in an ignition modeling configuration. This consists of two parts: (1) Burning of full-sized furniture in the open to provide a radiant flux map and burning rate data, and (2) tests of small specimens in a modified ISO ignition apparatus. Taken together, these data will permit analytical estimates of whether nearby furniture items will be ignited from the first burning item.

On a more detailed level, work has been resumed on developing a horizontal, uniform flux, linear flame spread test apparatus. Also, flame spread measurements are being set up to be measured in idealized sectional mockups of upholstered furniture.

\section{Parsons Table Fire Hazard Evaluation}

The data from a series of eighteen room fires, each involving a single plastic Parsons table as the only combustible item of furniture, were studied in an effort to assess the hazards of these products and to find correlations between the results from small laboratory and large room fire tests for the different table materials tested. Very good predictions of the total amount of smoke produced by the burning tables and rate of smoke production were made using the table weight loss data from the room fire tests and laboratory smoke chamber measurements of the mass optical density (MOD) for the table materials. The predictions of full-scale smoke generation using MOD smoke numbers with examples from the Parsons tables tests are included in the report "A Discussion of Smoke Chamber Data Reduction" currently under NBS review.

\section{Television Receivers}

A study to characterize ignition sources within a television receiver was recently completed. Four late model television receivers were studied. Selected locations within the circuitry were stressed by introducing full or partial short circuits to simulate the failure of electronic components. The temperature and increased power dissipation generated by short-circuited components were recorded. Although component temperatures greater than $500^{\circ} \mathrm{C}$ were achieved, no flaming ignition sources were generated.

For comparative purposes the energy release rate of the ignition source specified in the UL 1410 test procedure was measured. Supplemental measurements on the operating temperatures of chassis components under varying ventilation conditions were also made. 
A final report, Tech Note 1109, "Characterization of Electrical Ignition Sources Within Television Receivers" will be issued soon.

\section{Automated Fixed Guideway Vehicles}

The fire safety aspects of mass transportation vehicles used in fixed guideway systems had not been vigorously studied. The purpose of this project is to explore and formulate the fire safety guidelines to be required for automated vehicles used for the movement of people in congested urban areas. The results of this effort are needed to set reasonable requirements on the systems to be deployed in several cities under the Urban Mass Transportation Administration's "Downtown People Mover" (DPM) program. By reviewing existing systems similar to those that are expected to be used in the DPM program, scenarios have been formulated in order to establish the minimum levels of fire safety of the vehicles for several types of DPM systems. In addition to the materials and methods of construction, the interior finish materials, the means of fire detection and suppression, size of vehicles, accessibility, and operational environment have been considered for preparing these fire safety guidelines.

\section{Cellulosic Loose-Fill Insulation}

Activity related to fire performance testing of cellulosic insulation has been primarily for technical support for the Consumer Product Safety Commission (CPSC) interim standard for this product. Two interlaboratory programs have been completed. One program established that the reproducibility of the Attic Floor Radiant Panel Test (AFRPT) proposed for use by CPSC in the standard is 20.5 percent. The other program to evaluate the ASTM E 84 Tunnel test found the reproducibility of the tunnel test for cellulosic insulation is 35.2 percent.

Large-scale attic mock-up byrns were performed to determine if materials rated at or above $0.12 \mathrm{~W} / \mathrm{cm}$ critical radiant flux in the AFRPT would resist flame spread under simulated summer attic conditions.

\section{Therma11y Insulated Wiring Systems}

The steady-state operating temperatures for the jacket of electric cables was calculated for the simplified case of a cable buried axially in a cylinder of thermal insulation. These calculations show that thermally insulated electric cables carrying the rated current can exceed the $60^{\circ} \mathrm{C}$ or $75^{\circ} \mathrm{C}$ operating temperature limit for the cable jacket material. 
Associated Grants

1. IITRI, R. Pape and T. Waterman - "Pre-Flashover Room Fire Model Parameter Sensitivity Analysis and Development of a Sub-model for Burning Items".

2. FMRC, A. Tewarson - "Determination of Fuel Parameters for Fire Modeling". 


\section{CONSTRUCTION FIRE RESEARCH \\ FIRE SAFETY ENGINEERING DIVISION \\ CENTER FOR FIRE RESEARCH}

Professional Personnel

William J. Parker, Head

Billy T. Lee, Fire Protection Engineer

Lionel A. Issen, General Engineer

Jin B. Fang, Chemical Engineer

William D. Walton, Fire Protection Engineer

David P. Klein, Fire Protection Engineer

James R. Lawson, General Physical Scientist

David L. Chamberlain, Research Associate

David C. Jeanes, Research Associate

James R. Beyreis, Presidential Interchange Executive

Olivier J. Carret, Guest Worker

\section{Program Objectives}

The objective of the Construction Fire Research Proaram is to reduce the probability of the growth and spread of a fire and its combustion products in a building by developing fire test methods and acceptance criteria for construction materials and assemblies.

\section{Project Areas}

\section{Fire Test Standards}

The objective of this project is to develop laboratory fire test methods for evaluating the potential fire hazards of construction materials. The fire properties of concern are ionitability, heat release rate, flame spread, and smoke. The approach is to develop appropriate fire test methods, to perform interlaboratory evaluations of such tests, to make recommendations for performance standards and test criteria, fire performance and to participate actively in standards committee work of ASTM, NFPA, ISO, CIB, and qovernment wide croups.

Studies of the heat release rates of construction materials are heing conducted with the NBS research calorimeter. This instrument is capable of measuring the simultaneous heat and mass loss rates of vertical specimens $12 \times 12$ inches and horizontal specimens $6 \times 12$ inches at radiant fluxes up to $8 \mathrm{~W} / \mathrm{cm}^{2}$. In addition, a new type of calorimeter is being developed whereby the measurement of heat release rate is based on the rate of oxygen consumed by the burning material. The heat release rate of combustible construction is also being measured in a furnace conforming to the ASTM E 119 standard, using the oxygen depletion technique. A new flame spread test is being developed for studying lateral flame spread on a vertical surface as a function of the material's surface temperature and of the velocity, temperature and oxygen content 
of the air flowing across the material surface. Material testing is continuing with the NBS ease of ignition test by flame impingement. This latter test has been submitted for consideration as a standard test for ignitability of interior finish materials. The project leader is W. J. Parker and the other CFR investigator is J. R. Lawson. The professional personnel include D. L. Chamberlain, research associate from National Forest Products Association, and O. J. Carret, quest worker from France.

\section{Fire Spread and Growth}

The objective of this project is to evaluate the potential for fire spread and growth in various occupancies in terms of the materials of construction, the combustible contents, the building design and the probable ignition sources. The approach consists of (a) developing analytical models of fire growth based on heat and mass balance considerations which take into account the spread of flame over the combustible interior finish materials and their heat release rates,

(b) running full-scale fire tests for validation of these models, and

(c) conducting reduced scale fire tests, which permit verification of the model for many more combinations of parameters at considerable savings in time and money. The project leader is W. D. Walton. The other professional investigator is J. R. Beyreis, Presidential Interchange Executive from Underwriters Laboratories.

\section{Prison Cell Room Fire Study}

The objective of this project is to determine the rate of heat production of a prison cell with a representative fire loading under different ventilation conditions. The approach is to determine the total rate of heat produced by the fire from the measurement of the oxygen content and volume flow rate of the exhaust qases. A series of five room fire tests are planned to investigate the burning behavior of the combustible contents as a function of ignition location and three different size doorway openings. The individual fuel items will be burned on a weight loss platform positioned directly under the exhaust collector hood in order to provide the input data on the rate of heat release to an analytical model which will be used to predict the total rate of heat production in the cell. The project leader is $B$. T. Lee.

\section{Structural Fire Endurance}

The objective of this project is to predict the fire endurance of structural building components under typical fire exposure conditions using thermal and structural analysis and to verify it with full-scale tests. The basic analytical approach is to combine thermal analysis and structural analysis programs which include elasto-plastic material properties. A literature review is underway to determine the stateof-the-art capability of available analytical methods used for predicting the performance of steel structures exposed to fire and to identify the deficient areas where analytical work and/or experimental verification 
are needed. Much of this project has been carried out through the Center for Building Technology at NBS, the Portland Cement Association and the University of California at Berkeley. The project leader is L. A. Issen. The other professional investigator is D. C. Jeanes, Research Associate from the American Iron and Steel Institute.

\section{Fire Endurance of Floor Constructions}

The objective of this project is to develop a test procedure for evaluating the fire endurance of floor assemblies in residences and to recommend rational performance criteria for protected and unprotected load-bearing components. The approach is to conduct full-scale fire tests in a simulated basement recreation room using modern furniture with a typical fire load for that type of room. A series of 16 tests with varying room size, interior finish, and ventilation conditions has been completed. The fire was started with a newspaper on a couch with polyurethane cushions. The temperatures, heat fluxes and pressures recorded during those tests will provide the basis for the specification of a new fire endurance test. The time-temperature curve and the pressures will be duplicated in a gas-fired ASTM F 119 tvpe furnace and several types of floor constructions will be tested and the failure times will be compared with those obtained by the present ASTM E 119 test. An analytical prediction capability for fire growth is being developed along with the experimental testing. The project leader is J. B. Fang.

\section{Fire Safety in Mobile Homes}

The objective of this project is to document the effect of interior finish materials on fire growth and spread and on the attainment of untenable conditions in mobile homes in order to provide a rational basis for regulating these materials. The approach is to conduct full-scale fire tests on single-wide mobile homes using upholstered chairs and $14 \mathrm{lb}$ wood cribs as ignition sources in various areas of the mobile home. The chair is a realistic source of iqnition which will not lead to full involvement of the mobile home in the absence of combustible interior finish while the wood crib provides a relatively reproducible ignition source of smaller size. Temperatures, heat fluxes, smoke densities, and gas concentrations are monitored throughout the mobile home. The interior finish materials are characterized by their ASTM E 84 tunnel rating, heat release rate, time to ianition in the ease of ignition test, and the smoke density in the NBS Smoke Density Chamber.

Work is now in progress in duplicating the essential features of the full-scale test results using reduced scale modeling and in attempting to deduce the results by analytical prediction techniques. The project leader is D. P. Klein. 


\section{Shipboard Fire Research}

The objective of this project is to evaluate the potential fire hazard of shipboard and submarine hull insulations and to improve the application of laboratory fire tests for screening compartment lining materials. The approach is to subject the variety of shipboard and submarine hull insulations, some of which are protected with fire resistant materials, to laboratory fire tests on ignitability, flame spread, rate of heat release, and potential heat. The performance of these insulations are then examined in quarter and full-scale compartment fires. By comparing the time to flashover or the maximum temperature reached in the full size compartment with the results of the laboratory fire test methods improved acceptance criteria for materials can be derived. By comparing the performance of the material between the full and reduced scale fire tests, the usefulness of the quarter-scale model as a screening tool can be evaluated. At the same time analytical and experimental studies are being carried out to improve the ability of the quarter-scale model to predict full-scale fire behavior. The project leader is B. T. Lee.

\section{Fire Tests of Marine Construction}

The objective of this project is to develop a surface flammability test for bulkhead and deck finish materials in order to determine their suitability for use in marine construction. The test provides information on the ignitability, flame spread and heat release rate properties of the materials. The effects of the incident radiant flux distribution, the orientation of the specimen, and the details of the piloting on the measured flammability properties are being investigated. Data are being gathered on a wide range of materials as background for the running of an interlaboratory evaluation and the preparation of a test standard. The project leader is A. F. Robertson*.

\section{Fire Hazards of Insulation in Residential Occupancies}

The objectives of this project are: 1) to identify and determine the magnitude of the various fire risks associated with the use of particular types of insulation, 2) to recommend, and develop where necessary, the laboratory fire tests needed to control the use, 3) to determine the reproducibility of the fire tests between laboratories, 4) to provide data on the fire properties for generic types of insulation considered for use in the basements, wall cavities and attics of buildings, and 5) to recommend acceptance criteria suitable for adoption in the building codes. The project leader is L. A. Issen. The other CFR investigator is J. R. Lawson.

\footnotetext{
* Senior Scientist attached to CFR Center office.
} 
Associated Grants

University of California (Berkeley), Robert Brady Williamson - "Fire Growth Experiments - Toward a Standard Room Fire Test"

SRI International, Stanley B. Martin - "Effect of Retardants on the Heat Release Rate of Building Materials"

Portland Cement Association, Melvin S. Abrams - "Short Term Creep Tests at Elevated Temperatures"

Underwriters Laboratories, Inc., Robert Berhinig - "Measurement of Air Flow Around Doors Under Standardized Fire Test Conditions" 
FIRE PROTECTION SYSTEMS RESEARCH

FIRE SAFETY ENGINEERING DIVISION CENTER FOR FIRE RESEARCH

\section{Professional Personnel}

Edward K. Budnick, Head

Richard G. Bright, Senior Research Engineer

Richard W. Bukowski, Research Engineer

Warren D. Hayes, Fire Prevention Engineer

John G. O'Neill, Fire Prevention Engineer

John H. Klote, Mechanical Engineer

\section{Program Objectives}

In the event of a fire, certain fire protection systems are relied upon to: 1) alert the occupants prior to the attainment of conditions adverse to human safety, and 2) to actively prohibit or reduce the growth and spread of the fire and combustion products. The overall objective of this program is to provide research and engineering technology for such systems. To this end the program is divided into three areas of concentration: automatic fire detection, automatic fire suppression, and smoke control.

Specific aspects such as engineering design, installation, performance and reliability requirements are being studied for these fire protection systems in pursuit of overall design technology and appropriate test methods upon which to judge system capabilities. In addition, the development of design criteria and installation guidelines leading to subsequent reductions in costs plays a key role in the development of this technology.

\section{Project Areas}

1. Automatic Fire Detection: Considerable research is ongoing in this program to identify the key parameters and conditions which must be considered when measuring the performance of detection devices. Extensive full-scale and laboratory testing is being utilized as the basis for the identification process and will be extended to support program efforts to develop standard tests for measuring detector performance. Current activities also include studies on the arousal potential of state-of-the-art detector alarms and the reliability of detector components and systems. Much of the technology developed in this program is inputed directly to U.S. and international standards groups for automatic detection.

2. Fire Detection in Health Care Facilities: This project is designed to provide data and ultimately guidance on means of optimizing detection system performance in health care facilities. Fullscale tests are being conducted in a simulated health care environment to psovide data on performance of detectors under actual fire 
conditions. A technical report, NBSIR 79-1739, Tests on the Performance of Automatic Fire Detectors in Health Care Occupancies - A Preliminary Report, has been published based on the results of Phase I testing. Phase II is now ongoing. Field data is being collected and analyzed to assess the performance of detection systems currently being used in typical health care facilities. A significant output from this project has been the development of a portable aerosol generator for use as a field tester for installed detectors. A report, NBSIR 78-1480, "An Instrument to Evaluate Installed Smoke Detectors", has been published. Instruments, based on this design, are commercially available.

3. Smoke Detector Performance in Mobile Homes: An initial phase of this work, including full-scale detector siting tests in an actual single-wide mobile home, has been completed. A report, NBSIR 761016, "Mobile Home Smoke Detector Siting Study" has been published. The results of this initial work provided the basis for further experimental work in this area. Additional full-scale testing is now being conducted to examine the effects of key environmental conditions including air movement from both the heating and air conditoning systems and the outside ambient conditions during winter and summer periods.

4. Fire Detector Test Method Development: The development of a uniform and comparative test method for all types of automatic fire detectors is ongoing. The project is separated into two areas of interest: 1) the development of environmental stress tests, and 2) the development of a full-scale test protocol. The first area is planned for future investigation while the bulk of the emphasis to date and in the near future will be the development of a full-scale fire test protocol. Current test methods have been evaluated and a determination has been made of the most suitable approach to be used in developing the test. A full-scale test facility, based on this approach which is similar to the proposed International Standards Organization (ISO) full-scale test protocol, has been constructed. An initial experimental plan is under development.

5. Fire Safety Technology for Rail Transport of Class A Explosives: A study is being conducted to provide technical design information on the application of state-of-the-art fire detection and suppression equipment for protection of rail cars carrying Class A explosives. Output from this project will include equipment design specifications such as types and location of fire detectors, sensitivity levels and discrimination logic, design specifications for a low-pressure water fog nozzle, piping networks, and water supply/pressurization systems and the evaluation of passive structural protection such as flammability inhibiting fire retardant coatings. 
6. Automatic Fire Suppression: A great demand exists for technology advancement for automatic fire suppression systems. Efforts in this area have been directed toward full-scale performance testing under varying conditions and exposure fires. Initial work included an experimental study to develop design criteria for the use of automatic sprinklers for the protection of corridcrs from fires beginning in adjacent rooms with open doorways for multi-family and care-type facilities. Work has also been done to develop water distribution mapping techniques, factors affecting the geometric distribution of water from sprinklers, statistical parameters of water droplet populations from sprinklers as a function of pressure and deflector design, and the use of sprinklers in health care facilities.

In addition to this long range work, continuous efforts are made to assist in the development of U.S. and international standards for automatic sprinkler systems and components. This work has included analysis of water distribution patterns, K-factor (coefficient related to orifice pressure and flow rate) measurement techniques, and mechanical safety factors applied to sprinkler devices.

7. Fire Tests of Patient Rooms with Automatic Sprinklers: The objective of this study is to provide engineering design information on health care facilities incorporating automatic sprinklers. The effectiveness of sprinklers is being measured in terms of overall fire control, time available for evacuation, and the maintenance of tenable conditions for patients who cannot be evacuated. Current nationally used fire safety design criteria for health care facilities are being specifically examined from the viewpoints of life safety of the occupants and cost efficiency of system designs.

Phase I tests were conducted between August and November 1977 and a report of these tests, NBSIR 79-1749, Full-Scale Fire Tests with Automatic Sprinklers in a Patient Room, has been published. This phase of the test series developed important information on the movement and concentration of selected combustion gases throughout the test space.

Phase II tests, scheduled for completion in 1979, will examine variations in water flow rates and nozzle pressures of sprinklers. Improved techniques will be utilized to measure smoke movement and concentration in a corridor adjacent to the room of fire origin.

8. Sprinkler Protection of Open Stairways: The objective of this study is to develop engineering design information for alternative methods of protecting open stairways using sprinkler and spray nozzle systems. This work is designed to refine and update test results dating back to the 1940 's which serve as the basis for methods currently used in the National Fire Protection Association 
(NFPA) sprinkler and life safety codes. A propane burner serves as the energy source and currently is operated at two heat release rates, 5.5 and $13.6 \mathrm{M} \mathrm{Btu/hr} \mathrm{(} 1500$ and $4000 \mathrm{KW})$. Performance curves will be developed for these systems to indicate their capacity to inhibit passage of combustion gases into the stairway resulting from the convective heat flow from the burner. In addition, design information for these systems will be developed. Experimental full-scale testing was conducted in a specifically constructed four story facility.

In support of this work a report entitled NBSIR 78-1571, sprinklerVent and Spray Nozzle Systems for Fire Protection of Openings in Fire Resistive Walls and Ceilings - The State-of-the-Art and a Plan for Future Research Work, has been published. A technical report will be published, upon completion of the analysis of the full-scale experimental work.

9. Smoke Control Systems: The smoke control project has been in operation for a number of years. During that time the work has developed along two parallel and now converging directions. Initially work was done with simple computer modeling of smoke movement in buildings. This effort builds upon the work of the National Research Council of Canada and others. At the same time field tests were conducted in actual office, apartment and hospital buildings using sulfur-hexafluoride tracer gas to study the movement of simulated smoke under a variety of mechanical systems and climatic conditions. Included in the field work were several studies of buildings equipped with smoke control systems. In each case the building was evaluated both with and without the smoke control system in operation. This allowed for comparison of the relative effectiveness of the systems compared to a building without any smoke control. More recently, the output from the field survey program has been combined with a sophisticated computer program designed to predict the movement of air in a building as influenced by an air handling system. The result has been the generation of a computer-based design methodology for smoke control.

Work has also been done to compare the results of sulfur-hexafluoride smoke movement studies to actual movement of smoke in dwellings. This work demonstrated a qualitative correlation between the simulated smoke and real smoke. Future work will involve the development of smoke control methodologies for residential application.

The primary output mechanisms for the results of this research is through additions or changes to various voluntary standards including NFPA and the American Society of Heating, Regrigerating and Air Conditioning Engineers (ASHRAE) standards. 
10. Field Investigations of Smoke Control Designs: Field tests have been conducted using the sulfur-hexafluoride ( $\left.\mathrm{SF}_{6}\right)$ tracer gas technique to determine smoke flow patterns in various types of occupancies, including office, apartment and health care facilities. one recent investigation was conducted in the NIH Clinical Center in Bethesda, MD, in which both winter and summer conditions were tested. The objective of these tests was to gain understanding of smoke flow in buildings under normal operations, and under operation of the smoke control systems. A draft report is in NBS review.

11. Field Studies of Stairwell Pressurization Systems: The use of stairwell pressurization systems has grown in the U.S. over recent years. Field tests, including sulfur-hexafluoride $\left(\mathrm{SF}_{6}\right)$ tracer gas tests, pressure-velocity tests, and smoke candle tests have been conducted in buildings in Nashville, Tennessee which incorporate multiple injection systems. The results of the field tests have been analyzed and a draft report is in NBS review.

As an adjunct to this project a computer based model is being developed to simulate smoke migration in stairwells having pressurization systems. It is anticipated that this model will provide a useful tool for the design of stairwell pressurization systems in multistory buildings. A progress report of this effort is anticipated in early 1980.

12. Smoke Movement in Merchant Ships: This project will extend the use of the $\mathrm{SF}_{6}$ technique to study the smoke flow patterns aboard a merchant marine ship in order to provide recommended guidelines for smoke control in such vessels. The project is currently in the planning stage.

13. Computer Modeling of Smoke: Two computer programs designed to model smoke movement in buildings have been developed under contract to Integrated systems Inc. (ISI). One of the programs, designed to evaluate steady-state conditions, has been verified by field test results. Verification of the unsteady-state model is currently being pursued. These programs will jerve as a basis upon which to develop a methodology for analysis of building designs in order to optimize the design of the smoke control systems.

\section{Associated Grants}

University of Massachusetts (Amnerst), E. H. Nober - "Waking Effectiveness of Household Smoke and Fire Detection Devices". 


\section{DESIGN CONCEPTS RESEARCH \\ FIRE SAFETY ENGINEERING DIVISION \\ CENTER FOR FIRE RESEARCH}

\section{Professional Personnel}

Harold Nelson, Head

Bernard M. Levin, Research Psychologist

A. Jeffrey Shibe, Operations Research Analyst

Leonard Y. Cooper, Research Fire Protection Engineer

Program Objectives

The objectives of the Program are to synthesize and integrate research and technology to develop technically based rational approaches towards providing safety from fire in buildings of various types of usage; and to provide operating mechanisms for using these approaches in setting fire safety requirements in these facilities.

\section{Project Areas}

\section{HEW-NBS Life/Fire Safety Program (Health Care Facilities)}

The objectives of the HEW-NBS Life/Fire Safety Program are to develop technically based rational approaches towards providing safety from fire in health care facilities; and to develop an operating mechanism for using this approach in establishing rational and feasible fire safety features in these facilities. The mechanisms are to be usable by those expected to apply them, acceptable to both the federal and nonfederal authorities, and creditable in terms of applied engineering science and techniques.

The program is targeted towards the needs of HEW, voluntary standards organizations, state and local regulatory authorities, and practicing architects/engineers, facility operators and health care providers. The program outputs are directed at providing management tools for setting approved fire safety requirements, technical design data and guides for architects, fire protection engineers and others involved in the process of design of cost effective means of fulfilling safety objectives. Specific proposals and recommendations for the revision or improvement of fire safety codes, regulation, standards and advances in the stateof-the-art of applied fire protection engineering and fire technology are also provided.

The current phase of the program is of 5 years duration. Over 4 years of this period have been completed. Some significant accomplishments under the auspices of this program include:

A. The development of a fire safety evaluation system for grading the equivalency of alternative approaches to fire safety and health care facilities. 
B. The development of a 16 millimeter sound film entitled, "FLASHOVERPoint of No Return," directed at training nursing staffs in optimum fire safety actions to protect patients in case of fire.

c. The extensive collection of information and data and related investigations on the behavior of staff and residents/patients at time of fire emergency.

D. The development of a cost comparison model for determining cost effective alternative approaches to fire safety in health care facilities.

E. The development of a simulation model of emergency movement by occupants of buildings during fire exposure.

F. The extensive studies on the capabilities and limitations of speccialized fire protection equipment such as smoke detectors and automatic sprinklers relevant to their use in health care facilities.

G. The participation in and the support of significant test and research activities in detection, extinguishment, and the development of smoke control models and design tools.

A number of intermediate research programs are still underway in this program. In addition to summarizing the data produced, an attempt will be made to assemble the material and information as an overall, logical guide for those involved in making fire safety, regulatory, or related design decisions. Future work in this area will emphasize the resolution of design problems related to the individual subsystem and elements of health care facilities.

2. HEW/NBS Life/Fire Safety Program (Group Homes for the Developmentally Disabled)

A recent development in the care of the mentally retarded (and other developmentally disabled persons) is to provide for their custodial care in small home-like facilities in the community rather than in large remote institutions. Life/fire safety requirements have not been specifically developed for these types of facilities so the responsible authorities are using regulations designed for other purposes including the NFPA Life Safety Code standards for private homes, boarding houses and hospitals. The objective of this project is to develop life/fire safety performance criteria specifically geared for these group homes.

This 39-month project started in July 1977. During the familiarization phase of the project, over 50 group homes were visited; detailed information about the facilities and the residents was obtained for 9 of them. A report has been published on the "Behavioral and Physical Characteristics of Developmentally Disabled Individuals." (NBS-GCR-79167). 
The approach is to develop a variation and modification of the Fire Safety Evaluation System. This system will permit flexibility in the selection of fire safety features and the fire protection requirements will depend, in part, on the level of capabilities of the residents. The criteria will be developed with the advice of experts throughout the country.

A preliminary version of the evaluation system is now under development. Review and testing of the system will start later in 1979 and the system will be modified as needed based on the field tests and the comments of the reviewers.

\section{OSHA/NBS Means of Egress Study}

The objective of this project is to investigate the state-of-the-art; to conduct experiments to establish an improved data base, providing a basis for hazard assessment approaches; and to determine specific erigineering solutions relevant to yielding emergency escape criteria for means of egress arrangements. The effort includes: 1) an assessment of the state-of-the-art literature on the human factors relating to emergency egress in buildings; 2) a review and analysis of the current state of technology theories and test data involved in the growth of fire, controlling factors, and the speed and distribution of effects that interfere with or terminate the ability to escape from fire; 3 ) physical experiments to evaluate the effectiveness of water spray and/or draft arrangements to protect open stairwells and similar open floor penetrations; and 4) investigations towards the development of procedures to determine the smoke restricting capability of various qualities of stairwell doors.

The program, initially intended for two years, has been extended an additional year. The literature analysis of emergency egress has been completed and a report entitled "A Critical Assessment of the Technical Literature on Emergency Egress From Buildings" has been authored by Mr. Fred Stahl of the NBS Center for Building Technology. Tests have been conducted on a full size open stairwell test facility at NBS and, in cooperation with Underwriters Laboratories, tests have been initiated to evaluate a shroud method (ISO approach) for using the standard door furnace in a positive mode to determine leakage rate through fire doors during the course of fire exposure.

A $p$ ractical technique for estimating safe available egress times for workspaces subsequent to the detection of fires is being developed. This will be done by applying the best current knowledge of fire growth and smoke spread phenomenology, and by taking account of detector and alarm capabilities, as well as human tolerances to products of combustion (smoke).

4. Multi-Family Housing Life/Fire Safety Evaluation System

The objective of this project is the development of a fire safety evaluation system applicable to existing multi-family housing. The system will be designed to evaluate equivalency of alternative fire safety ap- 
proaches as compared to the normal requirements of the Departinent of Housing and Urban Development Minimum Property Standards.

The 18-month project was initiated in FY 1979. The evaluation system will be based on the relevance of the various elements of building design to the performance objectives of fire safety (e.g. prevention of ignition, litigation of fire development capability, confinement of fire, detection and extinguishment, and escape and rescue). A working tool that may be used as an alternative to the existing explicit reguirements will be developed.

5. Life/Fire Safety Evaluation Manual-Inmate Housing and Confinement Facilities In Penal Occupancies

The purpose of this project is to develop a fire safety evaluation system and supporting manuals to determine the relative level of safety in inmate housing facilities in prisons and similar penal institutions. The approach will be modeled after the other types of fire safety evaluation systems prepared or underway by the program. The project scheduled for $11 / 2$ years duration, was initiated in mid 1979. The project has been extended to include full scale test of the rate-of-energy release of fully involved prison cells.

\section{Extra-CFR Activities}

A major portion of the activities of Design Concepts Research are conducted outside of Center for Fire Research. These include:

Center for Building Technology, NBS.

1. "Simulation of Human Behavior in Fires: a Computer Model", Fred I. Stahl.

2. "Fire Safety in High Rise Buildings: The Rule of Communications", Arthur Rubin and Robert Glass.

3. "System for Cost Comparison of Fire Safety Alternatives", Robert Chapman.

4. "The Evacuation of Nonambulatory Patients From Hospital and Nursing Home Fires", John Archea.

5. "Time-based Provisions for Emergency Escape in Public Occupancy Buildings", Fred I. Stahl.

Center for Consumer Product Technology, NBS.

1. "Arousal From Sleep By Emergency Alarms", V. Pezoldt and $H$. Vancott.

2. "Safe Environments for the Developmentally Disabled", Ann Ramey-Smith and John Fechter. 


\section{Associated Grants}

1. Loyola University of Chicago, Leonard Bickman - "Behavioral Analysis of the Life Safety Code".

2. University of Maryland, John Bryan - "The Determination of Behavior Response Patterns in Fire Situations - Project People II"

3. "Life Cycle Cost Benefit Workbook", W. J. Griffith.

4. North Carolina State University, Richard Pearson - "Occupant Response Variability in Escape from Residential Fires".

5. University of Florida, Richard L. Francis - "Network Models of Building Evacuation". 
AD HOC WORKING GROUP ON MATHEMATICAL FIRE MODELING

CENTER FOR FIRE RESEARCH

\section{Professional Personnel}

Robert S. Levine, Chairman of Steering Committee

John A. Rockett, Chairman of Computer Committee

Irwin A. Benjamin, Chairman of Users Needs Subcommittee

James G. Quintiere, Chairman of Models Subcommittee

Note: The Modeling Committee is chaired by Professor Howard Emmons of Harvard University, and the Subprogram Committee by John DeRis of Factory Mutual.

A number of CFR personnel are members of the technical committees.

\section{Program Objectives}

The objectives of this committee are to facilitate the development and use of mathematical models of fire and to coordinate and facilitate research needed to improve the models. The steering committee includes members from other Government agencies who have influence on their agencies' $R$ and $D$ in this field. The coordination, of course, is voluntary.

\section{Project Areas}

Each applicable area is included in another Program abstract. The major portion of the CFR effort is in the Fire Physics Research Program.

\section{Associated Grants}

1. Harvard University/Factory Mutual Research Corporation, Howard Emmons and John DeRis - "Home Fire Project"

2. Several others as listed elsewhere 


\section{ARSON PROGRAM \\ FIRE SCIENCE DIVISION \\ CENTER FOR FIRE RESEARCH}

\section{Professional Personnel}

Nora Jason, Technical Information Specialist

James Brown, Research Chemist

Robert Levine, Division Chief

Richard Bright, Senior Research Engineer

Bernard Levin, Research Psychologist

\section{Program Objectives}

The objectives of the Arson Program are to carry out certain specific tasks in the U.S. anti-arson program. The overall program is coordinated by the U.S. Fire Administration in FEMA, and the Law Enforcement Assistance Administration in the Department of Justice.

\section{Project Areas}

The CFR tasks include:

1. Preparation of a handbook for Fire Investigators (Jason and Bright)

2. A device to calibrate "Sniffers" (used by fire investigators to detect accelerants) (Brown)

3. A consensus standard for the laboratory analysis for accelerants (Brown, FY 1980)

4. Psychology of Arson (Levin)

\section{Associate Grants}

1. University of North Carolina, Vreeland - "Psychology of Arson" 


\section{Professional Staff}

$\begin{array}{lll}\text { Daniel Gross } & - & \text { Supervisor } \\ \text { William H. Bailey } & - & \text { Supervisory Engineering Technician } \\ \text { James S. Steel } & - & \text { Physicist (Instrumentation) }\end{array}$

The following large-scale testing facilities are available at the Gaithersburg site for use by CFR programs as needed:

\section{Building 205}

This is a $60 \mathrm{ft}$. by $120 \mathrm{ft}$. test building with controlled environmental conditions; a large smoke collection hood serves the individual experimental facilities and is connected to a large stack with afterburner. The following facilities are contained within the building:

A room burn and smoke test facility. This is a two-story structure, $20 \mathrm{ft}$. by $20 \mathrm{ft}$. in plan view, which may be used for fire growth studies and for examining fire and smoke spread through ducts, dampers, doors, etc.

A corridor test facility. This is a $12 \mathrm{ft}$. wide, $30 \mathrm{ft}$. Iong corridor with several burn rooms attached which can be used for a variety of studies, including the contribution of furnishings and interior finish as well as sprinkler performance.

A research fire resistance furnace. This furnace is designed to meet the essential requirements of ASTM E 119 as well as to provide for more rapid heating of walls (10 ft. by $8 \mathrm{ft.}$ ), floor-ceilings (10 ft. by $8 \mathrm{ft.}$ ) and columns ( $8 \mathrm{ft}$. high). Structural loads up to 30 tons may be applied and furnace pressure may be adjusted from $-0.05 \mathrm{in}$. to t0.15 in. water gage. The furnace may be used to test components, innovative constructions, and the effects of joints in wall-floor ass emblies.

Building 205 also houses rooms for specialized calorimeters, small furnaces, and model enclosures. Laboratories are available for keeping and testing rats for toxicology studies in conjunction with large-scale fire experiments. Shops, instrument rooms, and service areas are also located in the building.

Mobile homes specially instrumented and outfitted to permit repetitive tests of fire growth and smoke movement and detection are adjacent to Building 205. 


\section{NBS Annex}

This is a former DOD facility adjacent to the NBS site which is available for special tests. It has a 3-story stair tower which can be used for smoke spread and sprinkler studies; a dormitory building containing a $60 \mathrm{ft}$. long loaded corridor with lobbies at each end; and a large laboratory designed for smoke detector testing.

\section{Instrumentation and Staff}

Each of the facilities is equipped with automatic data recording systems to collect a wide variety of information from the large-scale tests. A staff of 6 technicians and an instrumentation specialist are available to support CFR research programs. An instrumented van is available for field testing at distant sites. 

CONTRACTS AND GRANTS 

ANNUAL CONFERENCE ON FIRE RESEARCH

CENTER FOR FIRE RESEARCH

NATIONAL BUREAU OF STANDARDS

GAITHERSBURG, MARYLAND

August 22-24, 1979

Institution: Brown University

Grant No: NBS Grant G7-9009

Grant Title: Flame Propagation and Extinction for Solid Fuels

Principal Investigator: Professor M. Sibulkin

Division of Engineering

Brown University

Providence, RI 02912

Other Professional Personnel: A. Kulkarni, Graduate Assistant

S. Malary, Graduate Assistant

NBS Scientific Officer: J. Rockett

Technical Abstract

The objectives of this program are to advance our understanding of flame propagation and extinction for fuels involved in urban fires. An understanding of the theoretical basis of flame propagation which leads to quantitative predictions of flame spread rates is of importance in several areas of the fire problem. A knowledge of rate of flame spread on isolated components is necessary input information for the calculation of more complex room fire scenarios, and may be the determining factor in the time for fire build up to hazardous conditions. A more fundamental understanding of extinction mechanisms should enable improved methods of fire suppression to be developed more rapidly than by wholly empirical testing. In spite of the deficiencies of small scale tests, they continue to be essential for the materials development community. Our work aims to relate the results of such tests to the test geometry and the material properties. In the past we have examined the effects of gas phase extinguishing agents on propagation and extinction by a combination of experiment and mathematical analysis. Recent work is concentrating on the extinction of burning vertical surfaces. Different hypotheses as to the controlling physical mechanisms are tested by comparing the predicted conditions for extinction with the measured ones. Future work will attempt to extend these efforts to other materials and to solid phase extinquishing agents. 
Measurements on smal1, vertical samples of polymethyl methacrylate (PMMA) burning in variable oxygen/nitrogen atmospheres have shown that extinction occurs at $Y_{0, \infty}=0.18$ (which is considerably below the "Limiting Oxygen Index"). The mass burning rate at extinction, however, is about $70 \%$ of the burning rate at atmospheric conditions. Furthermore this decrease in burning rate can be predicted reasonably well by simple mass-transfer theory, but such a theory gives no indication of extinction. To investigate this situation, a mathematical analysis of burning on a vertical wall was made. Emphasis was placed on determining the effects of heat loss by radiation from the burning surface and of incomplete combustion on the extinction limit.

Using "local similarity" variables the laminar boundary layer equations are transformed to a set of ordinary differential equations. The thin flame model and Schvab-Zeldovich formulation are used; unity Lewis number, variable density but constant $c_{p}$ and $\rho \mu$, uniform molecular weight and ideal gas assumptions are made. The analysis differs from previous work because of the inclusion of surface radiation. The equations are solved numerically using a finite difference scheme. Results are obtained for the fuel concentration at the surface, the burning rate and the heat flux to the wall from the flame. Velocity and temperature profiles in the boundary layer were calculated and hence the velocity peak position and the flame standoff distance are obtained. The nondimensional surface radiation $\mathrm{R}^{*}$ is treated as a parameter which can be varied from zero to any desired value.

In the adiabatic case (i.e., without the inclusion of surface radiation) extinction does not occur as $Y_{0, \infty}$ is reduced although the heat transfer to the wall and burning rate decrease as expected. When a wall radiation parameter $R^{*}=0.23$ (corresponding to a PMMA surface temperature of $390^{\circ} \mathrm{C}$ ) is used, extinction is predicted at $\mathrm{Y}_{0, \infty}=0.12$ for complete combustion to $\mathrm{CO}_{2}$ and $\mathrm{H}_{2} \mathrm{O}$ (as compared to a measured value of $\left.\mathrm{Y}_{0, \infty}=0.18\right)$. When incomplete combustion to $\mathrm{CO}$ and $\mathrm{H}_{2} \mathrm{O}$ is assumed, extinction is predicted at $Y_{0, \infty}=0.18$. From another viewpoint, extinction is predicted to occur'at the experimentally observed value, $Y_{0, \infty}=0.18$, when the radiation parameter $R^{*}$ is increased to a value corresponding to a surface temperature of $470^{\circ} \mathrm{C}$ with completecombustion.

Thus it has been shown that extinction does not occur due to a lack of convective heat transfer to the burning surface. Radiative heat loss by the surface plays an important role in promoting extinction. If combustion is incomplete, this would also significantly affect the extinction limit. Future work will extend this analysis to include the effects of finite rate chemistry on burning and extinction.

\section{Reports and Papers:}

"Ignition and flame spread tests of cellular plastics," by K Annamalai and M. Sibulkin, J. Fire \& Flammability 9, 445 (1978). Also, 1979 International Symposium on Flammability and Fire Retardants, Nashville, TN, May 3-4, 1979. 
"Flame spread over combustible surfaces for laminar flow systems. I. Excess fuel and heat flux," by K. Annamalai and M. Sibulkin, Comb. Sci. and Tech. 19, 167 (1979).

"Flame spread over combustible surfaces for laminar flow systems. II. Flame heights and fire spread rates," by $K$. Annamalai and M. Sibulkin, Comb. Sci. and Tech. 19, 185 (1979).

"Effects of $\mathrm{N}_{2}$ and $\mathrm{CF}_{3} \mathrm{Br}$ on extinction of propagating and fully burning fires," by M. Sibulkin, M. W. Little, and A. Kulkarni, J. Fire \& Flammability 10 , (1979). 
ANNUAL CONFERENCE ON FIRE RESEARCH

CENTER FOR FIRE RESEARCH

NATIONAL BUREAU OF STANDARDS

GAITHERSBURG, MARYLAND

August 22-24, 1979

Institution: Brunswick Corporation, Defense Division

Contract No: EO-AO1-78-00-3577

Title: Experimental Studies on Pyrolytic Aerosols and Fire Detectors

Principal Investigator: Dr. Raymond L. Chuan

Brumswick Corporation, Defense Division

3333 Harbor Boulevard

Costa Mesa, California 92626

Other Professional Personnel: Houston D. Chen

NBS Scientific Officer: Tom Lee

Technical Abstract

The aerosols released in the course of the controlled pyrolysis of a standard material, $\alpha$-cellulose, are studied experimentally, in terms of their mass concentration and size distribution, in real-time, as the pyrolysis progresses. At the same time, the responses of two types of fire detectors - optical and ionization - are observed in relation to the aerosol characteristics. It is found that response characteristics of these two types of instruments are significantly different from each other at different stages of the pyrolysis. The optical instrument appears to respond best in an early stage of the developing fire when the aerosol particles are large and are optically absorbing, while the ionization detector shows better response at a later stage when the aerosols are smaller and are optically non-absorbing.

Some of the data from a typical test run are shown, as they were recorded during the test, in Figure 1 . These include the sample mass, opacity (one with an NBS instrument and the other with a commercial instrument) and the output of the MIC ionization detector. The aerosol characteristics acquired at several points during the run are tabulated in the figure. From the mass concentration and size distribution, the mass median diameter and the geometric standard deviation are obtained graphically. In all the tests, it is noted that the optical opacity response reaches a maximm before that of the ionization detector, and the maximm is followed by a significant dip, while the ionization detector continues towards a fairly broad peak. The decay in the relative response of the ionization detector is less rapid than that of the opacity instrument. 


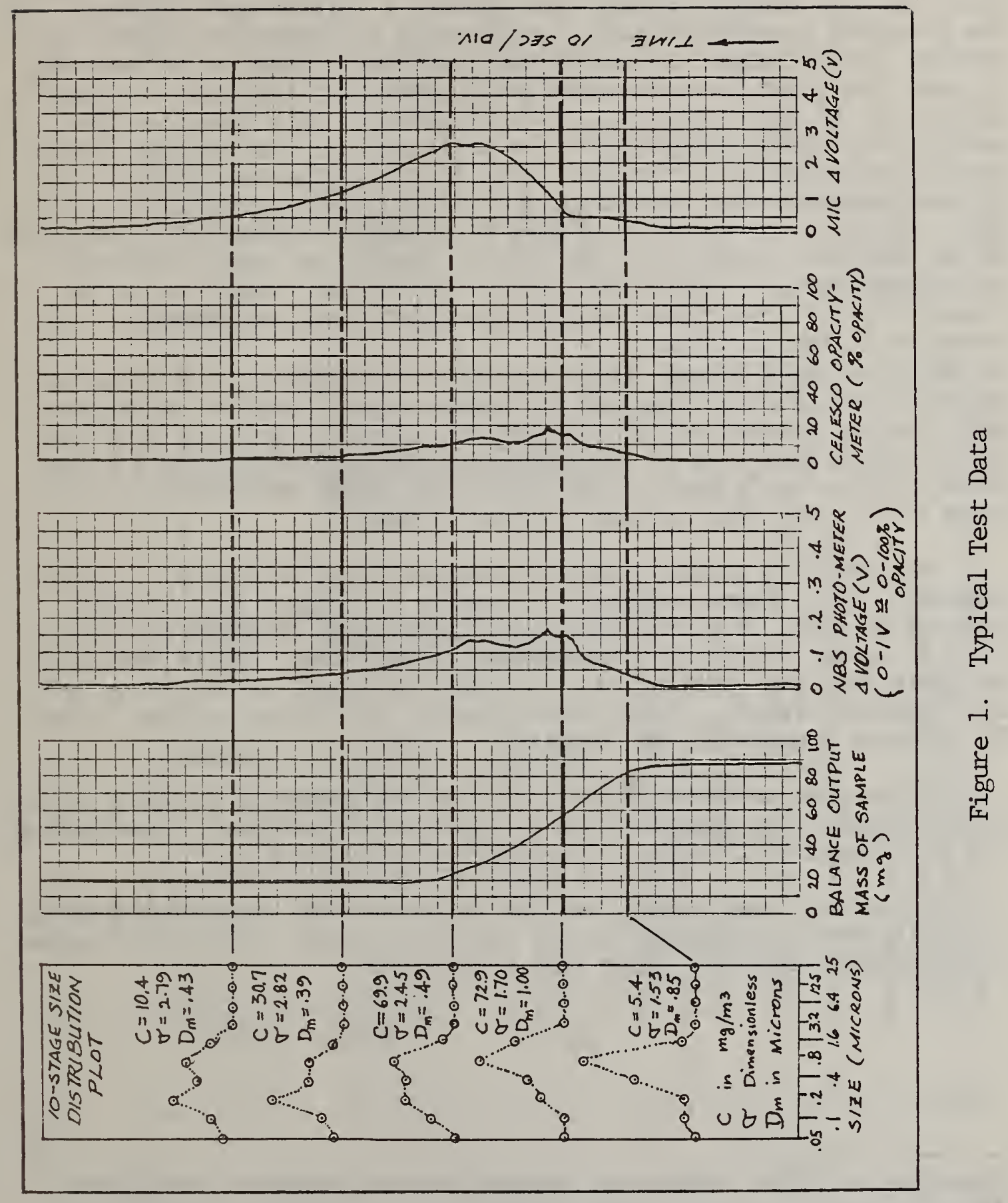


Attempts have been initiated to explain these differences in instrument response characteristics, with some success. It is noted that somewhere during the passage from a pre-combustion to a transition regime, the mass median diameter goes through a fairly rapid decrease, and the geometric standard deviation undergoes a correspondingly rapid increase. These changes are underlined in Table 1, where it is seen that $\mathrm{d}_{\mathrm{m}}^{\prime}$ goes from about $1 \mu \mathrm{m}$ to $0.5 \mu \mathrm{m}$; and $\sigma_{\mathrm{g}}$ from about 1.5 to 2 . An examination of the extinction properties of aerosols will show that the specific extinction coefficient of a white aerosol goes through a maximum at a mass median diameter of about $1 \mu \mathrm{m}$; and the magnitude of the maximm decreases with increasing 5 . Thus the observed decrease in size, coupled with the increase in $\sigma_{s}$ both tend to cause a ranid decrease in the specific extenction. The optical onacity has been calculated, using experimentally determined aerosol properties, resulting in two values, one for a white aerosol and the other for black aerosol. These are listed in Table 1.

In the three cases listed, it is seen that the maximm in white aerosol opacity occurs earlier than for the black aerosol; and the calculated white opacity matches better the observed opacity. There is some limited evidence from some of the tests that the aerosol acts as a black smoke into the early part of the transition regime (which in time is quite short), but then changes to a white smoke.

Scheidweiler* assumes that the response of an ionization detector depends on $\mathrm{Zd}_{\mathrm{a}}$. There are physical reasons to suggest that a better correlation would be with $\mathrm{Zd}_{\mathrm{a}}{ }^{2}$. Accordingly, both values are listed in Table 1, again calculated from measured aerosol data. It is seen in the table that the correlation of the MIC instrument is definitely with $\mathrm{Zd}_{\mathrm{a}}{ }^{2}$, and not with $\mathrm{Zd}_{\mathrm{a}}$. This also explains the delayed maximm in the $\mathrm{MIC}$ response compared to the opacity.

As the mass median size decreases and the geometric standard deviation increases, the specific area of the aerosol increases, thus leading to a corresponding increase in the ionization detector.

During next year's work, we plan to improve the experimental setup to acquire more accurate and better correlated data. It is also planned to investigate materials other than $\alpha$-cellulose.

"Scheidweiler, "The Ionization Chamber as Smoke Dependent Resistance", Fire Technology, pp. 113 - 123, May, 1976. 


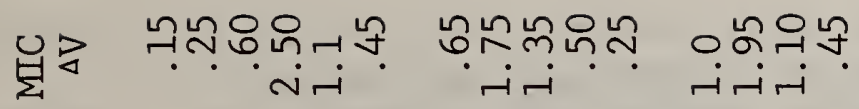

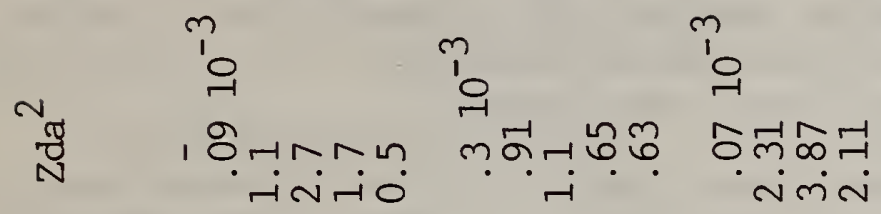

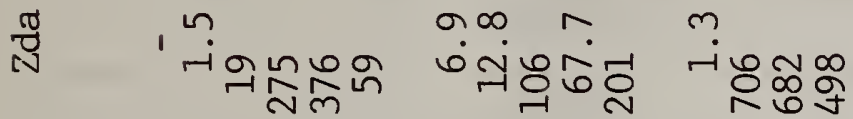

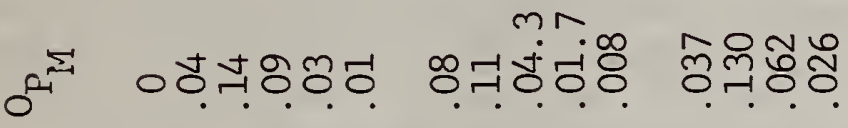

চ

$\stackrel{H}{\beta}$

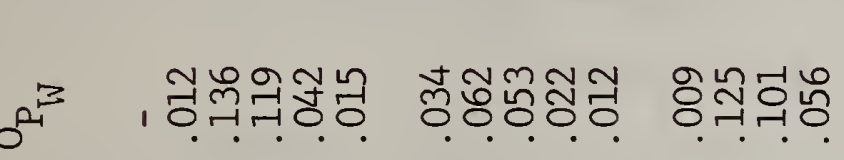

$\mathrm{m}_{E}$

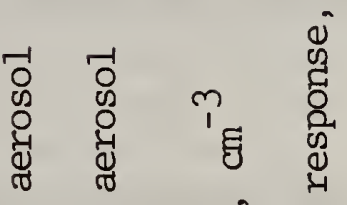

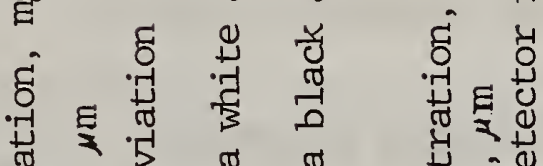

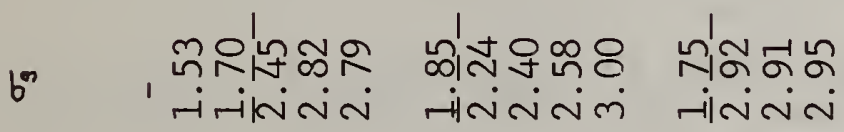

ఈ ,

हु

i 8

$\pi \pi$ प

प्山े

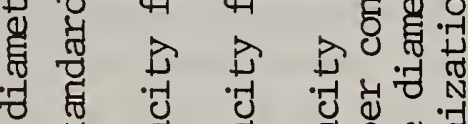

至

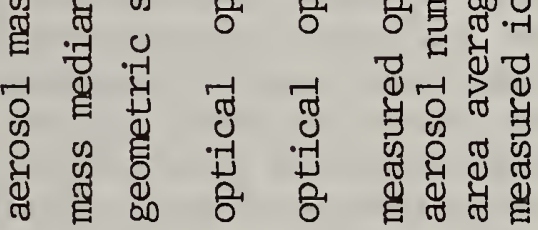

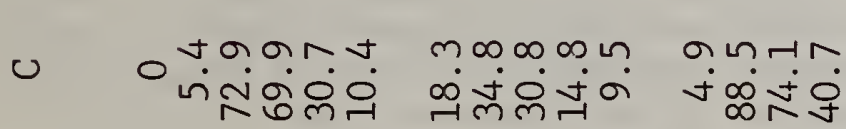

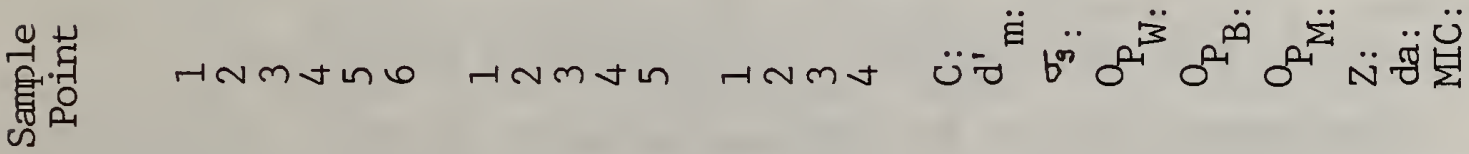

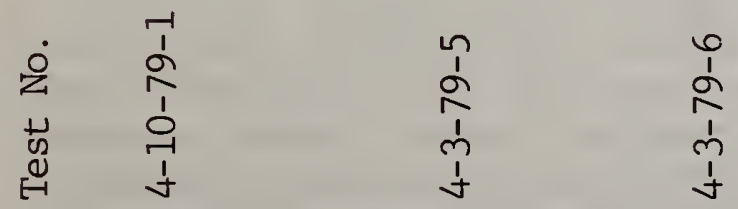




\section{ANNUAL CONFERENCE ON FIRE RESEARCH \\ CENTER FOR FIRE RESEARCH \\ NATIONAL BUREAU OF STANDARDS \\ GAIT HERSBURG, MARYLAND}

August 22-24, 1979

Institution: California Institute of Technology

Grant No: NBS Grant G8-9014

Grant Title: Experimental Study of the Environment and Heat Transfer in a Room Fire

Principal Investigator: Professor Edward E. Zukoski 301-46

California Institute of Technology

Pasadena, CA 91125

Other Professional Personnel: Professor Toshi Kubota

William Sargent, Ph. D. Candidate

California Institute of Technology

Pasadena, CA 91125

NBS Scientific Officer: Dr. John Rockett

$\underline{\text { Technical Abstract }}$

We are investigating a number of fluid dynamic problems associated with the pre-flashover fires in a multi-room structure. These investigations include studies of convective heat transfer to ceilings and walls of the fire room, and studies of the entrainment rates of fire plumes and door jets. This work has been guided in part by our attempt to develop a model from which fire spread phenomena can be predicted with at least modest accuracy. We hope to be able to use the computer model to investigate the effects on fire spread of changes in the material properties and geometric configuration of room furnishings including the wall, ceiling and floor coverings, and the features of the architectural design of buildings which directly affect the fire spread process. Our current research work is outlined in the following paragraphs.

Computer Model. We are continuing to develop a computer model which incorporates the results of experimental work when it becomes available. Our present efforts are directed toward the incorporation of the convective and radiative heat transfer models and the door mixing model as subroutines in our present computer program. In addition, we are trying to extend the model to include a larger number of rooms and include the possibility that the 
temperature of the cool or floor layer (of our two layer model) can have a temperature higher than the ambient temperature. A report covering the present revision of the program (the Third Revision)* will be available in August.

Experimental Program. One experimental program concerns measurement of convective heat transfer to room ceilings early in the fire when convective effects can be important. In order to correlate and predict the magnitudes of these effects we must be able to describe the velocity and temperature fields produced by a fire inside the room. The effects of fire size and location and the geometry of a single opening on convective heat transfer have been studied and a simple correlation has been developed. The conditions within the room have also been studied and we have found that the simple plume models presently available do not predict ceiling layer temperature and thickness with good accuracy.

The method used to correlate convective $e_{*}$, heat transfer rates is based on that described in earlier reports.** In addition, we assume that radial symmetry exists about the plume impingement point on the ceiling despite the rectangular shape of the room. Despite the low wall and gas temperatures present in the early stages of the fire, the influences of radiative transfer between solid surfaces is relatively large and must be taken into account. For most of our test conditions radiation from the gas phase can be ignored.

The influence of fire location has been found to be small when the fire is at least one diameter away from a wall, and when it is not in the direct path of a door jet and within a few door widths of the door. We are currently examining the effects of placing the fire in direct contact with a wall or in the path of a strong door jet.

One of the problems we encountered during our attempts to model the environment produced within a room by a small fire is that we cannot accurately describe the entrainment rate of the fire plume. A good knowledge of this rate is required if we are to be able to describe the environment and time scales for the preflashover fire and the convective heat transfer rates produced by the fire.

We are making measurements of entrainment rates based on the concept shown in the accompanying sketch. The basic idea is that the fire plume is caught in a hood and gas is removed from

\footnotetext{
*See: Reports and Papers.

*** Zukoski, E. E., Kubota, T. and Veldman, C. C. "An Experimental Study of Environment and Heat Transfer in a Room Fire", California Institute of Technology, October 1975.
} 
the hood through an instrumented vent line. Under many conditions of interest, the entrainment of cool air at the horizontal interface (between the hood gas and the air) has been shown to be negligible. Then a simple continuity argument shows that the plume mass flow at the interface height $Z$ must equal the mass flow through the vent line. Experiments based on this approach are being carried out now in a hood with a cross area of about 6 square meters and a depth of 2 meters. Values of $Z$ will vary from 0.5 meters to 2 meters. Natural gas, diffusion flames of 0.2 to 0.1 meter diameter and heat release rates from 10 to $200 \mathrm{kw}$ are being studied. Flames will be characterized by their geometry, heat release rate, and gross radiative properties. The shadowgraph technique will be used to investigate the plume and to relate the plume to the visible flame geometry.

Preliminary results have been obtained for natural gas diffusion flames with values of $Z$ of about 2 meters, a fire diameter of . 20 meters, a fire heat input rate between 15 and $150 \mathrm{kw}$, and fire heights from 1 to 2 meters. The measured entrainment rates of the fire plumes, measured with the technique described above, were roughly twice the value deduced from plume entrainment models based on a point source of heat and the Boussinesq approximation.

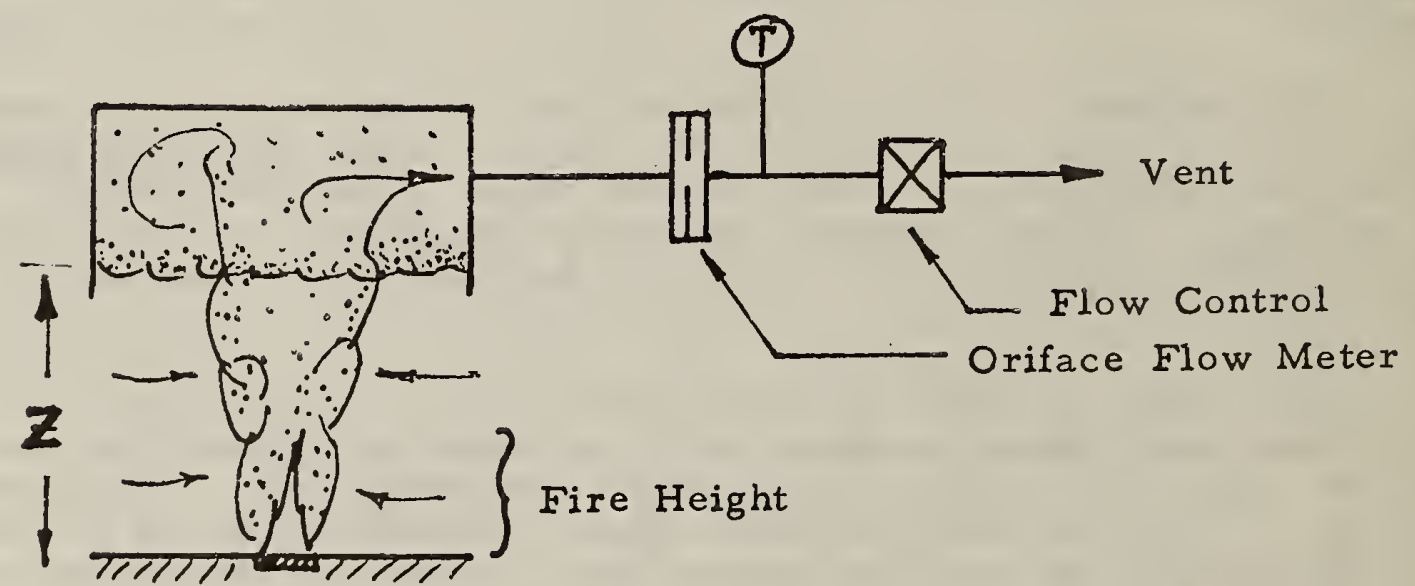

Reports and Papers

Zukoski, E.E. "Development of a Stratified Ceiling Layer in the Early Stages of a Closed-room Fire", Fire and Materials, Vol. 2, No. 2, 1978, pp. 54-62.

Kubota, T. and Zukoski, E.E. "A Computer Model for Fluid Dynamic Aspects of a Transient Fire in a Multi-Room Structure (Third Edition)", California Institute of Technology, August, 1979. 


\section{ANNUAL CONFERENCE ON FIRE RESEARCH \\ CENTER FOR FIRE RESEARCH \\ NATIONAL BUREAU OF STANDARDS \\ GAITHERSBURG, MARYLAND}

August 22-24, 1979

Institution: Clemson University

Grant No: NBS Grant NB79NADA0011

Grant Title: Antimony Oxide-Organohalogen-Polymer Substrate Interactions in the Solid Phase

Principal Investigator: Dr. M. J. Drews

Department of Textiles

Clemson University

Clemson, South Carolina, 29631

Other Professional Personnel: Dr. C. W. Jarvis

NBS Scientific Officer: Dr. R. Gann

Technical Abstract

The objective of this research is to elucidate the role of the polymer substrate in the generation of volatile antimony halides and oxyhalides, by characterizing the antimony oxide-organohalogen-polymer substrate solid phase interactions. These results will then be used to assess the relative importance of the observed solid state (as compared to gas phase) reactions in the flame retardant efficiency of antimony oxide/organohalogen additives and finishes.

The solid state interactions will be studied by characterizing the pyrolysis and oxidative pyrolysis products of model organohalogen compounds, model compounds in the presence of antimony oxide and organohalogen-antimony oxide-polymer mixtures. Pyrolysis experiments will be carried out using a thermo-gravimetric analyzer, single zone tube furnace and in the direct insertion probe of a mass spectrometer.

The effluent gas stream from the thermogravimetric analyzer or the tube furnace will be passed through a series of impingers and cold traps in order to collect the volatile decomposition products for subsequent analysis while soluble bromine will be continuously monitored. The principal volatilized organohalogens will be characterized by mass spectrometry after separation by high performance liquid chromatography. The pyrolysis residues will be analyzed for antimony, bromine, and carbon/hydrogen by elemental analysis. While direct pyrolysis in the mass spectrometer makes it possible to identify highly reactive radical decomposition products, the combination of mass spectrometry with the trapping techniques will offer dual confirmation of the more stable molecular decomposition products. 
The research has been divided into two phases. In the first phase, the interactions of model organobromine compounds with antimony oxides (empirically $\mathrm{Sb}_{2} \mathrm{O}_{3}$ and $\mathrm{Sb}_{2} \mathrm{O}_{5}$ ) are being studied in order to establish a data base for the polymer substrate studies included in the second phase. Organobromine rather than organochlorine flame retardants are being used in this study because of their higher molar efficiency in many applications. In addition, several reactions postulated as important in proposed retardant mechanisms for organohalogens would be more thermo-dynamically favored for brominated compounds. Three different organobromine structures will be investigated. These will include an al iphatic molecule which can release hydrogen bromide $(\mathrm{HBr})$ by beta elimination, an aromatic bromine molecule containing no hydrogen and either an aliphatic bromine which cannot readily eliminate $\mathrm{HBr}$ or an aromatic one which can. Several commercial flame retardants have been screened by thermal analysis for use as the model organobromine structures. On the basis of these results hexabromocyclododecane (HBCD) has been chosen as the model al iphatic bromine which can release hydrogen halide and decabromodiphenylene oxide as the totally brominated aromatic model. Several candidates are still being considered for inclusions as the third model compound.

Also during this phase of the research, the antimony oxidation state, particle size and antimony bromine mole ratio will be varied. The effect of the model organobromine's volatility and thermal stability on the antimony-bromine interaction will be studied by varying the heating rate and mode of pyrolysis.

The second phase of the study will consist of a similar series of experiments carried out in the presence of a polymer substrate. The polymers to be added in this phase include poly(ethylene terephthalate), poly (propylene), and poly(methylmethacrylate). These particular commercially important polymers have been chosen because they differ greatly in chemical structure, thermo-oxidative stability, and mode of decomposition. The results of the second phase will be used in an attempt to correlate any observed changes in the rates of antimony and/or bromine volatilization, the temperature profile of antimony and bromine release, and relative concentrations of the volatilized active species with polymer substrate structure and decomposition mode.

It is anticipated that once the solid phase ternary reactions between polymer substrate-organohalogen-antimony oxide are characterized with respect to organohalogen and polymer functionality, these results will lead to a better understanding of the system parameters necessary for more efficient and safer flame retardation of thermoplastic materials. In addition, the results of this work could provide the basis for new studies into the role of antimony oxide in flame retardant formulations. 


\section{ANNUAL CONFERENCE ON FIRE RESEARCH \\ CENTER FOR FIRE RESEARCH \\ NATIONAL BUREAU OF STANDARDS \\ GAITHERSBURG, MARYLAND}

August $22-24,1979$

\section{Institution: Factory Mutual Research Corporation}

Grant No.: NB79NADA0014

Title: Determination of Fuel Parameters for Fire Modeling

Principal Investigator: Dr. Archibald Tewarson

Applied Research Department

Factory Mutual Research Corporation

1151 Boston-Providence Turnpike

Norwood, Massachusetts 02062

Other Professional Personnel: Mr. James L. Lee, Research Specialist Mr. Russell F. Pion, Associate Research Scientist/Engineer

NBS Scientific Officer: D. D. Evans

Technical Abstract:

A study program is proposed for obtaining relationships between fuel parameters useful, for fire modeling and the chemical structure of the fuels over a wide range of experimental conditions. The proposed study program is an application of the principles and techniques developed by Factory Mutual Research Corporation (FMRC) for the Products Research Committee (PRC).

The study program will use the 'Flammability Apparatus' developed for PRC, in which fuel samples of about $0.008 \mathrm{~m}^{2}$ are used and a larger version of the apparatus developed by the Factory Mutual Research Corporation (FMRC) in which fuel samples about $0.09 \mathrm{~m}^{2}$ are used.

In the study, fuels will be selected reflecting a wide variation in chemical structure, i.e., aliphatic, aromatic and highly chlorinated type fuels. The fuels used will be granular and foamed. Fuel parameters will be obtained for individual fuels as well as for their combinations.

The experimental variables in the study will include: 1) combinations of external heat flux and oxygen concentration; 2) ratios of mass of fuel vapor to air used in combustion; 3) dilution of products captured in the sampling duct; 4) fuel sample size; and 5) natural versus forced air flow. 
The fuel parameters in the study will include: 1) fuel surface temperature and 'effective' energy for the ignition of fuel vapor/air mixture; 2) 'effective' heat of gasification of the fuel, 'effective' fuel surface reradiation loss, and critical mass loss rate or kinetic parameter for ignition; 3) flame convective and radiative heat flux to the fuel surface; 4) combustion efficiency of the fuel vapor and convective and radiative fractions of the theoretical stoichiometric heat release rate for complete combustion of the fuel vapor; 5) fraction of carbon and other major elements in the fuel converted to $\mathrm{CO}_{2}, \mathrm{CO}$, gaseous hydrocarbons, carbon, $\mathrm{NO}_{\mathrm{x}}$ and $\mathrm{H}_{2} \mathrm{O} ; 6$ ) the ratio of optical density per unit path length to mass concentration of the fuel vapors.

Thermodynamics and heat and mass balances will be used for data analyses. An attempt will be made to apply proposed mathematical mode1ing principles

to a few selected experiments in the study for a fuel. 


\section{ANNUAL CONFERENCE ON FIRE RESEARCH CENTER FOR FIRE RESEARCH \\ NATIONAL BUREAU OF STANDARDS \\ GAITHERSBURG, MARYLAND

$$
\text { August 22-24, } 1979
$$

Institution: Factory Mutual Research Corporation

Grant/Contract No: G7-9011

Title: The Home Fire Project (joint with Harvard University)

Principal Investigator: Dr. R. Friedman (FMRC), joint with Prof. H. W. Emmons (Harvard)

Other Professional Personnel: Task 1 - Leader, Dr. F. Tamanini Task 3 - Leader, Dr. A. T. Modak Task 4 - Leader, Dr. G. H. Markstein

NBS Scientific Officer: Dr. J. Rockett

Introduction: In this multi-task project with Harvard University, Factory Mutual is responsible for tasks 1, 3, and 4. Abstracts of these tasks follow. 


\section{Task Leader: Dr. Franco Tamanini}

Technical Abstract: The purpose of this task is to determine the effect of decreased oxygen concentration of the ambient air on the burning characteristics of pool fires. In particular, we plan to focus on the following quantities: radiation flame temperature, absorption coefficient, total radiation, gas-phase burning rate distribution in the flame, flame shape, combustion incompleteness (composition of the products). Construction of a $1.2-m$ diameter water-cooled enclosure, in which experiments will be run, is almost completed at the time of this writing. This facility is designed so that the air supply can be diluted with the products from a propane flame.

While waiting for the completion of the new apparatus, we have verified the feasibility of a technique for measuring the amount of unburnt fuel present at different heights in a fire plume. The technique is based on the use of a quencher (a car radiator for our preliminary tests) through which the flame gases are aspirated: the amount of suction is adjusted so as to reduce the disturbances induced in the flame under the quencher itself. By measuring the flow rate and the composition of the stream captured by the quencher, when positioned at different heights in the fire plume, we will determine the vertical distribution of the burning rate in the flame. We have purchased gas analysis equipment to measure $\mathrm{O}_{2}, \mathrm{CO}, \mathrm{CO}_{2}, \mathrm{H}_{2} \mathrm{O}$ and total hydrocarbons; we have completed the design of the gas sampling system and we are about to begin its assembly. We anticipate that this program will provide needed data to verify integral models of turbulent combustion, which are presently under development [1,2].

Our plans for experimental work in the $1.2-\mathrm{m}$ diameter enclosure contemplate using the .38-m diameter gas burner developed by L.Orloff for another task of the Home Fire Project: however, in order to fine tune the instrumentation needed for the measurements of radiative properties of flames, we have carried out a series of tests with plastic pools in a smaller enclosure (.76-m diameter) built with internal funds. These experiments involved $: 3-\mathrm{m}$ diameter PMMA fires burning in air diluted with nitrogen. The data [3] show that:1)rate of pyrolysis, total radiation, flame emittance, and radiated fraction all decrease with decreased oxygen concentration; however, 2) the equivalent (Schmidt) flame temperature is only weakly dependent on the oxygen content of the air in the range tested (from $21 \%$ to $18 \%$ by volume). Flame photographs are currently being digitized to determine the path length associated with each emittance data point and,therefore,obtain information on the flame absorption coefficient. Comparison of the results from tests in plain air with the data obtained by Markstein shows differences which are probably due to the effect of confinement on the fires used in this program.

Reports and Papers:

1. Tamanini, F., "Outline of Integral Model for Fire P1umes", FMRC Memorandum, Apri1 4, 1979.

2. de Ris, J., "Combustion of Turbulent Fuel Jets and Plumes", FMRC Memorandum, May 15, 1979.

3. Santo, G., "Influence of Oxygen Depletion on the Radiative Properties of PMMA Flames", FMRC Technical Report (in preparation). 
Task: Radiation from Pool Fires

Task Leader: Dr. Ashok T. Modak

Technical Abstract: The shapes of flames above a pool significantly affect the burning rate of pool fires and the radiation therefrom. To study flame shapes in pool fires, two water cooled sintered metal burners of diameter 0.4 and 0.8 metres were constructed. These burners are being used to measure the radiation (external to the fire and to the pool base) from gaseous fuels burning at different flow rates and to provide photographic ${ }^{2}$ correlations for flame shapes in pool fires. A 0.73 metre diameter pool with automatic feedback level control device was constructed to control the level of the fuel surface. This pool will be used to study large pool fires of plastic materials.

A numerical model to compute the radiative flux in pool fires was developed. This model can account for nonhomogeneous distributions of combustion products and for nonisothermal effects in pool fires. The input parameters required by this model are the radiative properties ${ }^{3-6}$ of the flames and flame shapes. Radiative properties are being measured in an accompanying program (Task 4) by Markstein. The comnutation costs of the numerical model were reduced to affordable levels (i.e., a couple of minutes of CPU time on an IBM 370/158) through efficient numerical schemes and by providing simple yet accurate analytic formuías for the radiative flux to the base of a pool fire. The accuracy of the analytic formulas was verified against numerical calculations.

The effects of non-gray radiation due to the presence of molecular emitters (such as $\mathrm{CO}_{2}$ and $\mathrm{H}_{2} \mathrm{O}$ ) in fire gases were studied. A computer program 7,8 for nongray radiation calculations was developed.

Reports and Papers:

1. de Ris, J., "Recent Advances in Radiation from Fires," Invited Paper 非, Eastern Section of the Combustion Institute, Miami Beach, Florida, November-December 1978.

2. Orloff, L.,"Lip Effects in Pool Fires," Paper 非3, Canadian Section of the Combustion Institute, May 3-4, 1979, Kingston, Ontario.

3. Orloff, L., Modak, A.T. and Markstein, G.H.,"Radiation from Smoke Layers," XVII Symposium (International) on Combustion, The Combustion Institute, 1979 (in press).

4. de Ris, J.,"Fire Radiation-A Review,"XVII Symposium (International) on Combustion, The Combustion Institute, 1979 (in press).

5. Modak, A.T., Editor, "Influence of Enclosures on Fire Growth, Volume II. -Analysis," FMRC Technical Report OAOR3.BU, RC78-BT-24, July 1978.

6. Modak, A.T. and Mathews, M.K.,"Radiation Augmented Fires Within Enclosures," J. Heat Transfer: 100, 544 (1978).

7. Modak, A.T., "Radiation from Products of Combustion," Fire Research, 1979 (in press).

8. Modak, A.T., "Exponential Wide B and Parameters for the Pure Rotational Band of Water Vapor," J. Ouant. Spectrosc. Radiat. Transfer 21, 131 (1979). 
Task: Study of Radiation from Flames and Smoke Layers

Task Leader: Dr. George H. Markstein

Technical Abstract: In many fires, energy transfer from the flame to the fuel and the surroundings occurs predominantly by thermal radiation. Knowledge about the spatial distribution of radiation sources within a fire is important for the quantitative evaluation of radiative transfer. A scanning radiometer is being used in this task for obtaining this information.

Measurements with this scanning radiometer on plastics pool fires have been continued. Because of the highly fluctuating nature of the radiation from turbulent flames, determination of reliable mean distributions of radiation sources requires averaging over many repeated scans. It was found that about 100 horizontal scans across the flame at each constant height are needed to obtain good average data. To record the large number of data obtained in this way within a reasonable time, the data acquisition system of the scanning radiometer has been upgraded by the use of a fast calculator (HP9825A) and a nine-track tape drive. With this system, 100 scans, each comprising 500 data points, can be recorded in about one minute.

Several alternative simplified models have been investigated for reducing the measured radiance distributions, to obtain a radial distribution of a suitable quantity.For the simplest model of an optically thin flame, an Abel integral inversion of the averaged radiance distribution yields a radial distribution of volumetric radiant power. It was found, however, that for $.38 \mathrm{~m}$ diameter PMMA pool fires the implied neglect of self-absorption introduces considerable error.

For this reason, models assuming either constant absorption coefficient or constant flame temperature have been examined. The latter model, which yields a radial distribution of the emissionabsorption coefficient, appears more realistic than that of constant absorption coefficient. As a further alternative, a mode1 that interprets the measured radiance in terms of a radial distribution of the probability density for the presence of flame elements of constant absorption coefficient and constant flame temperature is now under study.

The interpretation of the scanning data clearly can be aided substantially by independent measurements of the local absorption coefficient. An instrument for this purpose, consisting of a watercooled and nitrogen-purged fiber-optic probe and a corner-cube reflector has been built and is now undergoing initial tests. In this device, the absorption over an effective path of about $60 \mathrm{~mm}$ is measured by means of a square-wave-modulated infrared-emitting diode source and a silicon photodiode sensor.

Reports and Papers:

1. Markstein, G.H., "Radiative Properties of Plastics Fires," 17 th Symposium (International) on Combustion (in press); FMRC Technical Report RC78-BT-20, July 1978.

2. Markstein, G.H., "Distribution of Radiant Power in Plastics Pool Fires," Presented at the Fall Meeting, Eastern Section, The Combustion Institute, November 29-December 1, 1978, Miami Beach, Florida. 


\section{ANNUAL CONFERENCE ON FIRE RESEARCH \\ CENTER FOR FIRE RESEARCH \\ NATIONAL BUREAU OF STANDARDS \\ GAITHERSBURG, MARYLAND}

August 22-24, 1979

Institution: School of Aerospace Engineering, Georgia Institute of Technology

Grant/Contract No: G8-9003

Title: Investigation of Smoke Formation by Polymeric Materials: Smoke Reduction Methods and Chemical Characterization.

Principal Investigator:

Dr. Ben T. Zinn, Regents' Professor

School of Aerospace Engineering

Georgia Institute of Technology

Atlanta, GA 30332

Other Professional Personnel:

NBS Scientific officer:

\begin{abstract}
Dr. R. F. Browner, Assistant Professor, School of Chemistry

Dr. E. A. Powell, Assistant Professor

Dr. K. T. Joseph, Post Doctoral Fellow

Dr. M. Pasternak, Post Doctoral Fellow

Mr. C. Ndubizu, Graduate Research Asst.

$\mathrm{Mr}$. R. 0. Gardner, Graduate Research

Assistant, School of Chemistry
\end{abstract}

Dr. George Mulholland

Technical Abstract

This research program is primarily concerned with the development of means for the reduction of the smoke produced by commonly used polymeric materials during fires. This experimental research program consists of a systematic investigation of the properties and amounts of smoke produced by burning polymers when different additives are introduced into different parts of the pyrolysis region between the polymer and the flame. The choice of additives has been dictated by current understanding (and conjectures) of the mechanisms of smoke formation. The investigated classes of additives include (1) organic compounds that are believed to be precursors to smoke formation and are expected to increase smoke generation; (2) inorganic compounds that are expected to retard smoke formation by ionic and/or chemical mechanisms; and (3) inert diluents that might affect smoke formation by changing the thermal and diffusion conditions within the flame region. During the first year the investigations are primarily concerned with the smoke production by polypropylene, and in subsequent years the smoke production by other polymeric materials will be investigated. The results obtained under this program are expected to result in improved understanding of the mechanisms of smoke generation by polymeric materials 
and the development of recommendations for the use of specific additives in the substrate material that will result in a reduction in the smoke generated by the investigated polymers. A major contributor to this research program are the chemical analysis efforts that are concerned with the identification of the various classes of compounds present within and on the surface of the collected smoke particulates. These results will contribute to the understanding of the mechanisms of smoke formation as well as identify toxic compounds that may be present in the smoke.

Investigation of the Effect of Additives Upon Smoke Formation by a Polymeric Diffusion Flame. The experimental apparatus to be used for studying the effect of additives on smoke formation was assembled and used for trial tests. In these tests a known weight of the pure polymer was heated in a stainless steel cup. As the resin pyrolyzed an atomized solution of the additive was injected into the pyrolysis gas stream at a controlled rate. The mixture was then burned in a diffusion flame attached to the mouth of the pyrolysis cup. The amount of smoke formed was determined by measuring the optical density and also by collecting and weighing the smoke particulates. Results of these trial tests indicated that several modifications of the experimental apparatus were necessary. These changes were necessitated by the need for (1) a stable diffusion flame, (2) a more reliable method for introducing additives into the flame, (3) good mixing of the pyrolysis gases with the additive solution, (4) and more reliable and repeatable smoke collection procedures. Much time and effort was devoted to improving the apparatus to meet these criteria, and the improved version of the apparatus is shown in Figure 1.

Preliminary measurements have been made using the modified apparatus for polypropylene using calcium nitrate and barium chloride as additives. The results of this study are encouraging, hence more careful measurements will be made with these and several other additives. These additives include two categories of inorganic salts: (a) those that are known to reduce smoke in experiments with gaseous fuels and (b) those that are currently being used in polymers and other applications as flame retardants. Physical properties as well as the chemical composition of the smoke particulates with and without additives will be measured. These measurements will be used to answer the qustions as to how the additives function to reduce smoke and also whether the additives would increase or reduce smoke toxicity and other harmful effects.

Chemical Characterization of Smoke Particulates. As one of the major efforts for the Chemistry Group, the studies on volatile species adsorbed onto smoke particulates has continued. The instrumentation has now been fully modified and tested so as to provide a very compact system with minimal possibility of sample loss in transfer lines. The basic configuration has been improved by shortening transfer lines and using teflon surfaces at all points in the system other than the gas switching valves so that sample loss between the combustion chamber and the collection filter and also between the collection filter and the solid adsorbant trap has been found to be negligible. The entire system is heated to minimize condensation losses during collecting. 
In order to coordinate our current work with the detailed studies carried out during the last grant period on polynuclear aromatic species found in PVC smoke particulates, the same PVC sample formulations have been used in this work. These formulations include the pure PVC resin along with formulations containing the stabilizer lead sulfate, the plasticizer 6,10 phthalate, fillers calcium carbonate and alumina hydrate, and antimony oxide.

One of the most important features of this current study is to correlate the concentrations of species found adsorbed onto the particulates with the concentrations found in the vapor phase of the smoke. Consequently, recent work has concentrated on two main goals:(1) identification of the major components in the gas phase of the PVC combustion, and (2) comparison of these components with the components released readily from the particulates (i.e. weakly adsorbed species). Experimentally, as mild conditions as possible are used to release the volatiles from the smoke particulates. Heating to $80^{\circ} \mathrm{C}$ in a flow of He is found to release the volatile species nearly quantitatively, without any trace of thermal decomposition products induced by the releasing process. Release at a series of higher temperatures, namely $100^{\circ} \mathrm{C}, 120^{\circ} \mathrm{C}, 140^{\circ} \mathrm{C}$, produced no significant improvement in release efficiency and gave rise to the possibility of contamination from decomposition products. Consequently $80^{\circ} \mathrm{C}$ was selected as release temperature for all further studies. Results of these studies show that the plasticizer has the greatest effect on the vapor phase gas chromatograms for PVC, altering significantly the relative ratios of the compounds produced. In addition, as would be anticipated, the species found in greatest amounts adsorbed on the particulates are the least volatile components of the vapor phase.

Work is continuing to obtain quantitative data on the compounds present and also to examine other PVC samples. When complete, studies will be made of other polymer types, such as polyurethane and polypropylene, etc. In addition, attention will be focussed on the absorbed concentrations of $\mathrm{HCl}$ and $\mathrm{HCN}$ with all these sample types.

As part of our continuing effort to obtain meaningful and reliable data on the chemical composition of the smoke particulates generated from burning polymers, we have devoted much effort to developing and using a new separations scheme. A very great deal of effort has been used in order to ensure reliability of this scheme and separation efficiencies have been checked at each state. In addition, where derivitization has proved necessary in order to obtain chromatographic separations (i.e. of acids, bases, etc.) the reliability of the procedures used has been thoroughly tested in order to ensure that no major compounds are lost due to incomplete reaction or derivative instability. This separations scheme has been used in the analysis of smoke from polyurethane foam which has long been an intractable problem due to the particular chemical nature of the compounds formed and the great complexity of the combustion products mixture. As a result, we have now obtained what we believe to be the first really reliable (although as yet incomplete) data on polyurethane. 
Potential Applications The results obtained during this research program are expected to identify which additives are most effective in reducing the smoke production by burning polymeric materials. This information along with the results of the chemical analysis of smoke particulates will aid in the development of safer commercial materials and thus reduce the losses of life and property due to smoke produced in building fires.

\section{Reports and Papers:}

1. Zinn, B. T., Bankston, C. P., Browner, R. F., Powell, E.A., Joseph, K. T., Pasternak, M., Gardner, R. O., and Kailasanath, K., "Investigation of the Properties of the Combustion Products Generated By Building Fires," Final Report of National Bureau of Standards Grant No. G8-9003, November 1978.

2. Bankston, C. P., Zinn, B. T., Browner, R. F., and Powe11, E. .A, "Fundamental Aspects of the Mechanisms of Smoke Generation by Burning Materials," presented at the Combustion Institute Meeting (Eastern Section) on Chemical and Physical Processes in Combustion, Miami Beach, Florida, November 29- December 1, 1978 (Submitted for publication in Combustion and Flame).

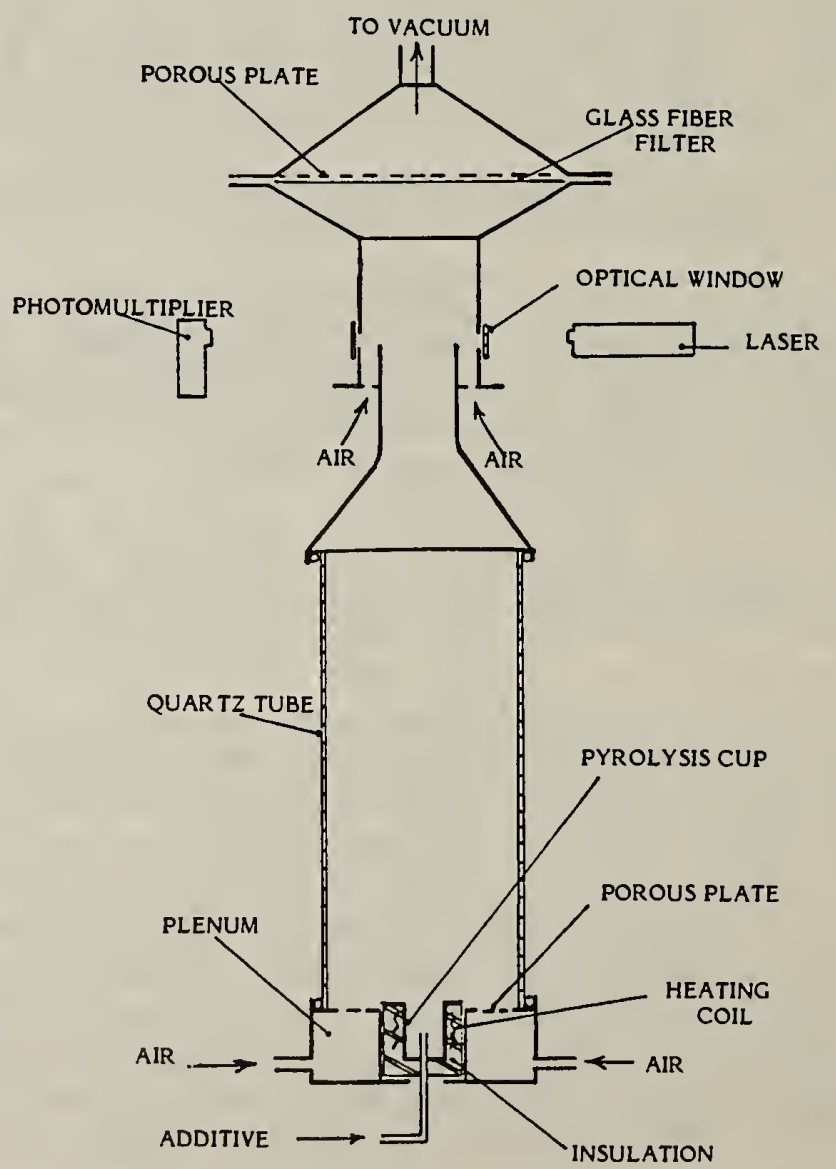

Figure 1. Modified Smoke Generation and Measurement Apparatus. 


\section{ANNUAL CONFERENCE ON FIRE RESEARCH \\ CENTER FOR FIRE RESEARCH \\ NATIONAL BUREAU OF STANDARDS \\ GAITHERSBURG, MARYLAND}

August $22-24,1979$

Institution: Harvard University

Factory Mutual Research Corporation

Grant No: NBS Grant 79011

Grant Title: Home Fire Project

Principal Investigators: Professor Howard W. Emmons Division of Applied Sciences

Harvard University

Cambridge, Massachusetts 02138

617-495-2847

R. Friedman

Factory Mutual Research Corporation

Norwood, Massachusetts 02062

$617-762-4300 \quad \times 570$

Other Professional Personnel: Dr. H. Mitler

Mr. Richard Land

J. Backovsky, Ph.D. Candidate

A. Atreya, Ph.D. Candidate

S. C. Tan, Ph.D. Candidate

J. Ramsdell, Ph.D. Candidate

NBS Scientific Officer: John Rockett

Technical Abstract

The Home Fire Project is directed toward the production of a fire code capable of computing a fire in a building from a drawing of the building and a description of its furniture. This consists of two parts:

1. The writing and testing of the equations and computer program itself, and

2. The development of the required understanding of the component phenomena which makes the computer program possible. owing:

Each of the tasks of the Home Fire Project is reviewed in the fol- 
Task 2: The Prediction of a Fire - H. Mitler and H. Emmons

The Harvard Computer Fire Code has now been under development for almost three years, and has reached a substantial level of sophistication and reliability. This is a mathematical model which "predicts" the development of a fire ignited on a horizontal surface, in a vented enclosure. The calculations can be carried forward through burnout and cooldown. Thorough discussion of the problem, plus a bibliography, are given in our Technical Report 非7, "The Physical Basis for the Harvard Computer Fire Code".

Progress has been made during the last year both in the application of physical laws to the dynamics of enclosure fires, and in the structure of the program which implements these. Some of the improvements and extensions to the physics were: the flame structure has been made more internally consistent. A correction was introduced to take into account the burning of the sides of a slab. Almost all the radiative flux calculations needed improvement, and got it. Also, all the significant fluxes which had not yet been calculated, were. The vent area is now taken into account in the heat transfer calculations. New, more general subroutines have been written for the pool fire and burning slab (includes now the possibility of burn-through in the center). We now have a subroutine which permits ignition of a target. Finally, a new subroutine has been prepared which calculates the $\mathrm{CO}, \mathrm{CO}$, and smoke (including hydrocarbon) concentrations in the layer, as well as the $\mathrm{O}_{2}$ concentration.

It has been found that a (fifth) vent regime is sometimes needed for a single vent in a single enclosure. The five regimes now used are:

1. cold flow only, driven by gas expansion (by the fire);

2. both hot and cold flow out, driven by gas expansion augmented by buoyancy;

3. hot gas out, cold gas in, when buoyancy outflow exceeds the gas expansion;

4. hot gas out, cold gas in, when under 3. the hot layer falls below the vent sill. This is choked flow and the fire is ventilation limited;

5. the fifth regime is hot gas only flowing out. It occurs for a small height vent high in the wall. It occurs when the buoyancy outflow is not sufficient to provide the required gas expansion. This regime is of short duration since the oxygen in the room is soon depleted and the fire slows down until regime 4. replaces 5.

If a vent connects two rooms, each of which may have hot and cold layers, the vent flow will depend upon two layer depths, four gas densities, in addition to its sill and lintel positions. There are a total of seventy possible flow regimes. A new approach to vent flow has been devised, coded, and checked as the above described calculations for a single vent in a single room. The new approach is not as complex as the above and is capable of identifying and calculating all seventy cases. The new vent subroutine will replace the entire present VENT subroutines as soon as it has been adequately checked out.

The program structure has been improved in the following ways: 
an INPUT routine has been written; also an alternative, more convenient output format. The debugging options have been expanded and made more flexible. The indexing scheme has been generalized and improved. Better predictors for a new time-step have been used, the degree and frequency of rescaling has been optimized, as well as the use of the most powerful but slowest mode, NWTN. The program has been made reasonably machine-independent.

There have been many other small changes, too numerous to mention, in both the physics and the programming. All of these have resulted in substantial improvement in the accuracy of prediction of the measured variables, with a simultaneous reduction in running time. As of June 1 , the program is essentially version IV, and is available on tape.

A number of further developments, both in the physics and in the numerical procedures, are underway; some of these may be ready for presentation at the August meeting. We may say that the program is evolving at a reasonably satisfactory rate. 
Task 5a: Experimental and Theoretical Study of Horizontal Fire Spread on Wood - A. Atreya

To prevent home fires it is necessary to have an understanding of how fire spreads on wood, under the conditions of external radiation (from a hot layer and other fires) and vitiated air. A 1iterature review was done on both fire spread and pyrolysis of wood. A plane section (defined by depth in the solid and direction of spread) of partially burned wood has a layer of charcoal followed by a semi-pyrolyzed region and finally virgin wood. A mathematical formulation of the complete solid and gas phase problem is quite complex. In view of these complexities a simplified model using a pyrolyzing surface approximation is proposed.

Before attempting to solve the proposed model, experimental work was started with an aim to determine:

1. mass pyrolysis rate;

2. flame spread velocity;

3. mass burning rate;

with radiation and eventually vitiation as parameters.

The procedure consists of:

a. instrumenting a slab of wood (sugar pine) with thermocouples;

b. placing it on a weighing table under a desired radiant flux;

c. igniting at the center with a pilot flame and measuring continuously the above mentioned quantities, as fire spreads on the horizontal slab of wood.

This turns out to be fairly hard to do experimentally.

At surface temperatures below $150^{\circ}$ to $160^{\circ} \mathrm{C}$ a sustained combustion was not obtained. Above these surface temperatures a sustained combustion is possible, but depending on the temperature profile inside the wood either continuous or disjoined propagating flame fronts are obtained. To obtain a continuous growing fire on a plane slab it is found to be necessary to allow the temperature of the entire slab to reach above $150^{\circ} \mathrm{C}$. Even under these conditions a regular repeatable spread geometry has yet defied several trials. A probable cause is a high sensitivity of the fire growth to the detailed properties of the wood. A correlation between the total burnt area and the mass pyrolysis loss exists. Experimental work on this is in progress. 
Task 5b. Experimental and Theoretical Study of Horizontal Fire Spread on Plastics - S. C. Tan

This task is in the literature review and equipment design (modification) stage. It will supply much needed additional data on fire growth on plastic materials.

Task 5c. 3 Perfect the Fire Spread Research Equipment - R. Land

The $28 \mathrm{~m}^{3}$ enclosure (Sears storage shed) used as a fire test chamber is being used for fire tests. The weighing system for measurement of the rate of pyrolysis is working excellently. The air flow distribution below the floor is still not wholly satisfactory since the flames still slightly lean preferentially in one direction. The rate of burning will be measured by oxygen depletion and heat release. An integrating hot wire thermometer has been installed in the exhaust duct taking advantage of a nearly flat velocity profile in that location. Thus the energy of the exhaust gases may be computed from the mean velocitr and the hot wire reading when properly calibrated. The present $.2 \mathrm{~W} / \mathrm{cm}^{2} \mathrm{ra}-$ diant external flux is being increased by more than an order of magnitude by new radiant units and a larger power supply.

A few burning tests have been performed with $4 \mathrm{ft}$. enclosure inside of the fire test enclosure. It was arranged with a small door and a closeable hole in the ceiling. With the hole closed, the fire grew at a linear rate after 160 seconds. With the hole open it grew exponentially with a 20 second doubling time. This rapid fire growth occurred because of increased ventilation in spite of the fact that the open hole at first decreased the hot layer. The importance of roof ventilation to fire fighting suggests that ceiling ventilation be added to our Computer Fire Code in the near future. Roof ventilation is important not only because of the immediate removal of the interior hot and smoky gases but also because of the danger to firemen who go to the roof to cut the hole.

Task 5d. The Theory of Boundary Layer Burning with Radiation J. Backovsky

The investigation of radiative effects in laminar, steady-state, boundary layer burning in forced and free convection was continued in these directions:

1. The parametric study in forced-convection burning with $\operatorname{Pr}=$ 0.73 was expanded, the previous results with Unity Prandtl number being significantly different. Among the physical quantities obtained were the mass pyrolysis rate, the burning rate, the flame radiative heat flux incident on the fuel surface, and the ratio of the radiative to the total heat flux transferred to the fuel surface.

2. Corresponding results were obtained specific to fourteen (14) real liquid fuels burning in forced convection. The fuels include alcohols, hydrocarbons, cyclic compounds, and such common organic compounds as acetone, napthalene and toluene, and it is hoped that a wide range of radiative characteristics are represented. While it was found that (for a given fraction of the heat evolved at the flame transferred as radiation) the ratio of radiative to the total heat flux absorbed by the fuel surface varies up to a factor of 3 , the radiant heat flux incident on the fuel surface varies only $20 \%$ among these fuels: i.e., the heat generated at the flame by the various fuels varies only by 
20\%. So a larger radiative fraction would be needed to account for a substantial difference in the radiant output of a flame--as is observed for turbulent flames. Flame temperatures and their decrease caused by radiative cooling is obtained, and correlations between the various radiative effects can be made. The sensitivity of the above results to the fuel surface absorptivity was also determined.

3. Work is in progress on the effects of variation of some transport properties as compared to the calculated radiative effects. The specific heat and viscosity are included as dependent on temperature and composition, with other transport properties varied in accordance with keeping the Prandtl and Lewis numbers constant.

Task 6. The Use of the Mathematical Model

Copies of the Computer Fire Code III have been made available to a few potential users. We have started some systematic uses to explore its usefulness and its weaknesses. So far only two subprograms have been supplied by others and both of these worked after some modest adjustments.

Reports and Papers

Emmons, H. W. "Fire," 8th National Applied Mechanics Congress, UCLA, June, 1978

Emmons, H. W. "A Note on Minimizing the Unknowns for Computation of a Large System of Equations," Home Fire Project, Tech. Report 非6, Harvard Univ. July 1978

Emmons, H. W., "The Prediction of Fires in Buildings," 17th Symposium (Inter.) on Combustion Aug. 1978

Shih, T. M., "Fire Characteristics Under the Influence of External Radiation," Home Fire Project, Tech. Report 非3, Harvard Univ. AuE. 1978

Mitler, H. E., "The Physical Basis for the Harvard Computer Fire Code" Home Fire Project, Tech. Report 非4, Harvard Univ. Oct. 1978

Emmons, H. W., MacArthur, C., Pape, R., "The Status of Fire Modeling in the U.S. $-1978, " 4$ th U.S./ Japan Coop Program on Nat. Resources, Tokyo, Feb. 1979

Mitler, H. E., "Users guide for the Harvard Computer Fire Code," Home Fire Project, Tech. Report 非37, Harvard Univ. Apr. 1979

Emmons, H. W., "Scientific Progress on Fire," Annual Reviews of Fluid Mechanics, 1979 


\section{ANNUAL CONFERENCE ON FIRE RESEARCH \\ CENTER FOR FIRE RESEARCH \\ NATIONAL BUREAU OF STANDARDS \\ GAITHERSBURG, MARYLAND}

August 22-24, 1979

\section{Institution: IIT Research Institute}

\section{Grant/Contract No: NB79SBCA0068}

Title: Preflashover Room Fire Model: Parametric Sensitivity Analysis and Development of a Submodel for Burning Furniture Items

Principal Investigator: Ronald Pape

Fire and Safety Research

IIT Research Institute

10 West 35 th Street

Chicago, IL 60616

$312 / 567-4786$

Other Professional Personnel: Mr. Thomas E. Waterman

Mr. Thomas V. Eichler

NBS Scientific Officer: V. Babrauskas

Technical Abstract

A two phase program has been undertaken to develop a model for burning furniture items within an enclosure. The model will be designed to be incorporated into a room fire computer model such as IITRI's RFIRES code. Phase 1 embodies the preliminary work required to establish the specific approach which will be followed in developing the model. Pertinent literature related to furniture item burning is being reviewed and summarized. The literature includes acticles describing flame spread models as well as pertinent literature on small scale and full scale experiments. NBS has been contacted to determine ongoing work at NBS and elsewhere. The literature review is to help identify the controlling phenomena and parameters which must be considered in developing the model as well as to identify existing submodels and applicable analytical techniques.

The burning item model must be compatible with the overall room fire model. In order to assure that the needs of the submodel can be satisfied and that the submodel generates the proper data required by the overall model, the structure of the RFIRES code will be evaluated. The output variables of interest will be identified, the governing equations will be outlined, and the hierarchies of phenomena will be developed based on the RFIRES model. The literature survey and discussions of ongoing research with NBS personnel will reveal certain areas where 
information or understanding is lacking. Some simple experiments will be necessary to help supply missing data required early in the program and to identify dominating phenomena. During Phase 1, much of the instrumentation required in later phases will also be set-up and checked. The Phase 1 effort will result in a report documenting the work performed. This report will include a plan for developing the burning item model in Phase 2. Phase 1 is scheduled for completion at the end of August 1979.

Phase 2 is to develop a preliminary burning item model. Phase 2 will begin with a parametric sensitivity analysis of the RFIRES code. This will identify parameters which must be predicted accurately by the burning item model, as opposed to insensitive parameters for which less accuracy is acceptable. In addition, sensitive and insensitive parameters for other aspects of the overall model will be identified. Based on the plan developed in Phase 1, a preliminary burning item model will be developed. Experimentation required to support the model development will be accomplished where appropriate. Phase 2 will result in a report describing the burning item model. A revised users manual for the RFIRES code will also be produced in order to consolidate the information presented in previous reports on the model.

At the conclusion of this two phase effort, a burning furniture item model will have been developed. The model will not be extensively tested, nor will it be incorporated into the overall room fire model. In a follow-on effort, the burning furniture item model should be validated and incorporated into an enclosure fire model. The complete room fire model, including the furniture item submodel, should be comprehensively tested.

The development of the burning furniture item model in a manner that it can be incorporated into a room fire model is expected to lead to the development of one or more furniture standard tests which characterize the fire hazard in a truly meaningful way. The tests will be defined by the requirements of the analytical model and the model can be used to correlate the test results to the full scale real fire situation. 
ANNUAL CONFERENCE ON FIRE RESEARCH

CENTER FOR FIRE RESEARCH

NATIONAL BUREAU OF STANDARDS

GAITHERSBURG, MARYLAND

August 22-24, 1979

Institution: The Johns Hopkins University, School of Hygiene and Public Health

Grant No.: G8-9001

Grant Title: Evaluation of Toxicity of Combustion Products

Principal Investigator: Zoltan Annau, Ph.D.

The Johns Hopkins University

School of Hygiene and Public Health

Department of Environmental Health Sciences

615 North Wolfe Street

Baltimore, Maryland 21205

(301) 955-3029

$\begin{aligned} & \text { Other Professional Personnel: } \text { Patricia McGuire, Ph.D., Research } \\ & \text { Associate } \\ & \text { John Campbel1, Research Technician }\end{aligned}$

NBS Scientific Officer: Dr. Merritt Birky

Project Summary: It is the purpose of this project to measure the potential toxicity of combustion products. We have developed an animal model in which we have evaluated the effect of the combustion products of flexible polyurethane foam on continuous avoidance behavior in rats. Rats trained to lever press to avoid a mild electric shock were exposed to four concentrations of polyurethane foam combustion products. As the concentration of toxic gases increased, the performance of the animals declined progressively. When the smoke was cleared from the chamber, performance of the animals returned to control in 30 minutes.

Progress Report: The behavioral paradigm has been described in previous progress reports. Briefly, rats are trained to press a lever to avoid a shock to the feet. Each lever press postpones the shock by 30 seconds. If the animal fails to respond, shocks are delivered every 5 seconds. A trained animal will.produce a continuous rate of responding with few shocks received during the experimental session. The avoidance chambers were placed inside a 200 liter plexiglas combustion chamber. This chamber was $58.8 \times 58.8 \times 58.8 \mathrm{~cm}$ with a modified Potts furnace underneath a $6 \mathrm{~cm}$ opening in the middle of its base. The avoidance chambers were placed approximately $20 \mathrm{~cm}$ from the top of the combustion chamber, 2 on each side. A stainless steel cone was placed over the quartz beaker holding the sample in order to 
contain the flames during combustion. The combustion chamber was designed to be a static system with a pressure relief balloon attached to one side. Gas sampling lines, return lines, and thermocouples were connected through airtight connectors at the level of the animal's chambers. A thermocouple inside the beaker was used to determine temperature at the bottom of the beaker. Carbon monoxide and oxygen concentrations were monitored at five minute intervals throughout the experiments, with the gas return lines ensuring constant conditions inside the chamber. Three $7 \mathrm{~cm}$ ports, two at the sides, one at the top were opened at the end of the 30 min experimental protocol in order to vent the combustion products. The entire combustion chamber, and furnace were placed inside a chemical hood connected to the exhaust system of the building.

Rats performing on the avoidance schedule described previously (see above), were exposed to $2.0,4.0$, or 8.0 grams of flexible polyurethane foam (PUF) (GM-21). Each rat was used for on1y one exposure. The furnace controller was set to rise to $650^{\circ} \mathrm{C}$. This provided a temperature ramp which, although not linear, was constant across exposure (Fig. 1). During the first five minutes there was little increase in the furnace temperature. From 5 minutes to 17 minutes the furnace temperature increased at approximately $30^{\circ} \mathrm{C}$ per minute. Smoke was first apparent 10 minutes, and the PUF burst into flames at 17 minutes. The furnace temperature increased to approximately $650^{\circ} \mathrm{C}$ during flaming. At the end of flaming the furnace temperature decreased around $50^{\circ} \mathrm{C}$ and then continued to increase at a lower rate (10-15 min) until it was turned off at the end of 30 minutes. The time course for combustion was consistent across concentrations of PUF and across exposures. When the furnace was turned off at 30 minutes, the chamber was cleared via the air ports described previously. Rats remained in the chamber performing on the avoidance schedule for an additional 30 minutes.

The heat generated from the furnace and from the combustion process caused an increase in the chamber temperature during the 30 minute exposure period (Fig. 2). At all concentrations, there was a slight increase in the chamber temperature during the first 17 minutes of the exposure. As is shown in Fig. 1, when flaming occurred, the chamber temperature increased as a function of the amount of PUF. Following flaming, the chamber temperature decreased, but remained at a temperature higher $\left(33-35^{\circ} \mathrm{C}\right)$ than the chamber temperature at the beginning of the exposure $\left(25^{\circ} \mathrm{C}\right)$. To control for the possible effects of chamber temperature, one group of animals was exposed to a temperature gradient which simulated the increase which occurred with burning 8 grams PUF.

Results:

Response rate during the 30 minute exposure period was not significantly affected at any of the concentrations of PUF tested. Shock rate showed a consistent increase of approximately $100 \%$ over control 
rate, regardless of concentration (Fig. 3). In the 30 minute period following the exposure, response rate showed a dose related decrease. Shock rate was also increased during the post-exposure period to $803 \%$ and $565 \%$ control at 6 and $8 \mathrm{~g}$ PUF, respectively.

The 60 minute session was divided in 5 minute intervals and the total number of responses or shocks in each 5 minute interval is shown. The effects of 2, 4 and $6 \mathrm{~g}$ PUF on both shocks and responses was inconsistent and showed considerable variability across animals. With $8 \mathrm{~g}$ PUF, there was a large increase in shocks and decrease in responses in the 30 minute period following exposure.

Increasing the chamber temperature by itself had little effect during the initial 30 minute period. There was a slight increase in response rate and decrease in shock rate in the 30 minute following the temperature increase. Response distribution was unaffected during the heat exposure but showed a slight increase in responses toward the end of the 30 minute post-exposure. Shock distribution was unaffected by the temperature changes.

Carbon monoxide and oxygen levels were determined at 5 minute intervals during the smoke exposure period (Figures 4 and 5). During the first 15 minutes (prior to flaming) there was no effect on either $\mathrm{CO}$ or $\mathrm{O}_{2}$. Following flaming (17 minutes) $\mathrm{CO}$ levels increased during the subsequent 15 minutes. The extent of the increase was related to PUF concentrations with an increase to greater than $2000 \mathrm{ppm}$ at $8 \mathrm{~g}$ PUF. $\mathrm{O}_{2}$ levels decreased in a concentration related manner during the same time period.

The disruption in behavior under these experimental conditions is less than those reported with restrained animals in a leg-flexion avoidance paradigm. These findings emphasize the importance of comparing behavioral disruption under different procedures. Exposure in the present studies were conducted using a temperature ramp with the exposure duration timed from the point when the furnace was turned on. The consequence of this was a total shorter period of exposure to the PUF. This could in part account for less behavioral disruption. Secondly, animals in our studies were unrestrained and whole body exposures were used. The more severe disruption seen in restrained animals using only nose exposures may represent enhanced toxicity of $\mathrm{PUF}$ as a consequence of intense stress.

Reports and Papers:

Society of Toxicology 18th Annual Meeting, March, 1979. Effects Of Heat And Carbon Monoxide On Continuous Avoidance Performance. W.F. Sette and Z. Annau, Dept. of Env. Hlth. Sci., Johns Hopkins Univ., Sch. of Hyg. \& Pub. Hlth., Baltimore, Md. 21205 Sponsor: R. Rubin Abstract No. 407 . 
FIGURE 1

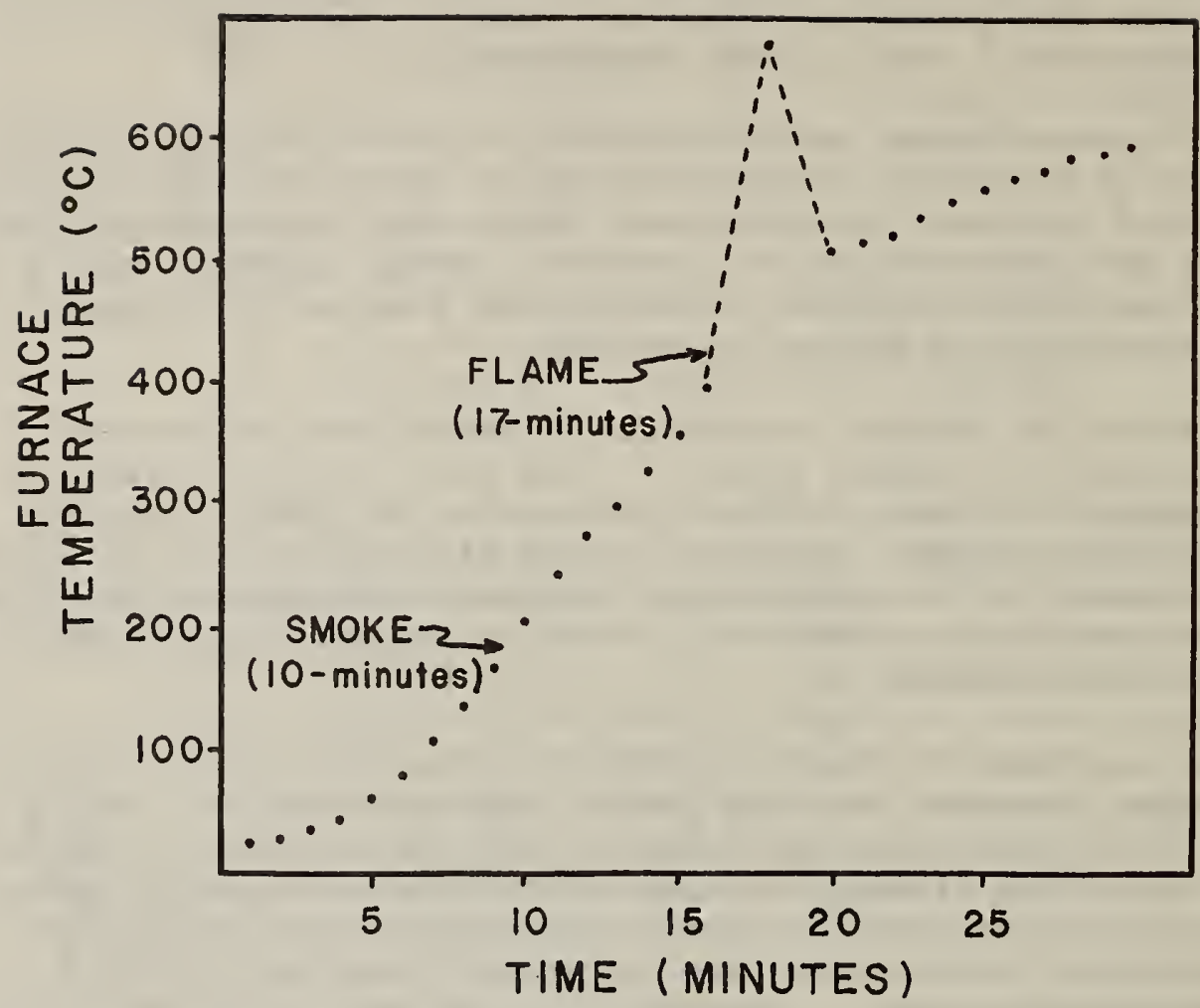

FIGURE 2

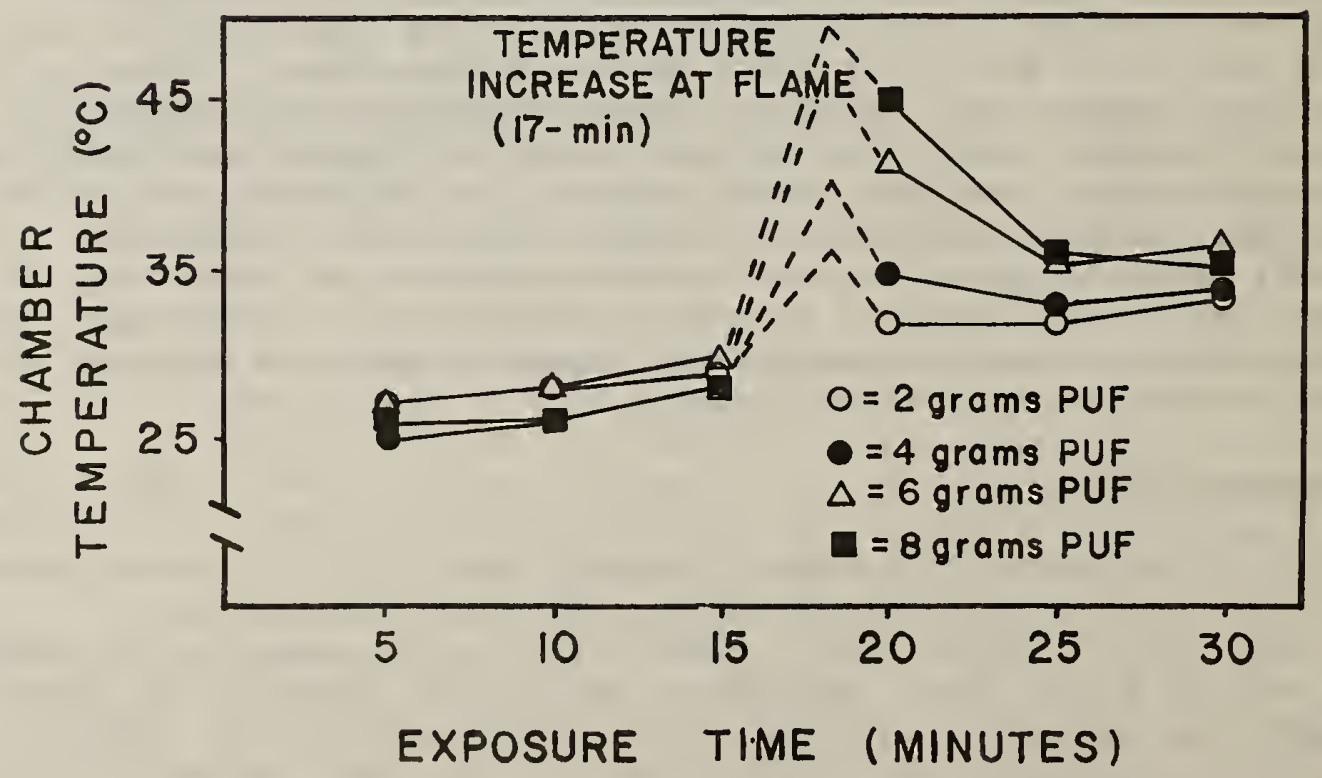


FIGURE 3

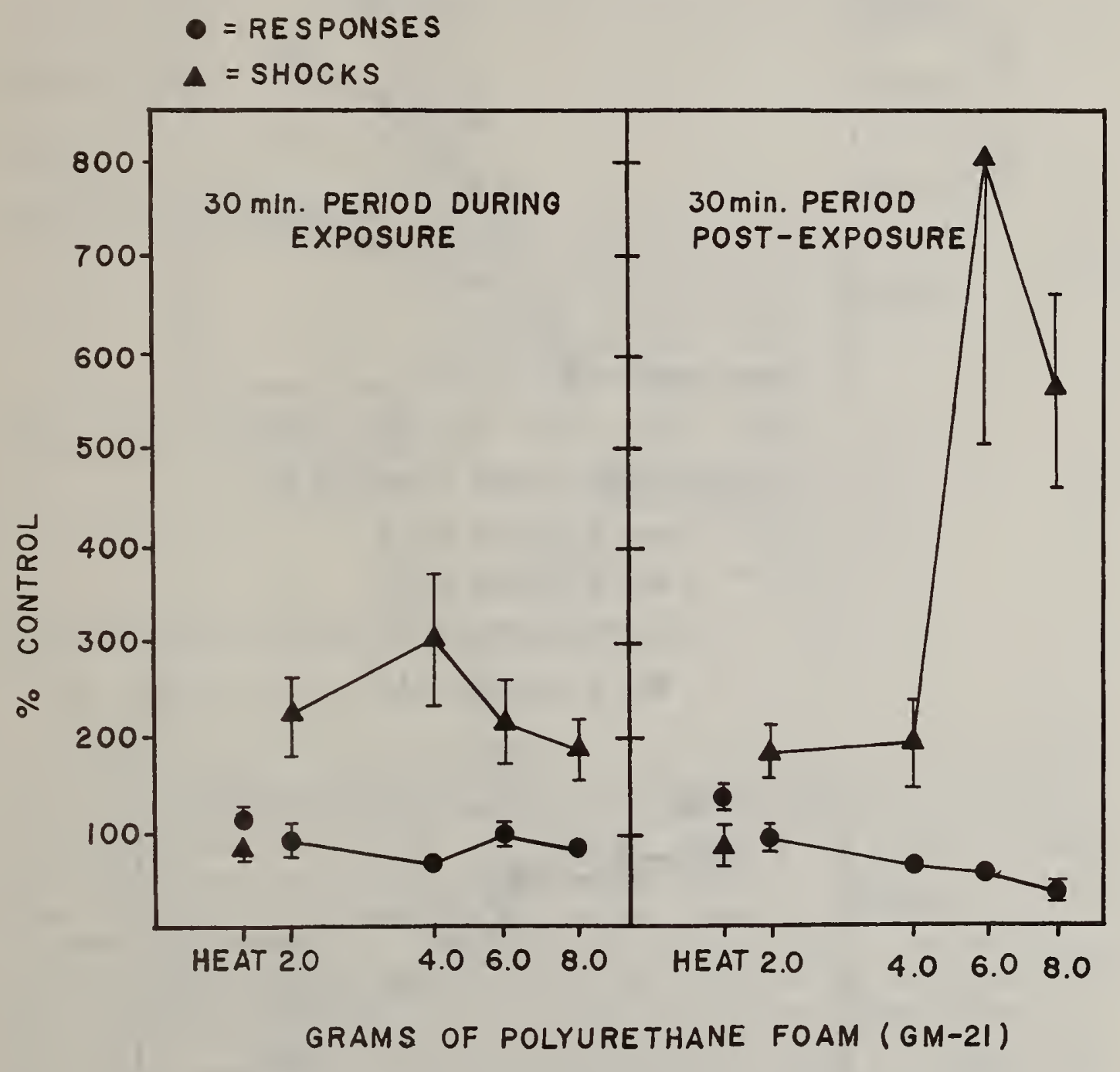




\section{FIGURE 4}

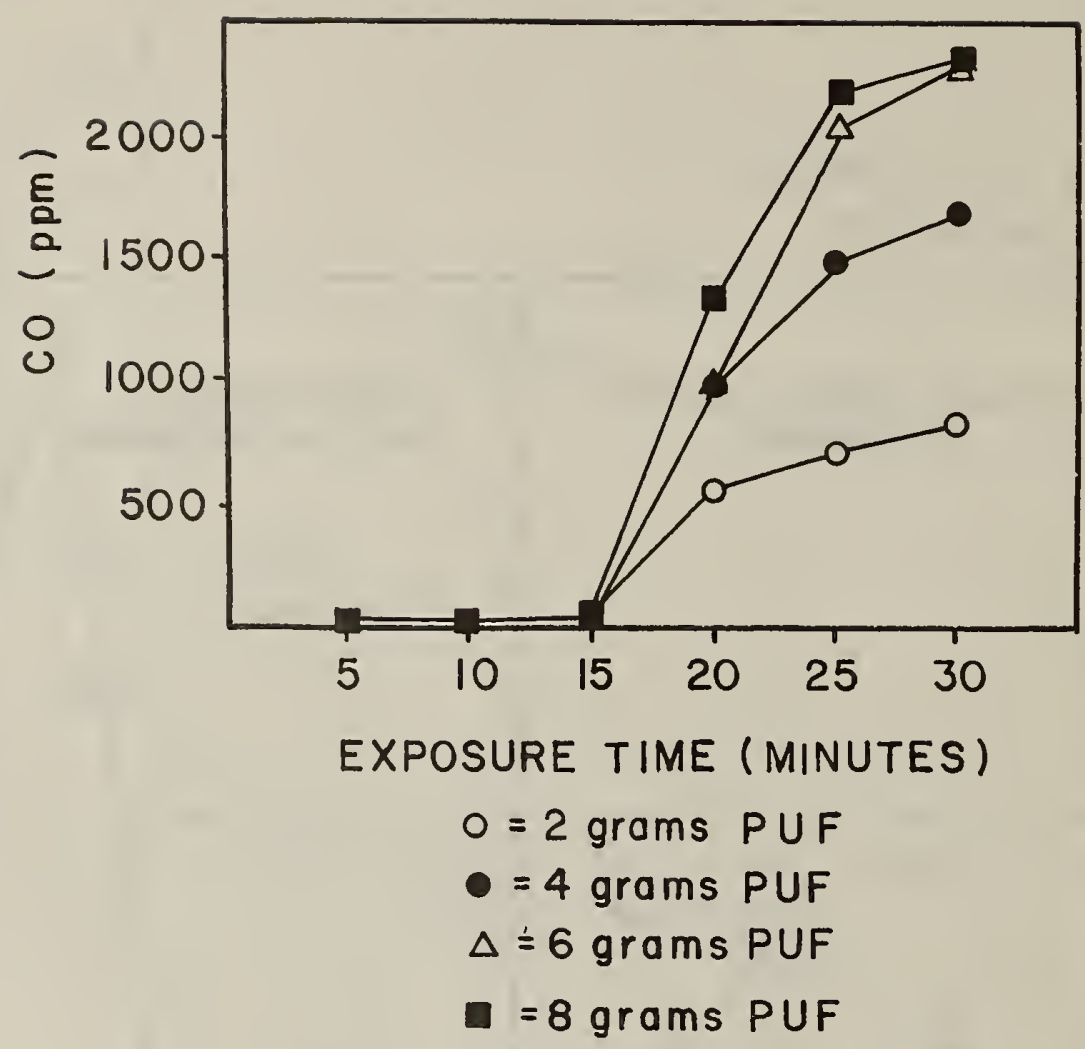

FIGURE 5

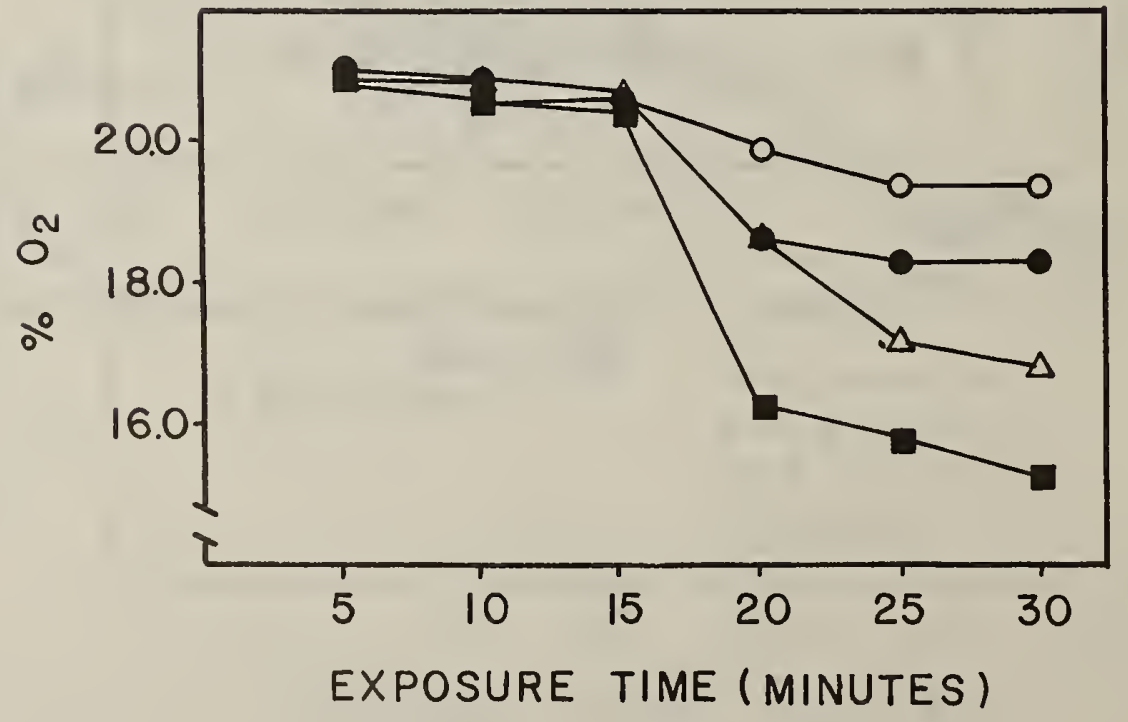


ANNUAL CONFERENCE ON FIRE RESEARCH

CENTER FOR FIRE RESEARCH

NATIONAL BUREAU OF STANDARDS

GAITHERSBURG, MARYLAND

August 22-24, 1979

Institution: The Johns Hopkins University/Applied Physics Laboratory

NBS Grant No: G7-9016

Title: Fire Casualty Study

Principal Investigators: Walter G. Berl

Byron M. Halpin

Applied Physics Laboratory

The Johns Hopkins University

Laurel, Maryland 20810

(301) 953-7100

Other Professional Personnel: Y.M. Caplan (Toxicology) *

O.J. Deters (Mathematics)

J.J. Diana (Chemistry)

R.S. Fisher (Pathology) *

R.M. Meyers (Medicien) *

NBS Scientific officer: Dr. M. Birky

A. FIRE CASUALTY STUDY

An overall review of the results of the study since its initiation in 1970 has been prepared (Ref. 1). An important goal of detailed studies is to gain an understanding of the causes of death and thereby to develop practical methods for reducing them in the future. Based on the Maryland study, it is evident that attention should be given to those sources that contribute the largest share to the fatal fire incidents, i.e. cigarettes. Bedrooms and living rooms in residences are the predominant areas of fire starts. Most of the incidents occur at night and most of the victims are found in bedrooms. The strong involvement of alcohol, causing accidental ignition and preventing adequate escape should be noted. The excess of fire deaths among black urban children and of the older generation in general identifies specific groups at higher than normal risk.

It was concluded that most of the directly traceable fire fatalities $(80 \%)$ occur within six hours of the fire incident. In most cases (75\%) the toxic gas inhalation was either solely or a strong contributing factor to the fatal outcome. Carbon monoxide is the predominant cause of acute death $(48 \%)$ with some contribution by hydrogen cyanide. Corrosive and other irritating combustion products acting on the pulmonary system, contribute importantly to the fatal outcome of delayed deaths. 


\section{B. FIRE INJURIES}

Since the formal initiation of the study (May 1978) the complex organizational arrangements for a cooperative effort (of which the most important is the referral of fire injuries to the Shock/Trauma Center of the Medical Institute for Emergency Medical Services by the fire jurisdiction of Baltimore City and 4 large surrounding counties) have been refined. An initial number of fire inhalation injuries and carbon monoxide inhalation cases have been dispatched to the Shock/Trauma Center for treatment and follow-up. A total of 32 serious fire injuries (of which 2 ended in delayed deaths), 22 carbon monoxide inhalation, were analyzed.

At this time, in only a few cases were all the clinical input data obtained, i.e. simultaneous analysis for carbon monoxide and hydrogen cyanide for blood samples taken at the fire scene and at different times during the detoxification treatment, breath analysis at the fire scene for carbon monoxide, detailed investigations of the fire scene for the cause of the fire and identification of the most likely materials involved in the generation of toxic products.

Figure 1 shows the trend toward increased referrals since the initiation of the program.

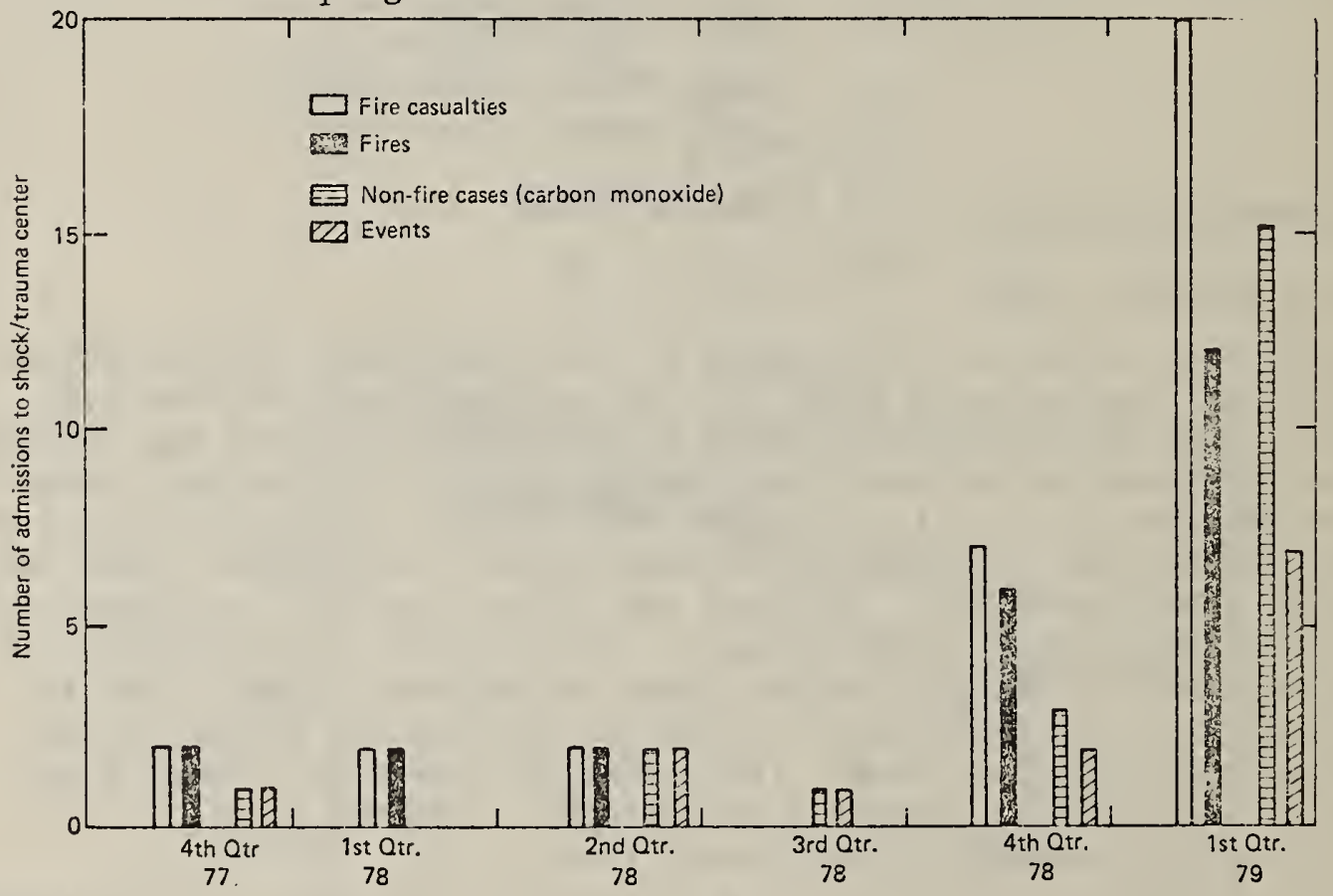

Figure 1

The intent of the Fire Casualty Study is to develop treatment methods for serious 'smoke' inhalation injuries. These treatments require that the causes of the injuries are understood so that the most appropriate countermeasures can be designed. The causes, in turn, are intertwined with the nature of the fire and the materials that are involved.

Reports and Papers: Ber1, W.G. \& Halpin, B.M., "Human Fatalities from Unwanted Fires" NBS-GCR-79-168 (Accepted for publication Fire Journal) 


\section{ANNUAL CONFERENCE ON FIRE RESEARCH \\ CFNTER FOR FIRE RESEARCH \\ NATIONAL BUREAU OF STANDARDS \\ GAITHERSBURG, MARYLAND}

August $22-24,1979$

Institution: Applied Physics Laboratory, The Johns Hopkins University

Grant Number: NBS Grant G7-9016

Grant Title: Fire Problems Research and Synthesis, Combustion Research

Principa1 Investigators: Drs. R. M. Fristrom and L. W. Hunter

Applied Physics Laboratory

The Johns Hopkins University

Johns Hopkins Road

Laure1, MD. 20810

Other Professiona1 Personne1: C. H. Hosha11, Engineer

NBS Scientific Officer: R. Gann

I. Polymer Flammability (L. W. Hunter)

I. (A) Technica1 Abstract

The effort divided into studies of ignition, propagation and steady burning.

An ignitability test for plastics was developed (Ref. 10). The test measures the delay time to ignition of a slab sample of the plastic in the wake of an $\mathrm{O}_{2}-\mathrm{rich}$ flame. The result is reproducible to better than $5 \%$. The delay time may be expressed in terms of the therma1 conductivity of the plastic and a surface temperature at ignition. The latter correlates with the surface temperature at the onset of flammable gas evolution, measured in a gas chromatograph with a flame ionization detector.

The role of surface oxidation in flame spread over plastics was studied (Refs 7-9). Evidence obtained in the low pressure Moving Wire Technique suggests that no net absorption of $\mathrm{O}_{2}$ occurs ahead of the flame front under conditions of horizontal flame spread over PVC (Ref. 9).

The steady state structure of a PVC flame was studied by the low pressure Moving Wire Technique (Refs. 3-5). Temperature and composition profiles were measured. In support of these experiments, a technique for measuring the heat transferred to the moving wire was developed earlier (Refs. 1 and 2). 
I. (B) Reports and Papers

(1) L. W. Hunter, C. H. Hoshall, C. Grunfelder, and R. M. Fristrom, "Moving Thermocouple Measurements of Heat Transfer in Hot Gases," Proceedings of the 10th Materials Research Symposium, Gaithersburg, (Sept. 1978).

(2) L. W. Hunter and C. Grunfelder, "Heat Transfer Measurements in the Moving Wire Technique for Studying Polymer Flammability," Comb. Flame. 34, 265-274 (1979).

(3) L. W. Hunter, C. Grunfelder, C. H. Hoshall, and R. M. Fristrom, "Combustion of Polyvinyl Chloride Studied by a Low Pressure Moving Wire Technique," Comb. Flame. 35, 169 (1979).

(4) L. W. Hunter, C. Grunfelder, C. H. Hoshall, and R. M. Fristrom, "Combustion of Polyvinyl Chloride Studied by a Moving Wire Technique," Proceedings of the Fall Technical Meeting (on Chemical and Physical Processes in Combustion) of the Eastern Section of the Combustion Institute, Miami Beach (November 1978), 4 pp.

(5) L. W. Hunter, C. Grunfelder, C. H. Hoshall, and R. M. Fristrom, "Combustion of Polyvinyl Chloride Studied by a Low Pressure Moving Wire Technique, Topical Report of Fire Problems Program, APL/JHU (August 1978).

(6) L. W. Hunter, "Extinction of Flame Propagation in a Mixture of Flammable Gas and $\mathrm{O}_{2}$ with a Steady Concentration Gradient," Topical Report of Fire Problems Program, APL/JHU (January 2, 1979).

(7) L. W. Hunter, "On the Role of Surface Oxidation in Flame Spread Over Solids," Topical Report of Fire Problems Program, APL/JHU (January 2, 1979).

(8) L. W. Hunter, "Fire Propagation with the Flow Inside a Thin-Walled Insulated Duct," Topical Report of Fire Problems Program, APL/JHU (February 14, 1979).

(9) L. W. Hunter and C. H. Hoshall, "Gaseous $\mathrm{O}_{2}$ Concentration Profiles Ahead of a Propagating Polymer Flame," Topical Report of Fire Problems Program, APL/JHU (April 19, 1979).

(10) L. W. Hunter and C. H. Hosha11, "An Ignition Test for Plastics," Topical Report of Fire Problems Program, APL/JHU (June 1979).

II. Flame Inhibition and Extinction (R. M. Fristrom)

R. M. Fristrom, C. H. Hoshall, and L. W. Hunter in collaboration with N. J. Brown (Un. of Calif., Berkeley) and P. J. Van Tiggelen (Laboratoire de Physico - Chimie de la Combustion, Universite de Louvain, Louvain la Neuve, Belgium). 
Flame inhibition and extinction have been examined using simple models which allow the inclusion of realistic chemistry for oxygen flames with $\mathrm{C}-\mathrm{H}-\mathrm{X}$ fuels and additives. The two zone model has been applied to an HCl inhibited hydrogen flame (Ref. 1, Fig. 2).

Using a normalize inhibition index, $\emptyset=\left(\mathrm{V}-\mathrm{V}_{\mathrm{In}}\right) \mathrm{O}_{2} /(\mathrm{V}$ In $)$, it was found that self-consistent additive atomic indices could be derived which would predict the index for any $\mathrm{H}-\mathrm{C}-\mathrm{X}$ molecule in a given flame $\varnothing=\emptyset_{\mathrm{C}}+\emptyset_{\mathrm{H}}+\mathrm{N}_{\mathrm{F}} \emptyset_{\mathrm{x}}$ (Fig. 2). The variation of halogen indices between flame system was interpreted in terms of the kinetics of two processes:

(1) scavenging in which a reactive radical is converted into a (relatively) unreactive radical or a saturated molecule, (2) recombination in which two radicals recombine to form a saturated molecule. Both processes depress the radical concentration which controls burning velocity. An analytical expression was derived relating the atomic index with scavenger stoichiometry and the ratio of halogen atom assisted recombination rate to the rate of branching $\phi(X)=\left[\mathrm{N}_{\mathrm{F}}+\mathrm{kx} / \mathrm{k}\right] \mathrm{K}_{\mathrm{F}}$. Inhibition has thus been quantitatively connected with the rates of elementary chemical reactions.

The zonal model has been extended to the complex chemistry of C-H-O-X flames (Ref. 3). This was accomplished using a modification of an existing Rocket Combustion Thermodynamic program. Burning velocity and flame microstructure can be calculated for any flame in this family. Excluding graphing the computational costs are less than $\$ 1$ per flame. The initial linear model using literature values for kinetics and transport with no adjustable parameters predicted burning velocities in five test cases which when compared with experimental values were systematically $30 \%$ low with a dispersion of $15 \%$ (see Table I).

Flame extinction can occur by two mechanisms. A physical one in which more than a critical amount of heat is lost and a chemical one in which radical generation mechanisms are disturbed. The physical mechanism commonly occurs when the burning velocity drop increases the flame thickness to the same order as the apparatus. This is called quenching and usually occurs when the burning velocity falls below a few $\mathrm{cm} / \mathrm{sec}$. Two chemical mechanisms were identified (Ref. 4): (1) Scavenging in which an added molecule converts all of the reactive radicals produced by the oxygen into unreactive species, (2) Recombination competition in which the kinetic constants and species concentrations are such that everywhere in the flame the rates of radical recombination exceed the rate of branching by $\mathrm{H}_{2} \mathrm{O}_{2}$. These mechanisms are being examined quantitatively using the new zonal model. Preliminary computations suggest that, (1) Fuel rich methane and ethane flammability limits result from scavenging by methyl radical, (2) The fuel rich limits of hydrocarbon flames beyond propane are due to competition between $\mathrm{H}+\mathrm{O}_{2}$ branching and $\mathrm{H}+\mathrm{O}_{2}+\mathrm{M}$ recombination (Fig. 3), (3) The fuel lean limits of hydrocarbons (with air) are due to quenching resulting from their low burning velocities. (4) The extinction limit of hydrogen ( $40 \%$ in air) by bromine may be due either to scavenging or to reduction of the burning velocity below the critical limit (Ref. 4). 
The concentration gradient apparatus for studying flame extinction has been constructed and is presently (June) undergoing tests. The theory of flame propagation in gradients has been examined (Ref. 5) to determine the regime of gradient in which the limit will approach that of a homogenous mixture.

\section{II. (B) Reports and Papers}

(1) N.J. Brown and R.M. Fristrom, "A Two Zone Model of Flame Propagation Applied to $\mathrm{H}_{2}$-Air and $\mathrm{HCl}$ Inhibited Flames", Fire and Materials, 2, No. 32117 (1978)

(2) R.M. Fristrom and P.J. VanTiggelen, "An Interpretation of the Inhibition of C-H-O F1ames by C-H-X Compounds", Seventeenth Symposium on Combustion, presented August 1978, (in Press 1979).

(3) R.M. Fristrom

(a) "A Thermodynamic Method for Calculating Stages in the Equilibration Zone of a Flame with Complex Chemistry" Internal memo (May 1979).

(b) "A Zonal Model for Flames with Complex Chemistry" Internal memo (May 1979).

(4) R.M. Fristrom

(a) "Flammability Limits and the Extinction of C-H-O F1ames by Halogenated Compounds" Internal memo (April 1978).

(b) "An Interpretation of the Flammability Limits of HydroCarbon-Oxygen F1ames" Internal memo (June 1979).

(5) L.W. Hunter "Extinction of Flame Propagation in a Mixture of Flammable Gas and Oxygen with a Steady Concentration Gradient", Topical Report of the Fire Problems Program APL/JHU (Jan.2, 1979)

Table I

Comparison Between Calculated and Experimental Burning Velocity

\begin{tabular}{ccc} 
Flame & $\begin{array}{c}\text { V Calc. } \\
(\mathrm{cm} / \mathrm{sec})\end{array}$ & $\begin{array}{c}\text { V Exp. } \\
(\mathrm{cm} / \mathrm{sec})\end{array}$ \\
\hline $46 \mathrm{H}_{2}, 54 \mathrm{Air}$ & 185 & 250 \\
$10 \mathrm{CH}_{4}, 20 \mathrm{O}_{2}, 70 \mathrm{Ar}$ & 41 & 64 \\
$41 \mathrm{H}_{2}, 57 \mathrm{Air}, 2 \mathrm{Br}$ & 170 & 245 \\
$10 \mathrm{CH}_{4}, 20 \mathrm{O}_{2}, 70 \mathrm{Ar}$ & 40 & 64
\end{tabular}




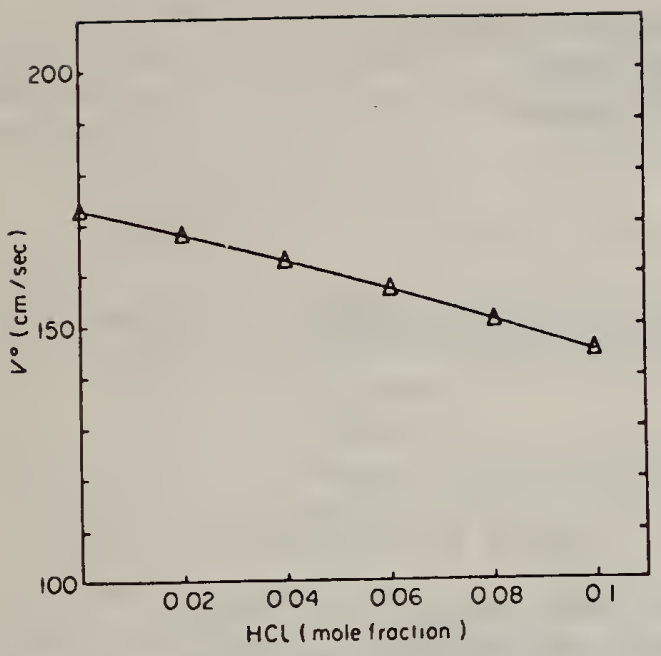

Fig. 1 Calculated propagation velocity $\mathrm{v}^{6}(\mathrm{~cm} / \mathrm{sec})$ as a function of $\mathrm{HCl}$ concentration (mole fraction).

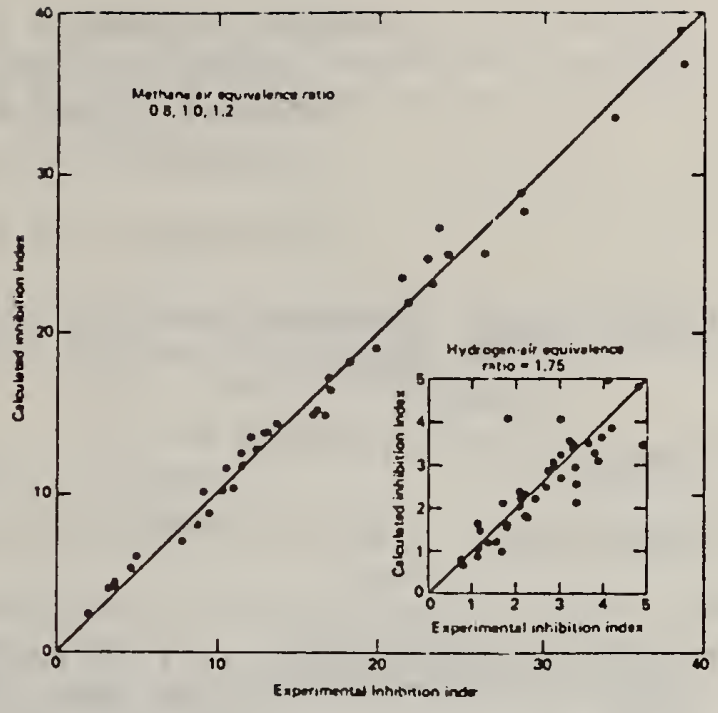

Fig. 2 Comparison between calculated and experimental inhibition indices for the methane-air and hydrogen-air systems.

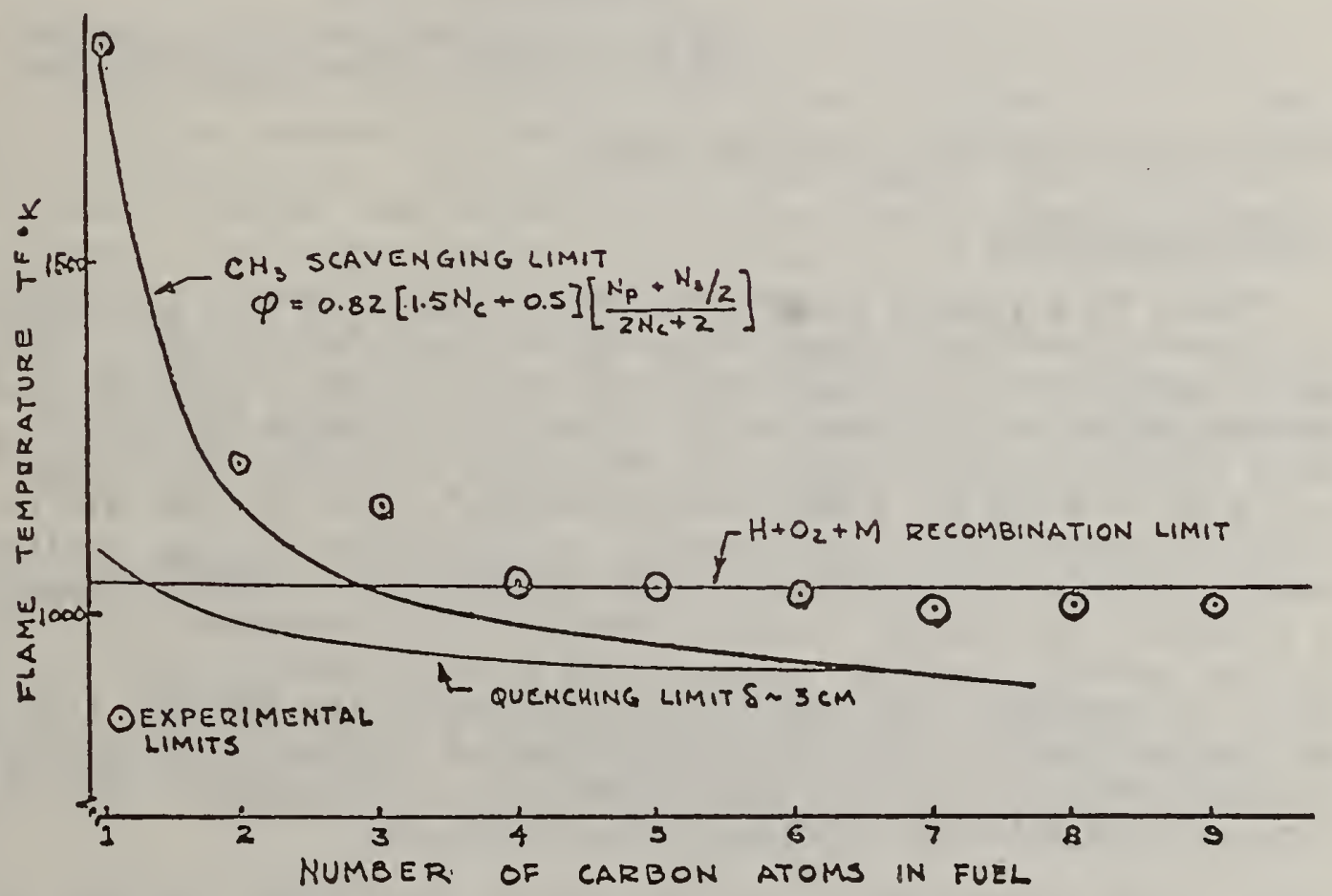

Fig. 3 Comparison of Theoretical Iimits For Three Mechanisms With Experimental Values For Fuel Rich Hydrocarbon Flames! 
ANNUAL CONFERENCE ON FIRE RESEARCH

CENTER FOR FIRE RESEARCH

NATIONAL BUREAU OF STANDARDS

GAITHERSBURG, MARYLAND

August 22-24, 1979

Institution: Lawrence Berkeley Laboratory, University of California, Berkeley

Grant No: P. 0. 812464

Grant Title: Fire Growth Experiments - Toward a Standard Room Fire Test

Principal Investigator: Professor Robert Brady Williamson

507 Davis Hal1

University of California

Berkeley, California 94720

(415) 642-5308

Other Professional Personnel: David Van Volkinburg, received Master of Engineering, 12/78

Wai-Ching Teresa Ling, Ph.D. candidate

Fred L. Fisher, Development Engineer

NBS Scientific Officer: William Parker

$\underline{\text { Technical Abstract }}$

There is a growing trend to use full scale room fire experiments, but there is not yet a standard version of the room fire test. The exact details of the standard room fire test are still being debated by working groups within ASTM, but it appears to be focusing in on an $8 \times 8 \times 12$ foot test compartment. The place of departure is the ASTM E603-77 Guide for Room Fire Experiments (1) which discusses the choices available for such parameters as compartment design, ignition source, instrumentation, test procedure, analysis of data and reporting of results. The current thinking favors a test compartment with a single door and the ignition source placed in one corner of the interior, away from the door. The exact size of the room, the doorway, the test specimen and particularly the ignition source have not been established. The test specimen could consist of complete panel assemblies that would form both the walls and ceiling of the test room.

(1) Annual Book of ASTM Standards. American Society for Testing and Materials, 1916 Race St., Philadephia, PA. 
The current project focuses on a series of six room fire experiments that are conducted in an $8 \times 12 \times 8$ foot test compartment with the following wall and ceiling lining materials on all walls and ceilings:

\begin{tabular}{cll} 
Test No. & \multicolumn{1}{c}{ Wall } & \multicolumn{1}{c}{ Ceiling } \\
1 & Gypsum Wallboard & Gypsum Wallboard \\
2 & Glass Fiber Insulation & Glass Fiber Insulation \\
3 & Plywood & Glass Fiber Insulation \\
4 & Plywood & Gypsum Wallboard \\
5 & Glass Fiber Insulation & Plywood \\
6 & Plywood & Plywood
\end{tabular}

Three experiments have been conducted at this time (Tests 1, 2, and 4) and the remaining three are planned for July 1979. The ignition source for these experiments has been a gas burner in the corner with $4.9 \mathrm{CFM}$ of $\mathrm{CH}_{4}$. Measurements have been made of (i) the oxygen depletion in the exhaust gases leaving the room (ii) the average upper air temperature in the room, (iii) the pressure and temperature profile from floor to ceiling in the center of the room, (iv) the surface temperature at the center of the ceiling and on a wall above the ignition source, and (v) heat fluxes at several locations.

The emphasis of this project has been to conduct experiments in which the contribution of the wall and ceiling finish material to the fire growth are measured by techniques which are practical for a standard room fire test method. The temperature measurements, heat flux, and photographic records have proven satisfactory during the first three experiments. The oxygen depletion measurements have been extensively modified since these first three experiments to allow a more accurate determination of the flow and oxygen content of the exhaust gases. An $8^{\prime} \times 8^{\prime}$ collection hood has been constructed outside the doorway of the test compartment and the oxygen cell has been moved to the duct on top of the building. It is expected that the final three experiments will be a critical test for the new duct and measurement apparatus.

Reports and Papers (This includes papers written under earlier projects but published during the current year)

"Toward a Standard Ignition Source," by D. R. Van Volkinburg, R. B. Williamson, F. L. Fisher, \& H. Hasegawa, LBL Report 8306, presented at the Western States Section, The Combustion Institute, Fall Meeting, Laguna Beach, California, October 16-17, (1978), Paper No. 78-64.

"Post-Flashover Compartment Fires: Basis of a Theoretical Model," by V. Babrauskas \& R. B. Williamson, Fire and Materials, 2, 2: pp. 39-53, (1978). 
"The Historical Basis of Fire Resistance Testing, Part II," by V. Babrauskas \& R. B. Williamson, Fire Technology, 14, 3: pp. 184-194, (1978).

"Temperature Measurement in Fire Test Furnaces," by V. Babrauskas \& R. B. Williamson, Fire Technology, 14, 3: pp. 226-238, (1978).

"Installing $\mathrm{ABS}$ and PVC Drain Waster and Vent Systems in Fire Resistant Buildings," by R. B. Williamson, Fire Journal, Vo1. 73, No. 2, March 1979, pp. 36-45.

"The Historical Basis of Fire Resistance Testing, Part II," by V. Babrauskas \& R. B. Williamson, Fire Technology, 14, 4: pp. 304-316, (1978).

"Application of Fault Tree Analysis to Ignition of Fire," by T. Ling \& R. B. Williamson, Fall Meeting of the Western States Section, The Combustion Institute, Laguna Beach, California, (1978), Paper No. 78-65. 
ANNUAL CONFERENCE ON FIRE RESEARCH

CENTER FOR FIRE RESEARCH

NATIONAL BUREAU OF STANDARDS

GAITHERSBURG, MARYLAND

August 22-24, 1979

Institution: Lawrence Berkeley Laboratory, University of California, Berkeley

Grant No.: 809252

Grant Title: Fire Modeling

Principal Investigator: Professor Patrick J. Pagni

Mechanical Engineering Department

University of California

Berkeley, California 94720

Telephone: (415) 642-0729

Other Professional Personnel: Charles M. Kinoshita, Ph.D. Candidate

Steven Bard, Ph.D. Candidate

Richard A. Beier, Ph.D. Candidate

Karen Den Braven, Ph.D. Candidate

Arthur Ortega (now at Sandia

Laboratories)

NBS Scientific Officer: Dr. Howard Baum

Technical Abstract:

The overall goal of this project is to develop physical and mathematical models of the detailed combustion phenomena which control a fire's growth within a compartment of origin and its subsequent propagation through a structure. These experimental and theoretical studies may provide bases for development of test methods and for evaluation of the real fire hazard of materials. This work is divided into three broad categories: (1) extensions and applications of excess pyrolyzate, (2) soot volume fractions in diffusion flames, and (3) flat flame burner design.

1. Excess Pyrolyzate: Several papers have been published describing the effect of fuel which is not consumed locally in the flame that produced it [1-3]. Emphasis has now shifted from the unburnt fuel as a fraction of the pyrolysed fuel to the flame height, since height is always indicative of excess pyrolyzate and is easier to measure. The following table gives predicted laminar flame extensions in units of fuel slab height, i.e. $X_{f l}^{*}=h_{f l} / l$, for typical PRC Sample Bank foams and cellulose. The samples are assumed to be flush mounted in a vertical wall with either free or forced flow with $\mathrm{Y}_{\mathrm{O}_{\infty}}=0.23, \mathrm{~T}_{\infty}=293 \mathrm{~K}$ and property data obtained from Tewarson. 


\begin{tabular}{|c|c|c|c|c|c|c|}
\hline $\begin{array}{l}\text { Material } \\
\text { (PRC No.) }\end{array}$ & 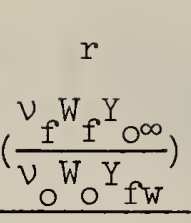 & $\left(\frac{\mathrm{Q}_{\mathrm{p}} \mathrm{Y}^{\mathrm{B}}{ }^{-\mathrm{h}_{\mathrm{W}}}}{\mathrm{L}}\right)$ & $\left(\frac{{ }^{\mathrm{BY}} \mathrm{ft}^{-\mathrm{SY}} \mathrm{O \infty}^{\infty}}{l+B}\right)$ & $\begin{array}{c}A \\
\left(\frac{Q_{p} o^{\infty}}{h_{W}}\right)\end{array}$ & $\begin{array}{l}x_{f l}^{*} \\
\text { wall } \\
\text { plume }\end{array}$ & $\begin{array}{l}x_{f \ell}^{*} \\
\text { wall } \\
\text { wake }\end{array}$ \\
\hline $\begin{array}{l}\text { Polystyrene } \\
(\text { GM-49) }\end{array}$ & 0.12 & 1.7 & 0.61 & 4.8 & 11 & 24 \\
\hline $\begin{array}{l}\text { Polystyrene } \\
(\mathrm{GM}-47)\end{array}$ & 0.15 & 1.1 & 0.49 & 4.1 & 8 & 15 \\
\hline $\begin{array}{l}\text { Polyurethane } \\
(\mathrm{GM}-21)\end{array}$ & 0.22 & 1.1 & 0.47 & 4.7 & 5 & 8.5 \\
\hline $\begin{array}{l}\text { Polyurethane } \\
\text { (GM-29) }\end{array}$ & 0.31 & 0.7 & 0.34 & 4.3 & 3 & 4.5 \\
\hline $\begin{array}{l}\text { Polyiso- } \\
\text { cyanurate } \\
(\mathrm{GM}-41)\end{array}$ & 0.43 & 0.4 & 0.23 & 4.0 & 2 & 3 \\
\hline $\begin{array}{l}\text { Cellulose } \\
\text { (filter paper) }\end{array}$ & 0.60 & 0.8 & 0.33 & 6.9 & 1.5 & 2 \\
\hline
\end{tabular}

The key parameter is the mass consumption number, $r$. As $r$ decreases, the flame height - and presumably the hazard of propagation beyond the compartment of origin - increases. This is a simple, easyto-use criterion for ranking materials; its accuracy is constrained by the fact that turbulence and radiation remain to be incorporated [7]. The details of the analyses and additional predictions are given in Ref. [3]. It is intended in the coming grant period: a) to obtain some experimental verification of these predictions, b) to add both external and flame-generated radiation to the analysis, c) to assess expected effects of turbulence, d) to consider energy feedback and oxygen vitiation in compartment configurations, e) to fit our numerical flame height results with simple functionals - $X_{f l}^{*}(r, B, A)$, and finally $f$ ) to explore incorporating these results in computational schemes currently under development elsewhere.

2. Soot Volume Fractions: Experimental values of $f_{v}$, the volume fraction of small turbulent diffusion flames occupied by combustion generated carbon particulate, have been reported [5]. Measurement of the attenuation at several wavelengths of monochromatic laser beams passing through a flame also determines approximate detailed size distributions for the carbon particles within the flame. Calculations of flame radiation back to polyurethane in a pool fire geometry yield good agreement with experimental mass pyrolysis rates [4]. Flame radiation is well accepted as the dominant heat transfer mode in full scale fires. This radiation is in turn controlled by the amount of soot in the flame which now can be measured in both laboratory and full scale flames by the 
techniques developed here. As discussed in Ref. [5], the next step is to examine the spatial variation of the volume fraction within a given flame and to determine proper scaling laws to allow small scale laboratory results to be accurately extrapolated to full scale fires.

3. Flat Flame Burner: The detailed temperature and velocity fields around a cooling coil embedded in a porous plug burner have been predicted assuming a low Reynolds number media [8]. The flat flame burner described is now in use in several laboratories and will permit useful comparisons of detailed flame structure experiments. Future work should examine the possibility suggested by the analyses that silversoldering the cooling coil to the upstream side of the porous plug may be as effective as embedding the coil within the sinter. It remains to examine the flow downstream of the plug as a field of interacting jets emanating from the pores. Alternatives to a water cooled porous plug as a flame stabalizer should also be considered. Our study of heat and mass transfer in wet concrete will be published shortly [6]. The conclusion is that there is not sufficient free water in concrete to cause significant departures from temperatures calculated under fire conditions assuming a dry medium. No further work in this area is planned.

\section{Reports and Papers:}

1. T.M. Shih and P.J. Pagni, "Laminar Mixed-Mode, Forced and Free, Diffusion Flames," Journal of Heat Transfer, 100, 253-259, 1978.

2. T. M. Shih and P.J. Pagni, "Analytic Incorporation of Probability Density Functions in Turbulent Flames," International Journal of Heat and Mass Transfer, 21, 821-824, 1978.

3. C.M. Kinoshita and P.J. Pagni, "Laminar Wake Flame Heights," American Society of Mechanical Engineers Paper No. 79-HT-68, 1979.

4. S. Bard, K.H. Clow and P.J. Pagni, "Combustion of Cellular Urethane," Combustion Science and Technology, 19, 141-150, 1979.

5. P.J. Pagni and S. Bard, "Particulate Volume Fractions in Diffusion Flames," Proceedings of the Seventeenth Symposium (Int'l) on Combustion, in press.

6. M.S. Sahota and P.J. Pagni, "Heat and Mass Transfer in Porous Media Subject to Fires," International Journal of Heat and Mass Transfer, in press.

7. T.M. Shih and P.J. Pagni, "Excess Pyrolyzate in Turbulent Wake Flames," in preparation.

8. P.J. Pagni, A.R. Ortega and R. Toossi, "Flat Flame Burner Analyses," in preparation. 
ANNUAL CONFERENCE ON FIRE RESEARCH

CENTER FOR FIRE RESEARCH

NATIONAL BUREAU OF STANDARDS

GAITHERSBURG, MARYLAND

August 22-24, 1979

Institution: Lawrence Berkeley Laboratory, Berkeley

Grant NO. : NBS Contract 805180

Grant Title: Polymer Combustion and Flame Chemistry

Principal Investigators: Dr. Nancy J. Brown

Lawrence Berkeley Laboratory

(415) 642-0289

Professor Robert F. Sawyer

Lawrence Berkeley Laboratory and

Department of Mechanical Engineering

University of California

Berkeley, California 94720

(415) 642-5573

Other Professional Personnel: Dr. Robert W. Schefer

William J. Pitz, Ph.D. Candidate

Minna W. Chan, undergraduate student

NBS Scientific Officer: Dr. R. G. Gann

Project Summary:

Polymer combustion, flame inhibition, and flame chemistry have been investigated experimentally and theoretically. Fundamental characteristics of polymer combustion (extinction limits, burning rates, mass transfer numbers and flame structure) have been measured with the objective of relating basic chemical and physical polymer properties to flammability. The flame inhibition studies have been directed toward gaining an improved understanding of inhibition mechanisms which prevail in different combustion environments.

Technical Abstract:

A modelling study of chemical flame inhibition has been completed for the inhibitors $\mathrm{HCI}$ and $\mathrm{HBr}$. The following variables were considered in the study: 1) inhibitor concentration 2) fuel type 3) fluid mechanics 4) equivalence ratio and 5) pressure. Perfectly stirred reactor equations were solved for a series of residence times and the corresponding compositions and temperatures between the blowout condition and thermodynamic equilibrium were obtained. Reaction rates and heat release rates for the various reactions considered were examined at the blowout condition. Computational studies of inhibited mixtures reacting in plug flow were completed. Quantities of interest were induction times, 
radical profiles, temperature profiles and heat release profiles. The complex trade-off between reaction exothermicity and radical scavenging ability for various inhibitor reactions was responsible for differences between $\mathrm{HCl}$ and $\mathrm{HBr}$. Inhibitor effectiveness was found to be dependent upon fuel type.

Major emphasis has been placed upon obtaining flame structure measurements for polyethylene, burning in an opposed flow diffusion flame. A gas chromatograph analytical system has been constructed, tested and calibrated. A new aerodynamic nozzle for oxidizer flow which provides a uniform velocity profile and a laminar-type flow across its exit has been constructed and characterized. The nozzle provides a very flat flame which greatly facilitates making composition measurements. The experimental variables considered in the structure studies were oxidizer flow velocity and the mole fraction of oxygen in the oxidizer flow. Profiles were obtained for flames near and far away from extinction conditions. Examination of the profiles revealed that little oxygen is transferred through the flame zone.

The gradient in oxygen concentration at the surface determines whether or not oxygen is transported to the polymer surface. Oxygen transported to the surface can oxidize the polymer, heterogeneously. Analysis of the structure data indicated that the oxygen gradient near the surface was zero for flames near extinction and very small for flames far away from extinction. As one approached extinction, $\mathrm{CO} / \mathrm{CO}_{2}$ ratios were found to increase significantly.

$\underline{\text { Reports and Papers: }}$

1. Brown, N. J., Eberius, K. H., Fristrom, R. M., Hayermann, K. H. and Wagner H. Gg. "Low Pressure Hydrogen/Oxygen Flame Studies," Combustion and Flame 33, 151 (1978).

2. Brown, N. J. and Fristrom, R. M. "A Two Zone Model of Flame Propagation Applied to $\mathrm{H}_{2}+\mathrm{Air}$ Flames and $\mathrm{HCl}$ Inhibited Flames," Fire and Materials 2, 117 (1978).

3. Brown, N.J. and Schefer, R. W., "A Computational Study of Physical and Chemical Flame Inhibitors," Western States Section/The Combustion Institute, Paper No. 78-43, 1978; also Lawrence Berkeley Laboratory Report LBL-6899, revised and in press.

4. Schefer, R. W., Brown, N. J. and Chan, M. W., "A Comparative Study of $\mathrm{HCl}$ and $\mathrm{HBr}$ Inhibition,"(in preparation).

5. Pitz, W. J. and Sawyer, R. F., "Inhibition Effects on Extinction of Polymer Burning," Western States Section/The Combustion Institute, Paper No. 78-32; also Lawrence Berkeley Laboratory Report LBL-6898.

6. Pitz, W. J., Sawyer, R. F., and Brown, N. J., "Flame Structure Measurements of Polymer Burning," (in preparation). 


\section{ANNUAL CONFERENCE ON FIRE RESEARCH \\ CENTER FOR FIRE RESEARCH \\ NATIONAL BUREAU OF STANDARDS \\ GAITHERSBURG, MARYLAND}

August 22-24, 1979

Institution: Lawrence Berkeley Laboratory, University of California, Berkeley

Grant No.: 809253

Grant Title: Thermal Radiation of Luminous Flames and Smoke

Principal Investigator: Professor Chang-Lin Tien

Mechanical Engineering Department

University of California

Berkeley, California 94720

Telephone: (415) 642-0877

Other Professional Personnel: G. L. Hubbard (now Assistant Professor at Penn State)

S. C. Lee (Ph.D. Candidate)

G. S. Shiralkar (Ph.D. Candidate)

T. W. Tong (Ph.D. Candidate)

NBS Scientific Officer: Dr. Takashi Kashiwagi

Technical Abstract:

The overall goal of this project is to establish a simple physical framework for complex fire and smoke radiation calculations. The basic research approach is based on developing approximate formulations by systematically experimenting and analyzing the fundamental aspects of the problem. The present research is focused on three topics: ( 1 ) experimental investigation on soot radiation in flames, (2) analysis of radiative heat transfer in scattering media, and (3) computation of fire radiation and plume convection in an enclosure.

Experiments on Soot Radiation: Measurements of optical and infrared radiation attenuation in small-scale flames of solid plastics are being carried out to provide more information on soot radiation and other related characteristics [1]. Of particular interest are the effects of various soot parameters such as optical constants, particle sizes, and particle number density on flame radiation. The experimental system is a modified version of the infrared radiation apparatus used by Buckius and Tien [2]. Major modifications include a large test chamber ( $3^{\prime} \times 3.5^{\prime} \mathrm{W} \times 5^{\prime} \mathrm{H}$ nominal), addition of a visible-laser system, controlled ventilation, controlled oxidizer content of feed-in gas, and computerization of the data system. 
Analysis of Radiative Transfer with Scattering: Soot and smoke particles absorb and scatter visible and infrared radiation. Radiative heat transfer in flames and smokes can be modeled on the basis of dispersed particles acting as independent absorbers and scatterers in the gaseous medium. Simple, convenient representation of the absorption field has been successfully made recently $[3,4]$. The scattering field is given by the Mie solution and the phase function for each scatterer is often expressed in a series of Legendre polynomials. The first term of the series characterizes isotropic scattering, while the first two terms represent linear anisotropic scattering [5]. The mean beam length formulation for Rayleigh and linear anisotropic scattering in planar geometry has been established, and extensions to cylindrical and spherical geometries is being conducted at present. Resistance network representation of an absorbingscattering system has also been developed on the basis of the two-flux model. Current effort is directed to further improvement in the modeling of anisotropic scattering and in the realistic computation of flame and smoke radiation.

Computation of Enclosure Convection and Radiation: Different computation schemes for enclosure convection (elliptic-type) have been examined carefully with their respective strengths and limitations [6]. Proposed refinements include more effective ways of handling boundary conditions [7] and the formulation of higher-order differencing schemes [8]. Progress has also been made in achieving simple approximate solution for radiation heat transfer in one-dimensional, non-planar geometries [9] and multi-dimensional geometries [10]. Interaction between enclosure convection and radiation is being pursued currently.

\section{Reports and Papers}

1. W. W. Yuen and C. L. Tien, "A Simple Calculation Scheme for the Luminous-Flame Emissivity," Proceedings of the 16th International Combustion Symposium, 1481-1487 (1977).

2. R. O. Buckius and C. L. Tien, "Infrared Flame Radiation," International Journal of Heat and Mass Transfer, 20, 93-106 (1977).

3. J. D. Felske and C. L. Tien, "The Use of the Milne-Eddington Absorption Coefficient for Radiative Heat Transfer in Combustion Systems," Journal of Heat Transfer, 99, 458-465 (1977).

4. G. L. Hubbard and C. L. Tien, "Infrared Mean Absorption Coefficients for Luminous Flames and Smoke," Journal of Heat Transfer, 100, 235-239 (1978).

5. A. Dayan and C. L. Tien, "Heat Transfer in a Planar Medium with Anisotropic Scattering," Journal of Heat Transfer, 97, 391-396 (1975). 
6. L. C. Chow and C. L. Tien, "An Examination of Four Differencing Schemes for Some Elliptic-Type Convection Equations," Numerical Heat Transfer, 1, 87-100 (1978).

7. L. C. Chow, Y. K. Cheung and C. L. Tien, "A New Finite-Difference Representation for the Vorticity at a Wall with Suction," Numerical Heat Transfer, 1, 417-423 (1978).

8. L. C. Chow, Y. K. Cheung and C. L. Tien, "A Higher-Order Difference Scheme for Convective-Diffuse Equations," AIAA Paper No. 79-1466.

9. W. W. Yuen and C. L. Tien, "Approximate Solutions of Radiative Transfer in One-Dimensional Non-Planar Systems," Journal of Quantitative Spectroscopy and Radiative Transfer, 19, 533-549 (1978).

10. W. W. Yuen and C. L. Tien, "A Successive Approximation Approach to Problems in Radiative Transfer with a Differential Formulation," Journal of Heat Transfer, in press. 


\section{ANNUAL CONFERENCE ON FIRE RESEARCH \\ CENTER FOR FIRE RESEARCH \\ NATIONAL BUREAU OF STANDARDS \\ GAITHERSBURG, MARYLAND \\ August $22-24,1979$}

Institution: Loyola University of Chicago

Grant No.: $\quad$ G8-9017

Grant Title: Behavioral Analysis of the Life Safety Code

Principal Investigator: Dr. Leonard Bickman, Director

Applied Social Psychology Program

Loyola University of Chicago

6525 N. Sheridan Road

Chicago, IL 60626

Other Professional Personnel: Mr. David Rivers

NBS Scientific Officer: B. Levin

Project Summary: The Life Safety Code, NFPA Standard No. 101, is one of many model codes that is used by various government agencies to establish minimum requirements for building fire safety. The Code is based on engineering and technical knowledge in the field of fire safety. However, behavioral and psychological perspectives were generally lacking in the development of the Code.

This research project consists of a behavioral analysis of selected provisions of the Life Safety Code. Each provision is analyzed according to the assumptions of and implications for human behavior. Research findings are cited which either support or contradict the provision. Aspects of the Code for which there are no relevant behavioral data available are noted as well as possible directions for future research.

In addition the results of a content analysis of the Code based on Bickman et al.'s (1977) "Model of Human Behavior in a Fire Emergency" are presented and discussed. Finally, the behavioral and content analyses are summarized and conclusions are drawn. 
ANIUAL CONFERENCE ON FIRE RESEARCH

CENTER FOR FIRE RESEARCH

NATIONAL BUREAU OF STANDARDS

GAITHERSBURG, MARYIAND

August 22-24, 1979

Institution: National Electrical Manufacturers Association

Contract No: Future Contract

Title: NEMA Fluid Filled Transformer Flammability Study

Principal Investigator: John H. Motherway

Power Equipment Division

NEMA

2101 L St., N.W., Suite 300

Washington, D.C. 20037

NBS Scientific Officer: Dr. Richard G. Gann

Technical Abstract

The overall purpose of this program is to simulate catastrophic failures of transformers containing substitute fluids for polychlorinated biphenyls to provide a technical basis for future fire safety testing. The cost of definitive series of full-scale transformer tests involving electrically induced disruptive failure is prohibitively high. Thus explosive charges will be used here instead. 'l'he energy release and time duration of the charges will be based on arc-induced failures. Transformer tanks filled with several fluids and heated to various temperatures will be thus exploded. The effect of saturation of the fluids with flammable gases will also be studied. High speed movies will indicate the extent of ignition of the expelled fluid and provide for comparison with prior data on arc-induced explosions. Combustible materials will be located at fixed positions around the transformers to indicate the ignition potential from expelled, flaming droplets. If successful, this study would lead to test transformer rupture. 


\section{ANNUAL CONFERENCE ON FIRE RESEARCH \\ CENTER FOR FIRE RESEARCH \\ NATIONAL BUREAU OF STANDARDS \\ GAITHERSBURG, MARYLAND}

August 22-24, 1979

Institution: National Fire Protection Association, Boston, MA

Contract No.: DOC A0-A01-78-001004

Contract Title: Investigation and Analysis of Major Fires

Principal Investigators: A. Elwood Willey, Director - Project Manager

Richard L. Best, Fire Analaysis Specialist

James R. Bell, Fire Analaysis Specialist

David A. Moore, Fire Analysis Specialist

Fire Investigations Department

Fire Information and Systems Division

National Fire Proection Association

470 Atlantic Avenue

Boston, MA 02210

(617) 482-8755

Other Professional Personnel: James K. Lathrop, Life Safety Code Specialist

David P. Demers, Fire Protection Engineer Wilbur Walls, Flammable Gases Specialist Robert Benedetti, Chemical Specialist Joseph Redden, Director, Public Protection Division

NBS Scientific Officer: Richard L. P. Custer

(COTR: Thomas Klem, U.S. Fire Administration, National Fire Data Center)

Project Summary: Under a cost-sharing contract between the National

Fire Protection Association, National Bureau of Standards and U.S. Fire Administration, in-depth field investigations are conducted of selected fire incidents. For each investigation an analysis is made of fire causal factors, spread factors, materials contributing to fire and smoke propagation, recreation of people movement and actions taken, fire propagation as a function of time, factors affecting fire propagation, performance of fire protection equipment, key life safety and property protection problems and of contributing factors resulting in loss of life and property damage. In addition to field work by investigators with fire protection engineering backgrounds, other specialists are consulted, including NBS researchers. In some cases, samples from fire scenes are tested for fire hazard characteristics at NBS and results included in reports.

This in-depth investigation and analysis activity gives an improved understanding of fire growth and development, smoke development and spread, and the actions of people in actual fire situations. 
Following submittal of contract reports to USFA/NBS, reports are published and distributed by NFPA to ensure that the facts and lessons learned are made available to the fire community in a timely manner. In addition to the literature, background data from the investigations is available at NFPA for research purposes.

Progress Report: A total of 14 incidents have been investigated under this contract, twelve of which were conducted since submittal of the last report in July, 1978. Reports have been submitted to USFA and NBS for eight of the twelve investigations and four investigations are currently ongoing.

Reports have been completed on the following incidents:

- A supermarket fire in Brooklyn, New York on August 2, 1978 in which roof collapse killed six fire fighters

- An apartment house fire in Dallas, Texas where fire-blocked exits contributed to the deaths of four adults and two children on September 12,1978

- The September 25, 1978 mid-air collison of a commercial airliner and a single-engine aircraft in San Diego, California which killed all occupants of both planes and seven ground victims

- A fire in a wood-frame resort hotel in Ayer's Cliff, Quebec which resulted in eleven fatalities on October 1,1978

- A department store fire in Des Moines, Iowa on November 5, 1978 where ten employees preparing to open for the day were killed

- A hotel fire in Greece, New York on November 26, 1978 which took the lives of ten guests

- The December 9, 1978 fire in an Ellisville, Mississippi mental hospital dormitory resulting in the deaths of 15 residents

- An incendiary fire in a tenement building which killed six in Hoboken, New Jersey on January 20, 1979

Accomplishments: This contract is the fourth in a series of NFPA/NBS fire investigation contracts since 1972. The two most recent contracts have also involved the USFA, with funding shared between the two agencies and NFPA in a cooperative effort. Since the original contract, 68 incidents have been investigated and reports prepared.

Selected abstracts of recent studies are included below: 
On Wednesday, August 2, 1978, six New York City fire fighters died while fighting a fire at Waldbaum's Supermarket at 2892 Ocean Avenue, Brooklyn, New York. The fire fighters died of burns received when the roof of the supermarket they were working on collapsed without warning. The roof system structurally consisted of seven 100-foot long medium-weight wood segmental trusses. At the time of roof collapse, there were approximately 24 operating personnel of the New York City Fire Department on the roof. The combination of a major fire in the combustible truss area, building construction features, the apparent lack of recognition by fire department operating personnel of the wood truss construction involved in this incident and the hazards associated with it, and the exposure of large numbers of fire fighters to those hazards were the primary factors that lead to the fatalities.

$$
* * *
$$

A Pacific Southwest Airlines Boeing 727 aircraft, Flight 182, collided in mid-air with N7711G, a Cessna 172, over San Diego on September 25, 1978. Both aircraft crashed into a residential area of San Diego, resulting in the deaths of all aircraft occupants and seven victims on the ground. A total of 144 persons died as a result of the crash. Approximately eight residential buildings were totally involved in fire following the crash and another four buildings were ignited.

The County of San Diego had developed Emergency Medical Services Advisory Planning Committees covering San Diego County and eight Emergency Medical Service areas. A Medical/ Health Emergency Disaster Plan was developed by the Office of Emergency Medical Services and had been distributed, but not fully implemented, when the air disaster occurred. The overall County response to the disaster was adequate, despite a breakdown in the planned communications system. The performance of the Disaster Plan was the focus of the study.

$$
* * *
$$

On October 1, 1978, eleven people died in a fire at the Ripplecove Inn in Ayer's Cliff, Province of Quebec, Canada. The wood frame hotel was equipped with a manual fire alarm system and single station battery powered smoke detectors. Extremely rapid fire development due to highly combustible interior finish, an open stairway, and weather conditions were the most significant factors leading to the fatalities. 
Even though the smoke detectors were of the type intended for one and two family dwellings, they did help to limit the total number of fatalities. The manual fire alarm system, as far as can be determined, was never activated.

$$
* * *
$$

On Sunday, November 26,1978 , at $2: 38$ a.m., a fire was reported at the Holiday Inn - Northwest in Greece, New York, a suburb of Rochester. Ten occupants died in this fire which was most likely incendiary in nature. The building was equipped with a fire alarm system. Initiating devices included manual pull stations and combination rate of rise, fixed temperature thermal detectors. Tlese alarm-initiating devices were located only in the corridors and the alarm system was not connected directly to the fire department. There was one fire alarm bell per corridor.

The report analyzes the primary factors that led to fatalities in this incident. These factors included highly combustible interior finish, unprotected openings that existed in the stairway and inadequate alerting of occupants. Extensive rescue efforts by fire fighters prevented a much higher life loss.

$$
\text { *** * }
$$

On December 9, 1978, a fire originating in a clothing storage room in a residential custodial care dormitory at a mental hospital outside Ellisville, Mississippi killed 15 and hospitalized 16 of 63 residents. Smoke spreading from the storage room simultaneously exposed two wards on the top floor of the two story fire resistive building. Primary factors resulting in the fatalities were the lack of compartmentation and automatic sprinkler protection of the storage room, lack of subdivision of the facility by a smoke stop partition, lack of automatic detection and alarm system, and lack of automatic alarm transmission to the fire department. Additional contributing factors to the loss of life included the lack of illumination during the evacuation of residents, limited fire service resources, and the mental and physical handicaps of the residents.

Potential Applications: The information gained from in-depth investigation and analysis of fire incidents has many uses both in the field and in the research environment. 
Reports contain commentary on the performance of fire detection and extinguishing equipment, building assemblies and systems and various measures of fire control. The studies provide an opportunity to measure the performance of requirements in national consensus fire safety codes and standards. Lessons learned from these investigations are of use to fire safety practitioners and researchers. Indicators for additional research are often included in reports.

In addition to the use of information by NFPA technical committees and in technical programs, information from investigations is utilized in training films and slide packages for use by the fire service and fire safety practitioners.

Future Milestones: Investigations are in progress on four incidents and reports will be prepared. These active studies include:

- A fire which occurred in a restaurant undergoing renovation in Lubbock, Texas resulted in the deaths of three fire fighters on March 25, 1979. Factors related to the fatalities, including self-contained breathing apparatus problems, are being examined.

- Another fire involving a fire fighter fatality which occurred in Los Angeles on May 12, 1979 is being investigated. Factors related to the death of the fire fighter is also the focus of this study.

- Two multiple death boarding home fires are under investigation, including the Farmington, Missouri fire of April 2, 1979 and the Washington, DC group care facility fire of April 11, 1979. Facility design, fire growth and development, staff actions and other people factors are being examined in these studies.

Reports and Papers: The following investigation reports have been submitted to USFA/NBS :

Be11, James R., "Fifteen Resident Fatalities - Ellisville State School - Ellisville, Missouri - December 9, 1978."

Best, Richard L., "Aircraft Collision and Crash - San Diego, California - September 25, 1978."

Best, Richard L., "Apartment House Fire - Hoboken, New Jersey January 20, 1979 - 21 Fatalities." (Letter report)

Demers, David P., "Ayer's Cliff, PQ, Canada - Hotel - 11 Fatalities - October 1, 1978." (Letter report) 
Demers, David P., "Hotel Fire - Greece, New York - Ten Fatalities - November 26, 1978."

Demers, David P., "Six Fire Fighter Fatalities - 2892 Ocean Avenue - Brooklyn, New York - August 2, 1978."

Lathrop, James K., "Apartment House Fire - Six Fatalities Dallas, Texas - September 12, 1978."

Lathrop, James K., "Younkers Department Store Fire - Ten Fatalities - Des Moines, Iowa - November 5, 1978."

Published reports:

Best, Richard L., Reconstruction of a Tragedy - Beverly Hills Supper Club Fire, NFPA, 1978.

Demers, David P., Fire in Syracuse: Four Fire Fighters Die, NFPA, 1979.

A Study of the Baptist Towers Housing for the E1derly Fire, NFPA, 1973.

Articles in NFPA publications:

Best, Richard L., "The San Diego Air Crash," Fire Command, February, 1979, NFPA.

Demers, David P., "Fire in Quebec Hotel Kills Eleven," Fire Journal, May, 1979, NFPA.

Demers, David P., "Brooklyn Roof Collapse Claims Six Lives," Fire Command, December, 1979, NFPA.

Demers, David P., "Four Fire Fighters Die in Syracuse Fire," Fire Command, October, 1978, NFPA.

Fire Investigations Department, "Hotel Fire Kills Ten," (Greece, New York) Fire Command, June, 1979, NFPA.

Fire Investigations Department, "Six Die in Dallas Fire," Fire Command, March, 1979, NFPA.

Major Presentations:

Bell, James, "The Ellisville State School Fire," presented at the NFPA Annual Meeting, St. Louis, Missouri, May 14-17, 1979. 
Best, Richard, "PSA Crash in San Diego and Beverly Hills Supper Club Fire," presented at the Michigan Building Officials Conference in Kalamazoo, Michigan, February 14-15, 1979.

Demers, David P., "Syracuse Fire Fighter Fatalities," presented at the FDIC, Memphis, Tennessee, March 22, 1979.

Willey, A. Elwood, "Fire Investigations For Loss Prevention Purposes," presented by Dr. John L. Bryan, University of Maryland, at the United States - Japan Panel on Fire Research and Safety, Tokyo, Japan, February 5-9, 1979.

Case Study NFPA Films and Slide Packages based on contract investigations:

Case Study Slide Packages:

$$
\begin{aligned}
& \text { SL - 13, "LP-Gas Explosion, Kingman, Arizona, July 5, 1973" } \\
& \text { SL - 22, "Hospital Fire, Osceola, Mo., Dec. 3, 1974" } \\
& \text { SL - 26, "Three Nursing Home Fires" (Wincrest Nursing Home, } \\
& \text { Chicago, Illinois, January 30, 1976; Cermak House, } \\
& \text { Cicero, Illinois, February 4, 1976; Plaza Nursing } \\
& \text { Centre, Niles, Illinois, February 18, 1976) } \\
& \text { SL- 38, "Reconstruction of a Tragedy - The Beverly Hills } \\
& \text { Supper Club Fire" }
\end{aligned}
$$

Films :

$$
\begin{aligned}
& \text { FL - 35, "Incendio!" (High-rise fire, Sao Paulo, Brazil, } \\
& \text { February 1, 1974) } \\
& \text { FL - 50, "The Beverly Hills Supper Club Fire ... A Case for } \\
& \text { Code Enforcement" }
\end{aligned}
$$




\section{ANNUAL CONFERENCE ON FIRE RESEARCH \\ CENTER FOR FIRE RESEARCH \\ NATIONAL BUREAU OF STANDARDS \\ GAITHERSBURG, MARYLAND}

August 22-24, 1979

Institution: North Carolina State University

Grant/Contract No: DA-0012

Title: Occupant Response Variability in Escape From Residential Fires

Principal Investigator: Richard G. Pearson, Professor

North Carolina State University

Dept. of Industrial Engineering

Box 5511, Raleigh, North Carolina 27650

Other Professional Personnel: Mahmoud A. Ayoub, Associate Professor

NBS Scientific Officer: Bernard Levin

Technical Abstract

A two-year program of research is proposed in which response times and behaviors of residential occupants to simulated fire emergency situations will be evaluated under laboratory and field conditions. A variety of egress scenarios will be used to provide data relative to such factors (constraints) as human physical and sensory ability characteristics, alertness, environmental designs, level of visibility, personal needs adjunct to egress, and responsibility for others and for property. Studies will involve emergency egress from a "living facility" laboratory containing two bedrooms and a hallway, from residential homes and apartments, from sorority dormitories, from a high-rise senior-citizens apartment building, and from a sleep state as confirmed by EEG recordings. Based upon collected data, a computerized simulation model will be developed for predicting the total time for egress under various conditions of fire behavior, building design, and occupant characteristics.

The descriptive behavioral data are expected to have educational value relative to occupant guidance for fire emergency egress. Response time data for egress, including specific component times, would be related to probabilities of successful egress. The sleep study will provide data on "sudden-awakening" behaviors and on signal characteristics required for subject arousal. Finally, the simulation model should have value in predicting total egress times under a variety of environmental and human constraints as related to fire survival. 


\section{ANNUAL CONFERENCE ON FIRE RESEARCH \\ CENTER FOR FIRE RESEARCH \\ NATIONAL BUREAU OF STANDARDS \\ GAITHERSBURG, MARYLAND}

August $22-24,1979$

Institution: The Pennsylvania State University

Grant/Contract No: NBS Grant 7-9020

Grant Title: An Investigation of Fire Impingement on a Horizontal Ceiling

Principal Investigator: Professor G.M. Faeth

Department of Mechanical Engineering

The Pennsylvania State University

214 M.E. Bldg.

University Park, PA 16802

Other Professional Personnel: H-Z. You, Ph.D. Candidate

NBS Scientific Officer: H. Baum

$\underline{\text { Technical Abstract }}$

The structure and heat transfer characteristics of turbulent fires and fire plumes impinging on a horizontal ceiling is being investigated in order to provide a more complete understanding of unwanted fires within buildings. The results of the study have application to modeling fires within structures, to determining heat transfer rates to structural members during fires, and to estimating the environment of fire detectors and fire suppression devices mounted near a ceiling.

Measurements are being made of convective and radiative heat fluxes to the ceiling and radiative heat fluxes to the ambiance. Detailed measurements of the structure of the flow are also being undertaken in order to provide a better understanding of flame radiation properties, air entrainment rates, energy release rates, rates of fuel consumption and ceiling heat transfer rates. These measurements include profiles of mean velocities and turbulent fluctuations using a laser Doppler anemometer, mean temperature using fine-wire thermocouples, mean concentrations of gaseous species $\left(\mathrm{CH}_{4}, \mathrm{C}_{2} \mathrm{H}_{6}, \mathrm{H}_{2}, \mathrm{CO}_{2}\right.$, $\mathrm{CO}, \mathrm{H}_{2} \mathrm{O}, \mathrm{O}_{2}$ and $\mathrm{N}_{2}$ ) using sampling and gas chromatography, and flame shape using dark-field photography. Wherever possible, the results are correlated with simple expressions that can be employed by the nonspecialist.

The experiments employ a laboratory-scale apparatus involving ceiling diameters of 610-1000 mm, ceiling heights of 58-940 mm, fire source diameters of 10-107 mm, flame heat release rates of 54-14250 W, and curtain wall lengths (to simulate confined ceilings within a 
structure) as large as the ceiling height. Fire sources are being simulated by liquid fuels burning from horizontal wicks as well as natural gas flames having low initial momentum leaving a cylindricalscreened duct.

The experiments have yielded correlations for flame shape and convective heat flux to the ceiling for both confined and unconfined ceilings. Free flame heights, $\mathrm{H}_{f}$, could be correlated according to a method suggested by Steward (Comb. Sci. and Tech. 2, 203, 1970):

$$
\mathrm{H}_{\mathrm{f}} / \mathrm{D}=10.96 \mathrm{~N}_{\mathrm{CO}} 0.211
$$

with

$$
N_{C O}=\frac{\dot{Q}^{2}\left(r_{s}+\omega \rho_{\infty} / \rho_{0}\right)^{2}}{\rho_{\infty}{ }^{2} Q_{c}{ }^{2} g D^{5}(1-\omega)^{5}}
$$

and

$$
\omega=\left[1+Q_{c} / r_{s} C_{p} T_{\infty}\right]^{-1}
$$

where $\mathrm{D}=$ source diameter, $\dot{\mathrm{Q}}=$ energy release rate, $\mathrm{r}_{\mathrm{S}}=$ mass of air per mass of fuel for stoichiometric combustion, $Q_{c}=$ heat of combustion, $g=$ acceleration of gravity, $C_{p}=$ specific heat, $\mathrm{T}_{\infty}=$ ambient temperature, and $\rho_{\infty}$ and $\rho_{\rho}$ are gas dehsities of the ambiance and at the fire source, respectively. The length of impinging flames along an unconfined ceiling, $H_{R}$, could be correlated in terms of the free flame height, as follows:

$$
\mathrm{H}_{\mathrm{R}} / \mathrm{D}=0.502\left[\left(\mathrm{H}_{\mathrm{f}}-\mathrm{H}\right) / \mathrm{D}\right]^{0.957}
$$

where $H=$ ceiling height. A clear trend of the influence of degree of confinement could not be established for confined ceilings. The ceiling layer composition depends upon whether the fire plume has entrained sufficient oxygen for complete combustion upon entering the layer. If the fire plume is fuel-rich, flame length is controlled by the consumption of entrained oxygen, while if it is lean, flame length is controlled by the consumption of fuel. Overall, the measurements could be correlated as follows:

$$
\mathrm{H}_{\mathrm{R}} / \mathrm{D}=0.692\left[\left(\mathrm{H}_{\mathrm{f}}-\mathrm{H}\right) / \mathrm{D}\right]^{0.887}
$$

yielding flame lengths up to 40 percent longer than for unconfined ceilings.

Ceiling heat fluxes in the stagnation region, $\mathrm{r} / \mathrm{H}<0.2$, where $r=$ radial distance from center of fire, could be correlated quite simply,

where

$$
\dot{\mathrm{q}}^{\prime \prime} \mathrm{H}^{2} / \dot{\mathrm{Q}}=31.21 \mathrm{Pr}^{-3 / 5} \mathrm{Ra}^{-1 / 6}
$$

Wha $=\mathrm{gBQH} / \rho \mathrm{C}_{\mathrm{p}} \mathrm{\nu}^{3}$

for $H_{f} / H<1.5, \operatorname{Pr} \sim 0.7$ and $R$ a in the range $10^{9}-10^{14}$. In Eqs. 
thermal expansion and $\nu=$ kinematic viscosity. Larger flame lengths resulted in lower heat fluxes due to lower velocities and temperatures in the core of the fire. These natural convection heat flux values were only 25-40 percent of the values obtained for forced flows under comparable conditions. Ceiling heat fluxes in the ceiling jet region, $\mathrm{r} / \mathrm{H}>0.2$, could be correlated as follows for an unconfined ceiling:

$$
\dot{\mathrm{q}}^{\prime \prime} \mathrm{H}^{2} / \dot{\mathrm{Q}}=0.04(\mathrm{r} / \mathrm{H})^{-1 / 3}
$$

for $\mathrm{Ra}$ in the range $10^{10}-2 \times 10^{13}, \operatorname{Pr} \sim 0.7$ and $\mathrm{H}_{\mathrm{f}} / \mathrm{H}<0.6$. The results were not much different for flame impingement $H_{f} / H<2.5$. Ceiling heat fluxes were somewhat higher for confined ceilings, but Eq. (8) still provides a reasonable fit of the data.

Current activities are devoted to measurements of flow structure and radiative properties. In order to provide stable, long-term operating conditions, these measurements are being undertaken with the natural gas fueled fire source. Four operating conditions are being examined involving heat release rates of $0.38,1.52,7.13$ and $14.25 \mathrm{~kW}$ from a $55 \mathrm{~mm}$ diameter burner with a $400 \mathrm{~mm}$ ceiling height. These conditions span the topological possibilities for the process: plume impingement, incipient flame impingement, flame at the start of the ceiling jet and flame in the ceiling jet region.

The results of this research provide heat transfer parameters that can be used in building design to reduce potential fire losses. Completion of structure measurements provide benchmark data obtained for well-defined conditions. This information can be employed to test both simplified and sophisticated models of fires within structures, advancing model development in order to reduce the need for expensive large scale tests for fire hazard evaluation.

\section{Reports and Paperș}

You, H-Z. and Faeth, G.M., "An Investigation of Fire Impingement on a Horizontal Ceiling," The Pennsylvania State University, 1978.

You, H-Z. and Faeth, G.M., "Fire Impingement on a Ceiling," 1978 Technical Meeting, Eastern Section of the Combustion Institute, Paper No. 9, November 1978 .

Liburdy, J.A., Groff, E.G. and Faeth, G.M., "Structure of a Turbulent Thermal Plume Rising Along an Isothermal Wal1," Trans. ASME, Series C, J. Heat Transfer, Vol. 101, 249-255, 1979.

Ahmad, T. and Faeth, G.M., "Turbulent Wall Fires," Seventeenth Symposium (International) on Combustion, The Combustion Institute, Pittsburgh, in press.

You, H-Z. and Faeth, G.M., "Ceiling Heat Transfer During Fire Plume and Fire Impingement," submitted to J. of Fire and Materials. 


\section{ANNUAL CONFERENCE ON FIRE RESEARCH \\ CENTER FOR FIRE RESEARCH \\ NATIONAL BUREAU OF STANDARDS \\ GAITHERSBURG, MARYLAND}

August $22-24,1979$

Institution: Princeton University

Grant No: NBS Grant 7-9004

Grant Title: An Experimental Investigation of Flame Spread Over Condensed Combustibles: Gas Phase Interactions

Principal Investigators: Professor I. Glassman, Dr. F.L. Dryer, and Dr. A.C. Fernandez-Pello

Department of Mechanical and Aerospace Engineering

Princeton University

Princeton, N.J. 08544

(609) 452-5199

Other Professional Personnel: S.R. Ray, Ph.D. Candidate

NBS Scientific Officer: B. McCaffrey

Technical Abstract

A research program has been undertaken to study the mechanisms controlling the process of fire spreading over solid materials. Modes of fire propagation with the oxidizer flow (natural or forced) opposing the direction of spread are currently being studied. The pathways of heat transfer for horizontal fire spread in natural convection have been analyzed for flames spreading over a thermally thick fuel. The effect of oxygen concentration of a forced gas flow on the fire spread rate has been studied for flames propagating over thick fuel sheets. In order to corroborate the conclusions of the above studies, further research will be performed for flames spreading over thermally thin fuels.

a). Heat transfer mechanisms in horizontal flame spread.

An experimental study has been performed of the magnitude of the different mechanisms by which heat is transferred from the flaming region to the unburnt fuel ahead of the flame for flames propagating horizontally over the surface of PMMA sheets $2.5 \mathrm{~cm}$ thick in a natural convective environment. The experiments are carried out in a quiescent test cell, with the operation of the experiment automatically controlled from outside the test cell to avoid perturbations in the flame induced flow field by environmental air currents. The experimental facility combines a two-dimensional laser doppler velocimeter, a thermocouple and radiometry probing set up and an optical indicator of flame location. Simultaneous measurements of the flame 
spread rate, the gas flow velocity, the solid and gas phase temperatures and arrival of the flame at the location of the measurements are obtained and recorded in a real time data acquisition system. Radiant fluxes at the fuel surface are measured by several independent techniques to corroborate the results. Measurements of the heat transfer parameters ahead of the flame in a particular case of laboratory scale are used to construct energy balances along control volumes in the gas and solid phases to determine the magnitude of the different heat fluxes. The results show that, for this particular case, although heat conduction through the solid is dominant (up to $60 \%$ of the total heat transferred), radiation from the flame contributes significantly to the heat transfer process (up to $40 \%$ ). An analysis of the development of the fire indicates that there is a transition in the mechanisms of heat transfer as the fire grows. While in the early stages of the fire, heat conduction through the solid is dominant, radiation from the flame becomes of increased importance as the size of the fire increases.

\section{b). Effect of the oxygen concentration of a forced flow on the spread rate.}

The rate of fire spread over the surface of thick PMMA sheets has been measured as a function of the velocity and oxygen concentration of a forced gas flow opposing the direction of flame propagation. The experiments are performed in a small scale wind tunnel with the gas flow provided by independently metered flows of oxygen and nitrogen. Gas velocities in the test section of the tunnel are measured with a laser doppler velocimeter. Maximum gas velocities attainable with the present experimental installation are $200 \mathrm{~cm} / \mathrm{sec}$. The flame spread rate is obtained by timing the time interval required for the flame front to pass markings on the fuel surface previously ruled at fixed intervals. For the experiments where the spread rate is very fast, a motorized photographic camera in combination with an electric clock is used to determine the velocity of flame propagation. The experimental results show that for low oxygen concentrations, after an initial region where the spread rate is practically constant, the velocity of flame propagation decreases as the velocity of the gas flow increases. However, for high oxygen concentrations the dependence is reversed, with the spread rate increasing with the flow velocity. Some characteristic parameters related to the flame spread process such as surface temperature and gas velocity in the boundary layer near the fuel surface are analyzed in order to provide further information about the effect of the gas flow on the flame spread process. Phenomenological arguments in conjunction with simplified analytical expressions describing the different mechanisms involved in the flame propagation process are used in an attempt to explain the nature of the results. It is shown that gas phase chemical kinetics plays a critical role in the mechanism of flame propagation particularly at low oxygen concentration. Two counteracting effects, one chemical and the other thermal, are identified as controlling mechanisms. As the opposing gas velocity increases, the chemical effects tend to decrease the spread rate, while the thermal effects favor the spread rate. The relative influence of both mechanisms determines the increase or 
decrease of the flame spread rate. The experimentally measured flame spread rate is correlated nondimensionally as a function of the Damköhler number (describing chemical effects) and of a nondimensional spread rate (describing thermal effects). Since for large opposed flow velocities gravity effects are negligible, the results of the present work apply to any fuel orientation.

A nondimensional correlation of the flame spread rate, such as the one obtained in this work, not only provides physical insight into the fire propagation problem, but represents a potential tool for predicting fire spreading behavior. It appears that it is possible to predict in nondimensional terms such effects as the influence of ambient pressure, oxygen concentration, velocity of the gas flow, gravity and initial temperature of the system. Such a predictive capability could simplify considerably the estimations of the development of fires under a variety of environmental conditions and could facilitate the extension of the flammability ratings for materials to conditions not currently tested.

Reports and Papers

Ray, S.R., Fernandez-Pello, A.C. and Glassman, I. (1978), "An Experimental Study of the Pathways of Heat Transfer in Horizontal Flame Spread", presented at the 1978 Fall Technical Meeting, Eastern States Section, The Combustion Institute, November 29-30, Miami Beach, Fla.

Fernandez-Pello, A.C., Santoro, R.J., Dryer, F.L., and Glassman, I. (1978), "Experimental Investigations of Flame Spread Over Condensed Combustibles: Gas Phase Interactions". Technical Report 1418, Princeton University, Department of Mechanical and Aerospace Engineering.

Fernandez-Pello, A.C. (1979), "Flame Spread in a Forward Forced Flow", Combustion and Flame (In press). Also 1978 Fall Meeting, Western States Section, The Combustion Institute, October 16-17, Laguna Beach, $\mathrm{Ca}$.

Fernandez-Pello, A.C. and Glassman, I. (1979), "The Effect of Oxygen Concentration on Flame Spread in an Opposed Forced Flow", presented at the 1979 Spring Meeting, Western States Section, The Combustion Institute, April 23-24, Provo, Utah.

Ray, S.R., Fernandez-Pello, A.C. and Glassman, I. (1979), "An Analysis of the Heat Transfer Mechanisms in Horizontal Flame Propagation". Accepted for presentation at the ASME/AIChE 18th National Heat Transfer Conference, August 6-8, San Diego, Ca. ASME publication 79-HT-25. 


\section{ANNUAL CONFERENCE ON FIRE RESEARCH \\ CENTER FOR FIRE RESEARCH \\ NATIONAL BUREAU OF STANDARDS \\ GAITHERSBURG, MARYLAND}

August $22-24,1979$

Institution: Princeton University

Grant: $\quad 4-9026$

Title: Smoldering Combustion Studies

Principal Investigator:

Prof. I. Glassman

Aerospace \& Mech. Engr. Dept.

Engineering Quadrangle

Princeton University

Princeton, NJ 08540
Dr. T. J. Ohlemiller

Aerospace \& Mech. Engr. Dept.

Forrestal Campus

Princeton University

Princeton, NJ 08544

Other Professional Personnel: F. E. Rogers

NBS Scientific Officer: Dr. J. Rockett

\section{Technical Abstract}

Objectives and Approach: Smoldering of loose-fill cellulosic insulation in residences has emerged as a significant fire safety problem in the past few years. This has prompted the present study of the underlying thermophysics and chemistry of smolder initiation and propagation in these materials. Our objective is a greater understanding of the conditions required to start self-sustaining smolder reactions and of the overall mechanism whereby these reactions propagate onward, producing toxic gases and the potential for flaming combustion.

For convenience of study, we have separated the ignition and propagation processes. Ignition is studied in a simple hot plate apparatus according to a technique first suggested by Bowes \& Townshend (Brit. J. Appl. Phys. 13, 1962, p. 105). The procedure of application is designed to yield the minimum plate temperature that just produces ignition in a layer of a given thickness. This mode of testing coupled with the one-dimensional heat flow produce a situation for which thermal ignition theory provides an approximate model and thereby a framework for interpreting the results.

Smolder propagation in realistic situations (e.g., an attic floor installation) is not closely describable by any simple analysis. It yields a complex wave structure that is only beginning to be studied. Prior to undertaking this examination of the 2-D propagation process, we 
have looked at the extreme opposite 1-D cases of forward and reverse smolder. (In the former, smolder propagation is in the same direction as the airflow; in the latter, they are in opposite directions.) Approximate models have more utility here in aiding our understanding of factors controlling propagation.

Thermal analytical techniques (TGA/DSC) complement the above studies of overall behavior. These provide a direct picture of the effects of smolder retardants on the oxidative degradation of the cellulosic material. They also facilitate the development of simplified kinetic schemes describing the overall weight loss and heat release processes; these kinetics are used in modeling overall behavior.

Summary of Progress: Using the hot plate apparatus, we have examined the thickness-dependent, minimum ignition temperature of three insulation compositions: unretarded material, the first plus $20 \%$ add-on of boric acid and the first plus $20 \%$ add-on of elemental sulfur. Boric acid is a widely used smolder retardant; elemental sulfur is an experimental retardant previously found effective in some other tests. The insulation layer thicknesses ranged from 3 to $7 \mathrm{~cm}$ with the maximum thickness dictated by $1-D$ heat flow requirements in the apparatus. The extremes of minimum ignition temperature over the whole test series were $265^{\circ} \mathrm{C}$ to $325^{\circ} \mathrm{C}$ but the variation was much less among compositions at a fixed layer thickness. Elemental sulfur had no retarding effect in these tests and boric acid only raised the minimum ignition temperature by about $20^{\circ} \mathrm{C}$.

These results can be extrapolated to layer thicknesses of more practical interest $(\mathrm{e} . \mathrm{g} ., 20-30 \mathrm{~cm})$ utilizing the thermal ignition theory model of Bowes and Townshend. This extrapolation implies that the minimum ignition temperatures at $30 \mathrm{~cm}$ may drop to $200-230^{\circ} \mathrm{C}$ but that the relative ordering of the three compositions will be about the same. Close examination of some of the assumptions in the Bowes and Townshend model (particularly neglect of reactant consumption) indicates that these extrapolated temperatures may be too low. Extrapolation using TGA-derived kinetics yields temperatures some $20^{\circ} \mathrm{C}$ higher.

Thermal analysis sheds more light on the ignition and propagation processes. We find that the oxidative degradation of these materials is describable by two overall steps, both of which are exothermic. Both steps then have the potential for producing smolder ignition in some circumstances but the second step, which we call char oxidation, is significantly slower. The results implicate the first overall reaction step as the cause of smolder initiation in practical cases. Retardant action should be focused on this step. Both steps are slowed by boric acid addition, especially the second. Sulfur addition effects cannot be reliably assessed by these techniques since it sublimes out of the sample at low temperatures.

Kinetic analysis of TGA results is greatly facilitated by improved procedures which suggest the most appropriate class of rate law and uniquely define best-fit kinetic parameters for that rate law. The 
kinetics thus derived have aided the above analyses.

We have also examined 2-D smolder propagation through the same insulation compositions as given above. In particular, we determined the minimum layer thickness that just supported lateral smolder propagation. The critical depths ranged from $3 \mathrm{~cm}$ for unretarded material to $6 \mathrm{~cm}$ for material with $20 \%$ boric acid add-on. $20 \%$ sulfur increased the critical depth only slightly.

We have examined, in a preliminary manner, the structure of the lateral smolder propagation wave and find that it resembles a combination of the two $1-D$ cases (forward and reverse smolder). At present it appears that the forward smolder section in the front of the wave is most responsible for its propagation and that this involves only the first overall oxidation step. However, there is a clear assist from the reverse smolder region in which char is oxidized. Because both steps are involved to some extent in propagation, the effects of additives may be different here than in ignition.

Potential Applications: A knowledge of smolder initiation and propagation mechanisms coupled with a knowledge of how retardants affect these mechanisms are clearly of benefit in the attempt to produce materials with minimal smolder tendency and attendant life hazard.

\section{Reports and Papers:}

F. E. Rogers and T. J. Ohlemiller, "Minimizing Smolder Tendency in Flexible Polyurethanes," Journal of Consumer Product Flammability, Vol. 5 (June 1978), p. 59 .

T. J. Ohlemiller and F. E. Rogers, "A Survey of Several Factors Influencing Smolder Combustion in Flexible and Rigid Polymer Foams," Journal of Fire and Flammability, Vol. 9 (October 1978), p. 489 .

T. J. Ohlemiller, J. Bellan and F. E. Rogers, "A Model of Smoldering Combustion Applied to Flexible Polyurethane Foams," to be published in Combustion and Flame.

F. E. Rogers and T. J. Ohlemiller, "Smolder Characteristics of Flexible Polyurethane Foams," to appear in January 1980 issue of J. of Fire and Flammability.

F. E. Rogers and T. J. Ohlemiller, "Pyrolysis Kinetics of a Polyurethane Foam by Thermogravimetry; A General Kinetic Method," submitted to Journal of Macromolecular Science. 


\section{ANNUAL CONFERENCE ON FIRE RESEARCH \\ CENTER FOR FIRE RESEARCH \\ NATIONAL BUREAU OF STANDARDS \\ GAITHERSBURG, MARYLAND}

August 22-24, 1979

Institution: SRI International

Contract No: EO-AO1-78-00-3559

Title: The Effect of Fire Retardants on the Heat Release Rate of Building Materials

Principal Investigator: Stanley B. Martin, Director

Fire Research Department

SRI Internationa1

333 Ravenswood Avenue

Menlo Park, CA 94025

Other Professional Personnel: Robert G. McKee, Jr.

Raymond S. Alger

NBS Scientific Officer: William J. Parker

Technical Abstract

Fire losses are a direct result of heat released by burning materials during the course of fire. Therefore, it would be of great practical utility to know how to modify materials to limit their ability to release heat during fire exposure. It may be unrealistic to expect to reduce appreciably the time-integrated quantity of heat released (per unit mass of material) when a material suffers prolonged fire exposure, sufficient to oxidize even the most resistant chars, but it is well within the current state-of-the-art knowledge of fire retardant technology to markedly slow the rate of release by enhancing char formation. It has been assumed that the main effect of char-yield enhancement is to reduce the carbon content of the volatiles produced; however, charenhancing additives in cellulose also increase the rate of volatilization (reduce both the activation energy and the heat of gasification). Accordingly, it is equally plausible to suggest that the main effect of char-yield enhancement (at least a major contributing effect) is the establishment of an insulating layer to retard heat transfer to undecomposed material, thereby slowing the rate of volatile fuel supply. The objective of this research effort is to evaluate experimentally the relative importance of these effects of char production in cellulose.

Experimental techniques are being developed to permit measurements of rates of char development and heat conduction in cellulose, with and without addition of inorganic char-yield enhancing additives (such as $\mathrm{Na}_{2} \mathrm{~B}_{4} \mathrm{O}_{7}$ and $\mathrm{MgNH}_{4} \mathrm{PO}_{4}$ ), during determination of rates of heat release in 
the SRI/HRR Calorimeter. Residual chars will be analyzed for their elemental composition, and thermochemical heats of combustion will be ascertained.

Techniques of sample preparation, including pulp casting and lamination of sheets with cellulose ethers and related carbohydrate derivatives are presently being developed. Not only are such techniques needed to provide means for transducer implanting in the cellulose matrix, but also to provide specimens of sufficient size and thickness that their conduction will closely approximate one-dimensional conduction in a semi-infinite solid. Non-aqueous solvent systems for the application of additives are also being sought to minimize such side effects as swelling.

As of this writing, we have no experimental results to report.

\section{Reports and Papers}

None. 
ANNUAL CONFERENCE ON FIRE RESEARCH

CENTER FOR FIRE RESEARCH

NATIONAL BUREAU OF STANDARDS

GAITHERSBURG, MARYLAND

August 22-24, 1979

Institution: SRI International

Contract No: EO-AOI-78-00-3569

Contract Title: Continuation of Decision Analysis Studies in Fire Hazard Analysis

Principal Investigator: Dr. Fred L. Offensend

Decision Analysis Group

SRI International

333 Ravenswood Ave

Menlo Park, CA 94025

Other Professional Personnel: Dr. Burke E. Robinson

Mr. Daniel A. Levinthal

NBS Scientific Officer: Benjamin Buchbinder

Technical Abstract:

The objective of this project is to develop and demonstrate methodology for setting fire safety policy. The project is being performed jointly by SRI International and the Center for Fire Research, using a decision analytic approach. The underlying methodology provides an integrating framework for taking into account the many technical, social, and economic factors that must be addressed in setting fire safety policy. Provision is made for the exp.licit treatment of uncertainty and value trade-offs.

The methodology is being demonstrated with applications to three separate fire safety problems. The first application, begun under a previous contract, addresses the problem of upholstered furniture fire safety. The analysis compares and evaluates three alternatives for reducing upholstered furniture fire losses: a policy of taking no formal action at all, a policy requiring at least one smoke detector in all U.S. residences, and the proposed upholstered furniture standard currently under consideration by the Consumer Product Safety Commission. Probabilistic models have been developed to assess the losses occurring under each alternative. Cost assessments are also made of each intervention strategy. The analysis shows that the most attractive strategies over a broad range of input assumptions are either the proposed standard or detector alternative. A final report will be issued in early summer, 1979. 
A second demonstration of the methodology is conducted for the electric transformer fluids fire safety problem. Several alternatives are considered ranging from testing and inspection programs to fluids specifications to vaulting requirements. A probabilistic model that addresses failure and subsequent fire spread is developed for assessing the losses under each intervention strategy. Estimates are made of the costs of each alternative. The resulting analysis shows that the most attractive alternative is very sensitive to risk attitude, the degree to which one is willing to pay to avoid major losses. A final report will be issued in summer, 1979 .

A third investigation is developing a framework for evaluating strategies for reducing residential fire losses. A generic framework is being developed that sequentially addresses the public acceptance and implementation of the jintervention strategy, ignition, detection, evacuation, suppression, and ultimate loss. This framework will be demonstrated with the pilot evaluation of three to five representative intervention strategies.

\section{$\underline{\text { Reports and Papers }}$}

Helzer, S.G., Buchbinder, B., and Offensend, F.L., "Decision Analysis of Strategies for Reducing Upholstered Furniture Fire Losses," available from Center for Fire Research, Summer 1979.

Offensend, F.L., Helzer, S.G., and Buchbinder, B., "Evaluation of Strategies for Reducing Upholstered Furniture Fire Losses," in preparation for Fire Journal.

Levinthal, D.A., "Application of Decision Analysis to a Regulatory Problem: Flammability Standards for Liquid Insulated Transformers," available from Center for Fire Research, Summer, 1979. 


\section{ANNUAL CONFERENCE ON FIRE RESEARCH \\ CENTER FOR FIRE RESEARCH \\ NATIONAL BUREAU OF STANDARDS \\ GAITHERSBURG, MARYLAND}

August 22-24, 1979

\section{Institution: SRI International}

Contract No: Future contract

Title: Polymer Degradation During Combustion

Principal Investigator: Dr. S. K. Brauman

Polymer Sciences Department

SRI International

333 Ravenswood Avenue

Men1o Park, CA 94025

NBS Scientific Officer: R. G. Gann

\section{Technical Abstract}

Although the degradation of synthetic polymers under fire conditions is important to fuel production and combustion, it has received 1ittle attention, mostly because of experimental limitations. SRI has developed a novel driven-rod, radiant pyrolysis apparatus that can be used to study steady-state linear regression of vertically mounted polymer rods degrading under nonflaming conditions that simulate those of combustion. Absence of the flame simplifies experiments and analysis. We propose to use this technique to study the degradation of polystyrene under fire conditions. The investigation will entail: (1) steadystate linear regression rate studies to relate the radiant pyrolysis situation to the combustion situation, and to provide samples and information (temperature profiles, oxygen involvement) needed for analysis; (2) characterization of radiant pyrolysis residues and off-gases to provide mechanistic information of the condensed-phase degradation processes; and (3) kinetic analysis of the degradation rates. Results should provide understanding of the detailed degradation processes occurring in the condensed phase of a burning polymer and allow prediction of the effect of certain thermal or chemical variables on the mechanism or rate. With this knowledge, understanding of the effectiveness of and even prediction of improved fire retardants used to control fires by altering fuel production become possible. 
ANNUAL CONFERENCE ON FIRE RESEARCH

CENTER FOR FIRE RESEARCH

NATIONAL BUREAU OF STANDARDS

GAITHERSBURG, MARYLAND

August 22-24, 1979

Institution: Underwriters Laboratories Inc.

Grant No: G8-9010

Grant Title: Measurement of Air Flow Around Doors Under Standardized Fire Test Conditions

Principal Investigator: Robert M. Berhinig

Underwriters Laboratories Inc.

333 Pfingsten Rd.

Northbrook, IL 60062

$312-272-8800$

other Professional Personnel: G. T. Castino

Managing Engineer

Fire Protection Department

NBS Scientific officer: Lionel Issen

Technical Abstract

The goal of this investigation is to measure the volume of alr flow between a door and door frame during a standardized fire test method. The test method is entitled "Smoke Control Door and Shutter Assemblies - High Temperature Tests" proposed by the International Organization for Standardization (ISO-DP5925). The test method provides for a $9 \mathrm{ft}$ high by $9 \mathrm{ft}, 6$ in. wide collection hood mounted on the unexposed surface of the test sample. The collection hood includes a 12 in. diameter outlet to which is mounted a venturi. The collection hood also includes movable top and bottom sections to permit venting of heated air from within the hood during the test.

The test method requires the furnace pressure to be 10 Pascals above ambient at the top of the door being tested. The general principle of the test method assumes the positive furnace pressure will result in air flowing through the openings between the door and the door frame, into the enclosure and out of the enclosure through the venturi. The velocity of the air flowing through the venturi is measured and, thus, the volume of air flowing through openings between the door and door frame is 
calculated.

To date, two tests have been conducted. The door assembly for both tests was a $3 \mathrm{ft}$ by $7 \mathrm{ft}$ hollow metal type, stiffener design without glass. The first test was conducted on June 13,1978 .

During this test, the air velocity measured at the center of the venturi was much lower than anticipated, yet emission of smoke through the upper half of the venturi indicated that a significant outward flow existed there. This suggests that countercurrent flows occurred in the venturi with alr leaving at the top and entering at the bottom. This phenomenon is a consequence of the higher temperature, and lower density, of the air inside the hood, as compared with ambient conditions. There were also problems brought about by deflection and leakage in the hood itself.

To further investigate this effect, the second test was conducted with sturdier hood and 40 additional thermocouples installed in the hood and venturi.

A cursory review of data from the January 25 test indicates that steady state conditions did not occur within the collection hood when the ventilation doors were closed. For example, Table I shows temperatures measured in the venturi during the period when the ventilation doors were closed. 
TABLE I

Time

(Min: Sec)

$40: 02$

$40: 07$

$40: 12$

$40: 18$

$40: 23$

$40: 29$

$40: 34$

$40: 39$

$40: 45$

$40: 50$

$40: 56$

41:01

41:07

$41: 12$

$41: 17$

$41: 23$

$41: 28$

$41: 34$

$41: 39$

$41: 44$

$41: 50$
Temperatures In Ventur 1 (F)

Upper Quarter Center Lower Quarter

94

112

129

144

159

169

178

185

190

194

198

200

202

203

206

207

207

208

209

210

211
94

112

130

145

155

161

164

168

164

160

158

157

156

153

150

146

144

140

139

137

134
93

110

127

140

148

148

142

138

133

128

123

119

114

111

107

104

101

98

97

94

93

Future work under the grant is dependent upon the results of the data analysis currently being conducted by the Bureau.

Reports and Papers: None. 


\section{ANNUAL CONFERENCE ON FIRE RESEARCH \\ CENTER FOR FIRE RESEARCH \\ NATIONAL BUREAU OF STANDARDS \\ GAITHERSBURG, MARYLAND}

August 22-24, 1979

Institution: The University of Arizona

Grant/Contract No: NBS Grant 8-9016

Title: Evaluation of the Combustion Toxicology of Several Polymeric Materials

Principal Investigator: J. Wesley Clayton

Professor of Toxicology

Toxicology Program

The University of Arizona

Room 303 Biosciences West

Tucson, AZ 85721

Other Professional Personnel: J. R. Sehr, M.S. candidate

NBS Scientific Officer: Merritt Birky

Objectives

The purpose of this research is to evaluate the combustion toxicity of 5 types of polymeric materials (Douglas fir, wool, PTFE, modacrylic and polyisocyanurate).

The field of combustion toxicology, or more precisely stated, the inhalation toxicology of combustion products, is in developmental stages. Thus, the parameters for evaluating toxicity have not yet been firmly established in a systematic way. It may even be extremely difficult, if not impossible, to arrive at a "standard" test procedure because of the complexities which inhere in this special area of inhalation toxicity.

Accordingly, investigations need to be conducted in order to assess toxicity and identify polymers which yield products of unusual toxicity. The objective of this research is to determine the acute inhalation toxicities of the designated samples and to assess the relative toxicities from the data which emerge from the experiments in accordance with the classification system proposed by NBS.

Methods

Polymer samples of the desired weight were cut from stock supplied by NBS. Samples were decomposed at two temperatures: $15^{\circ} \mathrm{C}$ below the predetermined autoignition point, and $25^{\circ} \mathrm{C}$ above the autoignition point, flaming being assured by addition of several drops of ethanol and a hot-wire ignition source. 
Six male, Sprague-Dawley rats were exposed for a duration of 30 minutes in a 60-1iter octagonal, static exposure chamber (University of Utah type), and observed for gross behavioral changes during exposure. Four rats per exposure were wired for a conditioned avoidance response, and time to loss of the response was noted.

Chamber atmosphere analyses for $\mathrm{CO}, \mathrm{CO}_{2}$ and $\mathrm{O}_{2}$ were conducted at 5 minute intervals, and additional gasses, depending on polymer type, were analyzed at regular intervals.

Each animal was given a behavioral examination immediately following exposure to assess: corneal reflex, righting response, character of respiration, chromorrhinorrhea, and lacrimation. Animals were followed for two weeks after exposure to measure weight changes and any obvious change in health status.

Gross necropsies were conducted at time of death or at two weeks.

$\underline{\text { Results and Discussion }}$

LC50 Determinations (Data Summary, Table I)

Preliminary results are presented in Figure I for the smoldering mode, and in Figure II for the flaming mode for acute lethality. From the Miller-Tainter plot in Figure I, the LC50 of smoldering combustion of Douglas fir is $17 \mathrm{~g} / \mathrm{m}^{3}$. This compares favorably with results obtained in an identical system at the University of Utah, which found an LC50 of $19 \mathrm{~g} / \mathrm{m}^{3}$. The LC50 for smoldering decomposition of wool is found to be $12 \mathrm{~g} / \mathrm{m}^{3}$.

From Figure II, we calculate the LC50 for Douglas fir in the flaming mode to be $40 \mathrm{~g} / \mathrm{m}^{3}$. This is nearly twice the $\mathrm{LC}_{50}$ of $24 \mathrm{~g} / \mathrm{m}^{3}$ found at the Flammability Research Center, but considering the different strains of rats used in each laboratory, and inherent biological variation within each strain, the difference is not considered to be significant.

Also conducted, but not represented in Figures $I$ and II, are the results of experimentation on Teflon (R) PTFE resin (tape form, small chunks) in both modes, and the LC50 results for wool in the flaming mode.

The lethal effect of flaming combustion of wool leaped from $0 \%$ lethality at a level of $20 \mathrm{~g} / \mathrm{m}^{3}$ to $100 \%$ lethality at a level of $40 \mathrm{~g} / \mathrm{m}^{3}$, a truly unexpected finding. For this reason, and because of difficulties in incorporating this result onto the Miller-Tainter Plot, these data are not presented in that form. Further experimentation is planned to elucidate the true lethality of flaming combustion of wool.

The investigations so far completed on Polytetrafluoroethylene have shown extreme toxicity. We have encountered $100 \%$ lethality at all levels between $5 \mathrm{~g} / \mathrm{m}^{3}$ and $1.25 \mathrm{~g} / \mathrm{m}^{3}$ in both experimental decomposition modes. Once again, further experimentation is expected to elucidate the actual value of the $\mathrm{LC}_{50}$ in both modes.

Loss of Conditioned Avoidance Response (EC50 Determinations)

Miller-Tainter Plots of data for loss of the conditioned avoidance response are shown in Figures III and IV. 
For Douglas fir, we found the EC50 for smoldering decomposition to be approximately $9.4 \mathrm{~g} / \mathrm{m}^{3}$, which once again compares favorably with the $5 \mathrm{~g} / \mathrm{m}^{3}$ obtained at the University of Utah.

Loss of conditioned avoidance response for rats exposed to the products of smoldering decomposition of wool follows a steeper curve than does that of Douglas fir. Consequently, though wool shows a lesser effect than Douglas fir on the response at low dose levels (below $3.5 \mathrm{~g} / \mathrm{m}^{3}$ ), it nevertheless shows greater effects at higher doses and, consequently, the EC50 is lower $-6 \mathrm{~g} / \mathrm{m}^{3}$.

As with lethality, Polytetrafluoroethylene shows a much higher level of toxicity than does either Douglas fir or wool. We found the EC50 for pyrolysis of PTFE in the smoldering mode to be approximately $3.5 \mathrm{~g} / \mathrm{m}^{3}$. Further experimentation is expected to allow the value to be estimated more precisely.

Figure IV, loss of avoidance response for flaming combustion, follows the same sequence as do the pyrolysis data.

We estimate the $\mathrm{EC}_{50}$ for flaming combustion of Douglas fir to be $20 \mathrm{~g} / \mathrm{m}^{3}$, once again a favorable comparison is made with data obtained at the University of Utah $\left(13 \mathrm{~g} / \mathrm{m}^{3}\right)$.

Wool is estimated to have an EC50 of $11.3 \mathrm{~g} / \mathrm{m}^{3}$ and PTFE to have an $\mathrm{EC}_{50}$, in the flaming mode, of $5 \mathrm{~g} / \mathrm{m}^{3}$, thus iterating the high inhalation toxicity for Polytetrafluoroethylene.

TABLE I. DATA SUMMARY*

Material

Douglas Fir

Wool

PTFE

Douglas Fir

Woo1

PTFE
EC50 (incapacitation)

Smoldering Mode

$9.4 \mathrm{~g} / \mathrm{m}^{3}\left(5 \mathrm{~g} / \mathrm{m}^{3}\right)$

$6 \mathrm{~g} / \mathrm{m}^{3}$

$3.5 \mathrm{~g} / \mathrm{m}^{3}$

Flaming Mode

$20 \mathrm{~g} / \mathrm{m}^{3}\left(13 \mathrm{~g} / \mathrm{m}^{3}\right)$

$11.3 \mathrm{~g} / \mathrm{m}^{3}$

$5 \mathrm{~g} / \mathrm{m}^{3}$

LC50 (1ethality)

$17 \mathrm{~g} / \mathrm{m}^{3}\left(19 \mathrm{~g} / \mathrm{m}^{3}\right)$

$12 \mathrm{~g} / \mathrm{m}^{3}$

$<1.25 \mathrm{~g} / \mathrm{m}^{3}$

* University of Utah data in ( ).

Work is continuing on this project to more accurately define the $\mathrm{LC}_{50}$ of wool in the flaming mode; to find the LC50 of PTFE in both modes; and to assess toxicity of two further materials: modacrylic and polyisocyanurate. 
Figure I. Mortality Data, Smoldering Mode

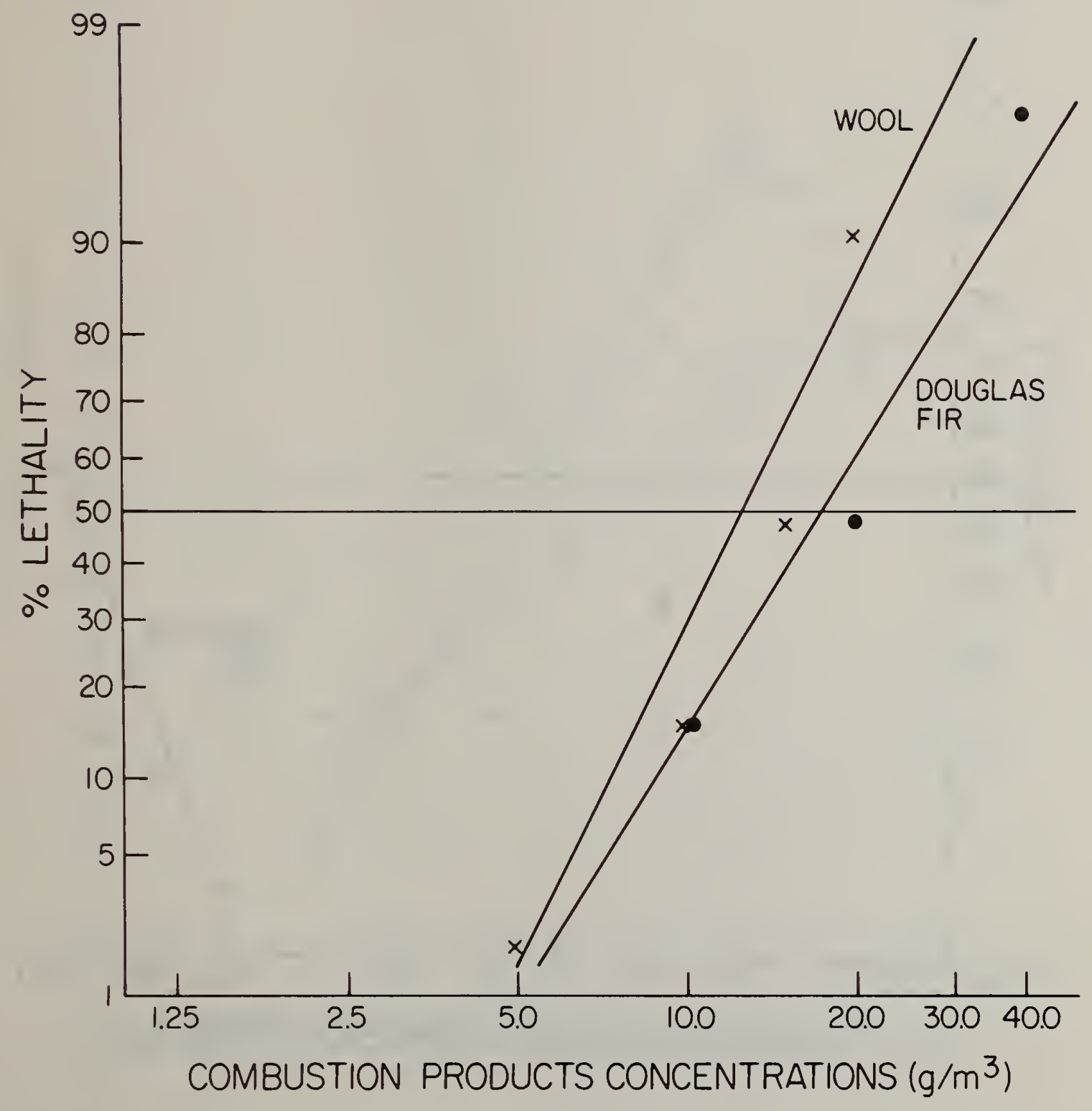


Figure II. Mortality Data, Flaming Mode

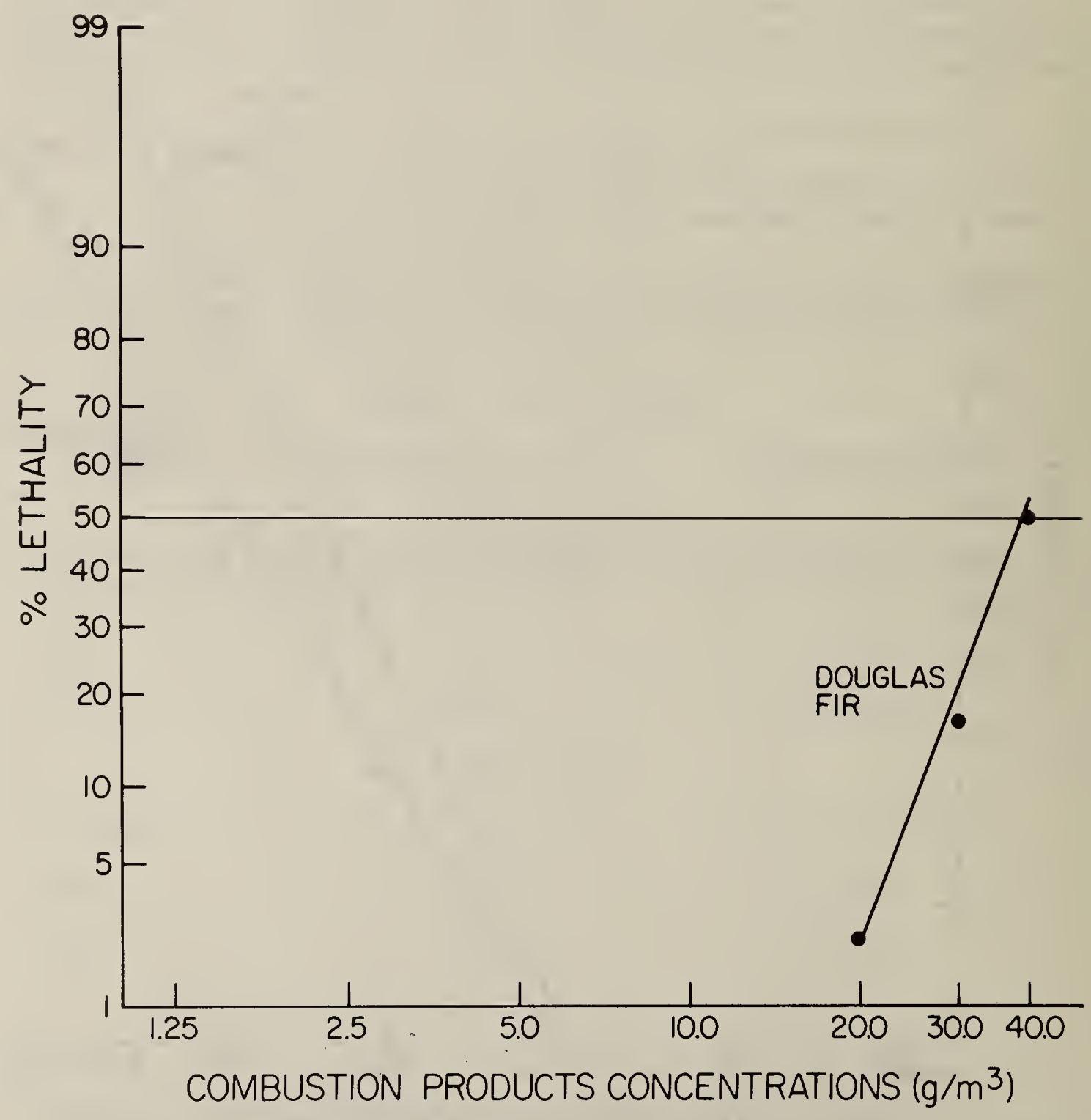


Figure III. Loss of Avoidance Data, Smoldering Mode

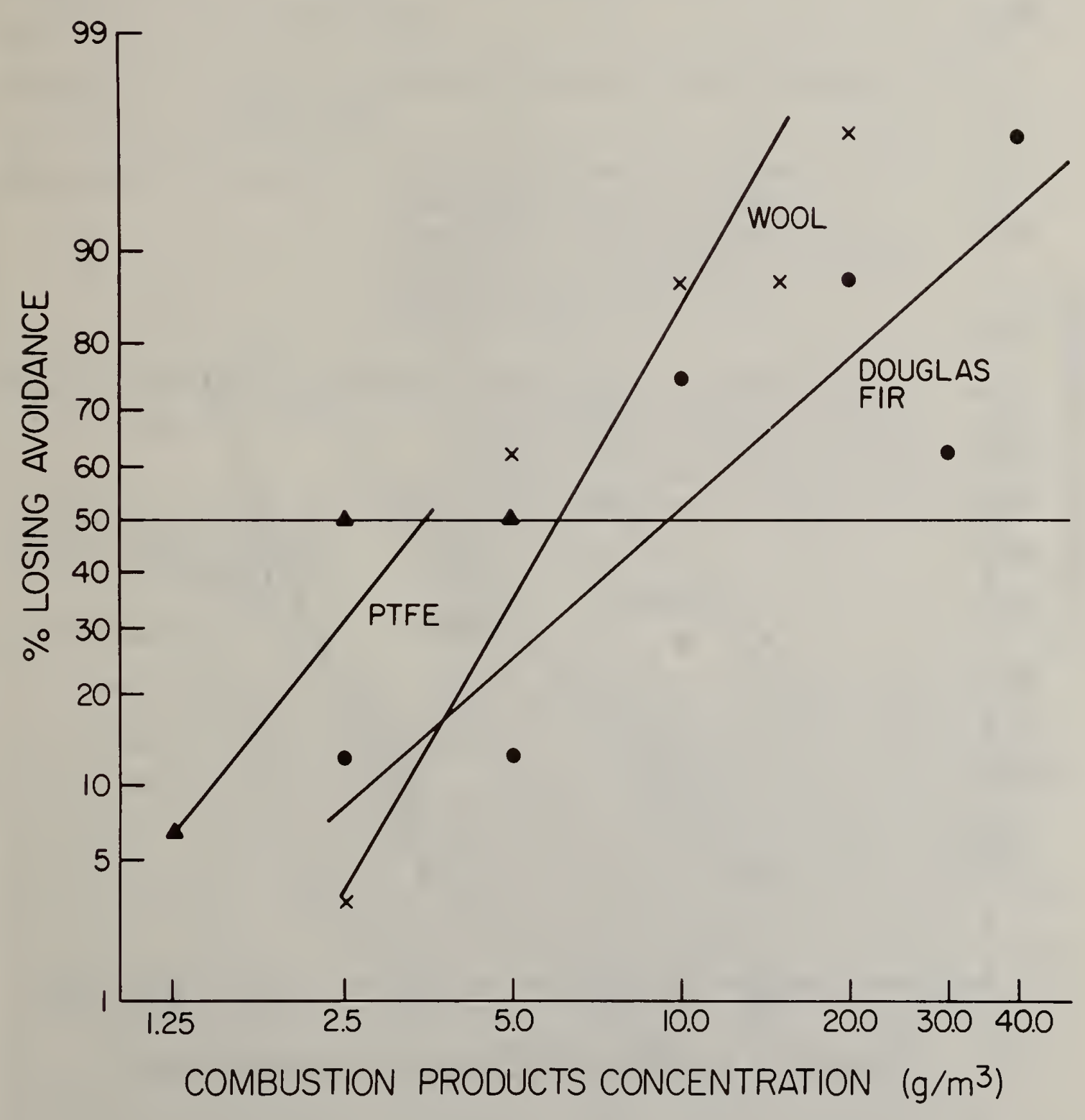


Figure IV. Loss of Avoidance Data, Flaming Mode

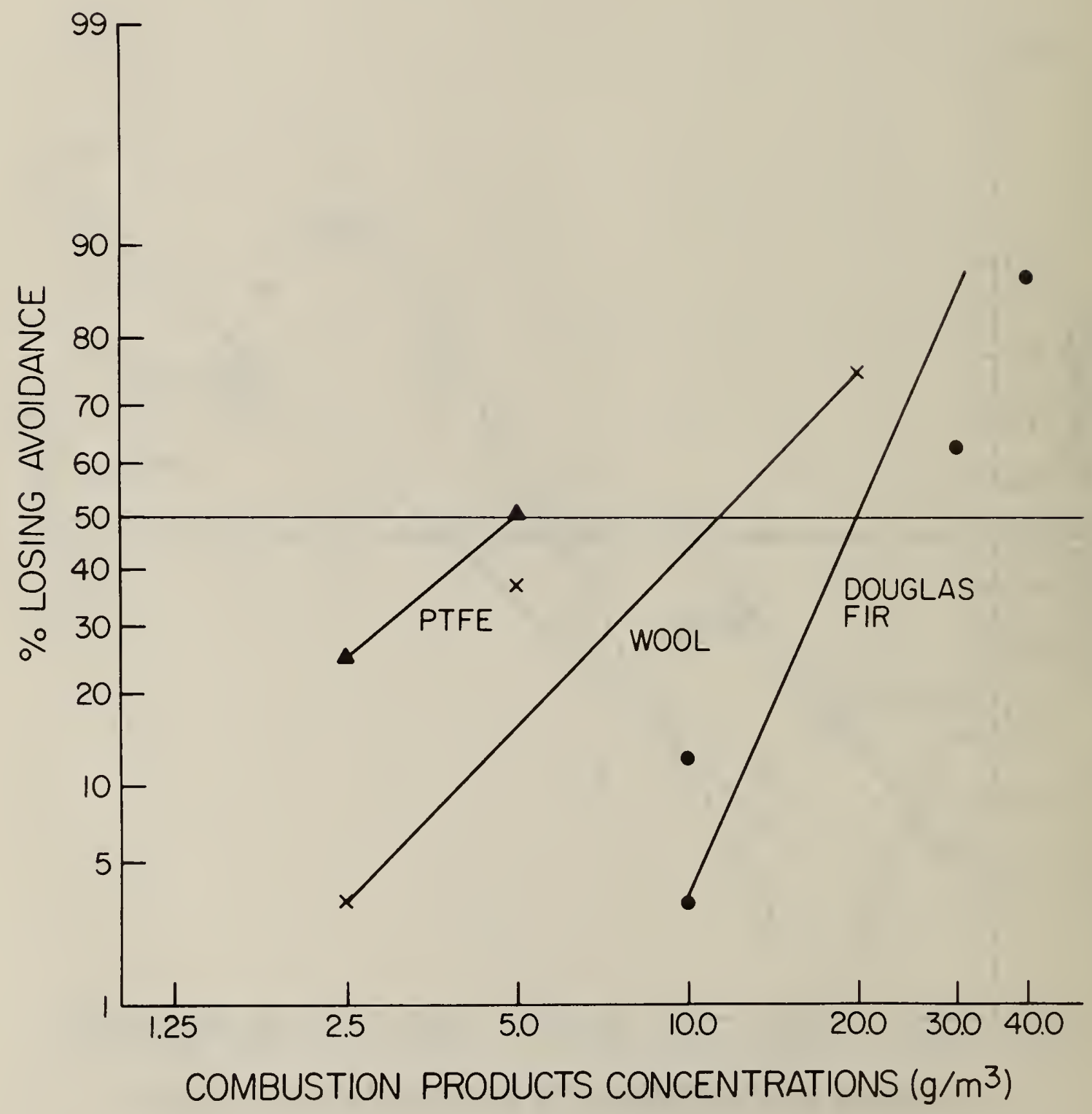




\section{ANNUAL CONFERENCE ON FIRE RESEARCH CENTER FOR FIRE RESEARCH NATIONAL BUREAU OF STANDARDS \\ GAITHERSBURG, MARYLAND}

$$
\text { August 22-24, } 1979
$$

Institution: University of California, San Diego

Grant No: NBS Grant G8-9005

Grant Title: Studies of Flame Extinction in Relationship to Fire Suppression

Principal Investigator: Professor Forman A. Williams

Department of Applied Mechanics

and Engineering Sciences

University of California, San Diego

La Jolla, California 92093

(714) 452-3172

Other Professional Personnel: Tohru Mitani, Graduate Student

Cia Sohrab, Graduate Student

Paul Clavin, Visiting Professor

Alvin S. Gordon, Adjunct Professor

NBS Scientific Officer: T. Kashiwagi

Technical Abstract

The objective of this work is to develop an improved understanding of mechanisms of fire suppresion by studying flame extinction in the presence of suppressive agents. Main suppressants considered are nitrogen, halons and powders. Principal configurations studied are the downward propagation of premixed flames through quiescent mixtures contained in tubes and the counterflow diffusion flame produced by directing an oxidizing gas stream, containing suppressant, downward onto the burning surface of liquid or solid fuel. Data include concentrations (obtained by sampling and gas chromatographic analysis), temperature profiles (measured with thermocouples), flame shapes, flame speeds and extinction conditions. Results are interpreted on the basis of theory which specifies a critical Damköhler number of extinction. Plan is to apply the theory to extract overall chemical kinetic information under conditions near extinction, to attempt to relate such information to chemical kinetic mechanisms underlying suppresion, to ascertain differences in the thermal, flow and kinetic aspects of extinction by the different agents, and to develop theoretical descriptions of cellular structures that occur under premixed conditions and of their influence on extinction. 
Most of the progress made during the past year concerns studies of premixed flames in mixtures of hydrogen, oxygen and nitrogen. Progress made in studies of diffusion flames includes setting up a dye laser for measuring $\mathrm{OH}$ and observation of counterflow extinction of flames above polyethylene and polyformaldehyde in flows of mixtures of oxygen with nitrogen. Since this work is still in progress, results will not be discussed here. Preliminary indications through spectroscopic observations have suggested that the yellow-orange emissions observed when $\mathrm{CF}_{3} \mathrm{Br}$ is added arise mainly from a carbon continuum rather than from line emissions by species containing bromine. In future work, plans are to reintensify efforts to study diffusion flames, with attention directed toward investigation of chemical kinetics with and without halon addition, measurements with $\mathrm{HBr}$ application and analysis of effects of radiation and of high molecular weights of fuels. Also, if time permits, studies will be initiated on dry-powder extinction in the diffusion-flame apparatus. The rest of this report addresses the results obtained in the studies of premixed flames.

Theoretical formulas, based on activation-energy asymptotics, have been obtained for propagation velocities of two-reactant flames. These formulas have been checked and compared with results of other investigators and are used in interpreting experimental results on flame speeds in hydrogen-oxygen-nitrogen mixtures. The results suggest that the theory provides an adequate description of these flames even though the steady-state approximations needed for their justification clearly are invalid, especially for $\mathrm{H}$ atoms.

The linear stability of two-reactant flames that leads to cellular structure was analyzed within the framework of the thermal-diffusive flame model. Effects of properties of deficient and abundant components were investigated with activation-energy asymptotics. The stability of two reactant flames is governed by the perturbations of the temperature and of the concentration of the abundant component at the perturbed flame front. The former depends on the departure of the Lewis number of the deficient component from unity. The latter is controlled by the stoichiometry of the mixture, the difference between Lewis numbers of two components and the reaction order for each reactant. The perturbation of the abundant components becomes important either near the stoichiometric point or for a mixture whose deficient component has a Lewis number very close to unity. The results show that the stability behavior of two-reactant flames can be related to that of one-reactant flames by introduction of a reduced Lewis number and that cellular instability in the flame appears if the reduced Lewis number is sufficiently small. The results account for preferential diffusion of reactants in a system with a large excess of diluent. Cell sizes calculated from the theory were found to be in good agreement with measurements on hydrogen-oxygen-nitrogen systems, in view of uncertainties in Lewis numbers and in the experimental definition of cell diameter. The comparison is shown in the figure, where the solid points are data and the lines theory, the cell diameter being given in units of the flame thickness.

Downwardly propagating flames in pyrex tubes $66 \mathrm{~cm}$ long, with 
diameters of $2.5 \mathrm{~cm}$ and $5.1 \mathrm{~cm}$, were studied experimentally under conditions near the flammability limit, viz. at volume-based nitrogen percentages ranging from $60 \%$ to $84 \%$, at flame temperatures ranging from $900^{\circ} \mathrm{K}$ to $1400^{\circ} \mathrm{K}$ and at flame speeds ranging from $10 \mathrm{~cm} / \mathrm{s}$ to 40 $\mathrm{cm} / \mathrm{s}$. The pressure was maintained at $1 \mathrm{~atm}$ and the initial temperature at $295^{\circ} \mathrm{K}$. Cell sizes were measured photographically to demonstrate the decrease in cell diameter with decreasing hydrogen-oxygen ratio; the cells are made visible by addition of less than $0.4 \% \mathrm{CF}_{3} \mathrm{Br}$. Other measurements that were made include the nitrogen dilution required to prevent flame propagation, as a function of the hydrogen-oxygen ratio, the flame speed as a function of nitrogen dilution for various hydrogen-oxygen ratios, approximate profiles of temperature through flames, obtained from measurements with fine thermocouples, the maximum flame temperature as a function of nitrogen dilution for various hydrogen-oxygen ratios, the rate of decrease of temperature behind the flame, resulting from conductive heat-loss, and the amount of hydrogen remaining after flame passage, as a function of dilution for various hydrogen-oxygen ratios, obtained through sampling followed by gas-chromatographic analysis.

A theory was developed for estimating the magnitudes of conductive heat-losses from cellular flames and for obtaining the influence of such losses on flame propagation and extinction. Consistency was found between measured leakage of hydrogen through flames and measured flame temperatures, on the basis of theoretical ideas. In addition, measured rates of decrease of temperature behind flames were found to be largely consistent with theoretical estimates. From these results, an explanation was developed for the observation that the peak in the curve of nitrogen dilution required for extinction occurs at fuel-lean conditions. In general, the present work has achieved some clarification of mechanisms whereby cellular-flame structures influence nearlimit and extinction behavior of downwardly propagating premixed flames in tubes.

Information obtained from these results ultimately may afford improvements in techniques for fire supression, derived from increased understanding of mechanisms of flame extinction, taking into account interactions between chemical kinetics, fluid flow and heat transfer. These studies present the possibility of extracting basic information on both the fluid mechanics and the chemical kinetics of combustion near extinction, which may be useful in analyzing extinctions under widely different conditions of burning and of suppressive action. Consequent improvements in fire supression may reduce fire loss.

Reports and Papers

Bregeon, B., Gordon, A. S. and Williams, F. A., "Near-Limit Downward Propagation of Hydrogen and Methane Flames in Oxygen Nitrogen Mixtures", Combustion and Flame, 33, 33-45 (1978). 
Seshadri, K. and Williams, F. A., "Structure and Extinction of Counterflow Diffusion-Flames above Condensed Fuels: Comparison between Polymethylmethacrylate and its Liquid Monomer, both Burning in NitrogenAir Mixtures", Journal of Polymer Science: Polymer Chemistry Edition, 16, $1755-1778$ (1978).

Seshadri, K., "Structure and Extinction of Laminar Diffusion Flames above Condensed Fuels with Water and Nitrogen", Combustion and Flame 33, 197-215 (1978).

Mitani, T., "Studies of Premixed Hydrogen Flames", Ph.D. Thesis, University of California, San Diego, 1979.

Mitani, T., "Propagation Velocities of Two-Reactant Flames", submitted for publication, 1979 .

Joulin, G. and Mitani, T., "Linear Stability Analysis of Two-Reactant Flames", in preparation, 1979.

Mitani, T. and Williams, F. A., "Studies of Cellular Flames in HydrogenOxygen-Nitrogen Mixtures", in preparation, 1979.

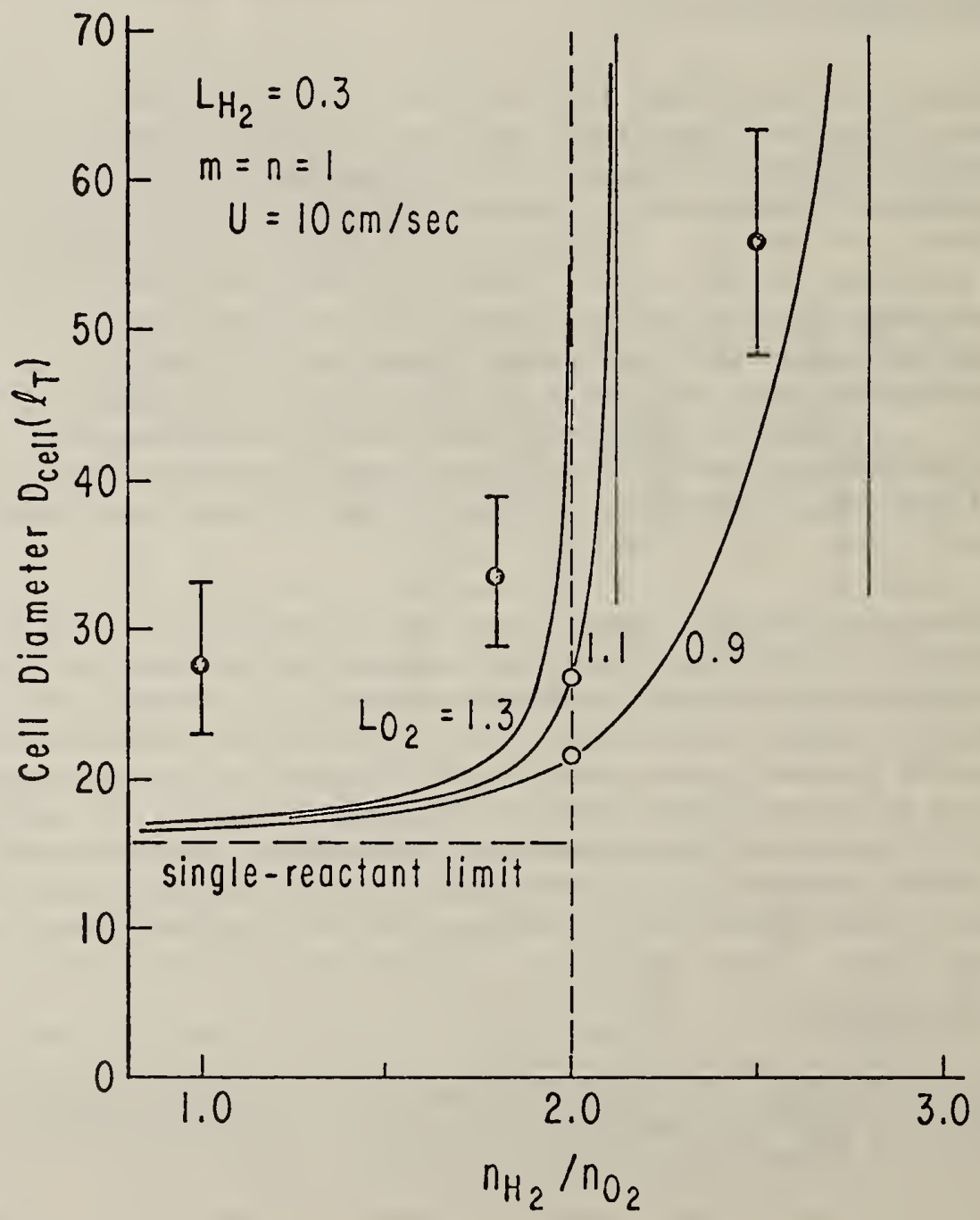




\section{ANNUAL CONFERENCE ON FIRE RESEARCH \\ CENTER FOR FIRE RESEARCH \\ NATIONAL BUREAU OF STANDARDS \\ GAITHERSBURG, MARYLAND}

August $22-24,1979$

Institution: University of Florida

Grant/Contract No: Pending

Title: Network Models of Building Evacuation

Principal Investigator: Professor Richard L. Francis

University of Florida

Department of Industrial and

Systems Engineering

303 Weil Hall

Gainesville, Florida 32611

Other Professional Personnel: Professor Luc G. Chalmet

Graduate student to be determined

NBS Scientific Officer: Leonard Cooper

$\underline{\text { Technical Abstract }}$

The research deals with the further development of the EVACNET approach as presented in the report NBSIR 79-1593, "EVACNET: Prototype Network Optimization Models for Building Evacuation." Basically, the author proposes to develop modeling guidelines to help make EVACNET accessible to non-technical users, and to develop simpler auxiliary models of building evacuation.

In brief, EVACNET work to date has consisted of a pilot project conducted to analyze the evacuation of buildings by means of computer-ized network flow optimization models. A major effort during this study involved constructing such an evacuation model of Building 101, an eleven-floor building located at the Gaithersburg, Maryland campus of the National Bureau of Standards. A "skeletal" network model of the building has been constructed which represents the following entities (as well as paths of movement between them): workplaces, halls, doors between workplaces and halls, stairwells, doors between halls and stairwells, doors between stairwells and the lobby, and lobby doors. The model determines by itself an evacuation routing of the people in the building so as to minimize the time to evacuate the building. Further, the model is dynamic, in the sense that it represents the pattern of the building evacuation over time. Just as one might imagine photographing an actual building evacuation using automatic time-lapse cameras which take pictures of relevant evacuation activities over regular time inter- 
vals, so the model depicts the evacuation of the building as it changes over time: time is divided into discrete time periods, and the model indicates the changes in the evacuation status during each time period, as well as the evacuation status at the end of each time period.

Data for the model include such things as the numbers of people in workplaces prior to evacuation, stairwell flow-rate capacities, hall and lobby flow-rate capacities, as well as static capacities such as the total number of people a hall, workplace, or stairwell can accommodate. By making repeated computer runs of the model with different data sets, "what if" questions of interest, such as the following, can readily be addressed:

- What if there is a fire on the tenth floor?

- What if we could use "express elevators" to facilitate evacuating the building?

- What if a fire blocks a stairwell and/or some halls?

- What if we add more building exits?

- What if we add more stairwells?

- What if we want to identify evacuation bottlenecks?

- What if we want to determine the minimum time to evacuate the building, as well as routes people could follow so as to evacuate the building in the minimum time?

The fact that the model is computerized greatly facilitates asking such "what if" questions: answering them usually entails only changing model data and then making a computer run. Such data changes can of ten be made by an operator sitting at a remote computer terminal. Computerization permits answering such questions quickly, and is particularly useful when the model is large enough to be unwieldy if dealt with manually. Such a computer model has clear advantages over such other approaches as the use of graphical models, pictorial representations of building evacuation, and actual trial building evacuations: the computer model is often quicker, cheaper, can handle larger problems, and greatly facilitates the comparison of many alternatives. In the long run, it is hoped that such computer models will facilitate the study of the interrelationships of building evacuation with building design, building redesign, and building evacuation standards, and also will lead to improvements in design for evacuation.

While the particular model we have studied (to date) is for a specific building, the modeling methodology we have developed is rather general, and should facilitate modeling the evacuation of other buildings. 
ANNUAL CONFERENCE ON FIRE RESEARCH

CENTER FOR FIRE RESEARCH

NATIONAL BUREAU OF STANDARDS

GAITHERSBURG, MARYLAND

August 22-24, 1979

Institution: University of Maryland, College Park

Grant No: NBS Grant 7-9014

Grant Title: The Determination of Behavior Response Patterns in Fire Situations, Project People II.

Principal Investigator: Dr. John L. Bryan, Professor and Chairman

Department of Fire Protection Engineering

University of Maryland

College Park, Maryland 20742

(301) $454-2424$

Other Professional Personnel: Mr. Philip J. DiNenno, Research Assistant

NBS Scientific Officer: Dr. Bernard Levin

Technical Abstract

The study involves the identification and analysis of the behavior patterns of building occupants in fire situations. Intensive in-depth open-ended interviews are conducted with participants, supplemented with a structured questionnaire. The interviews have been conducted by the research study personnel at the scene of the fire incident between one to four weeks following the fire incident.

The study population is currently limited to health care and educational occupancies, with other significant occupancy fires within the following criteria for the selection of fire incidents: 1 . Any known nursing home or hospital fire in the State of Maryland that involved staff procedural action, the evacuation of one or more rooms, the operation of a fire extinguisher, or the occurrence of any personnel injuries. 2. Any known school fire that involved the evacuation of the students, and procedural extinguishment action by the public fire department. 3. Any known fire in a business, residential, mercantile or public assembly occupancy that involved the evacuation of more than 200 occupants.

The detailed information from the interviews and the questionnaires is studied to determine the behavior response patterns of the participants, and the psychological, sociological, educational, and physical variables influencing the predisposition to the adopted response. Thus, the total interactional context of the individual, the 
functional population, the time variables, the parameters of the fire incident, and the physical environment of the structure in relation to detection, alarm, protection and evacuation variables is being studied. The study has obtained data on minor or successful fires, in which the fire incident was successfully controlled by personnel without the assistance of the public fire department. The behavior response patterns from the fire incidents of the non-threatening type are being compared with the fire incidents which were perceived to be threatening to the extent the assistance of the public fire department was requested by the occupants. The concept of realms and episodes, with mapping techniques developed by Lerup have been applied to these studies.

A total of forty-five fire incidents were under study and analysis as of May 1, 1979, with a total of thirty-two reports having been submitted to the Center of Fire Research.

Reports and Papers:

Bryan, John L. and Philip J. DiNenno, An Examination and Analysis of the Dynamics of the Human Behavior in the Fire Incident at St. Joseph's Hospital, Philadelphia, Pa. on August 10, 1977. College Park: University of Maryland, Fire Protection Engineering, May 31, 1978.

Bryan, John L. and Philip J. DiNenno, An Examination and Analysis of the Dynamics of the Human Behavior in the Fire Incident at the Kensington Gardens Nursing Home on January 1, 1978. College Park: University of Maryland, Fire Protection Engineering, June 30, 1978.

Bryan, John L. and Philip J. DiNenno, An Examination and Analysis of the Dynamics of the Human Behavior in the Fire Incident at the Manor Care, Hyattsville Nursing Home on January 10, 1978. College Park: University of Maryland, Fire Protection Engineering, June 30, 1978.

Bryan, John L. and Philip J. DiNenno, An Examination and Analysis of the Dynamics of the Human Behavior in the Kitchen Fire Incident at the Manor Care, Adelphi Nursing Home on March 1, 1978. College Park: Department of Fire Protection Engineering, University of Maryland, July $31,1978$.

Bryan, John L. and Philip J. DiNenno, An Examination and Analysis of the Dynamics of the Human Behavior in the Patient Room Fire Incident at the Manor Care, Adelphi Nursing Home on March 1, 1978. College Park: Department of Fire Protection Engineering, University of Maryland, July 31, 1978.

Bryan, John L. and Philip J. DiNenno, An Examination and Analysis of the Dynamics of the Human Behavior in the Fire Incident at the Harford Memorial Hospital on March 9, 1978. College Park:

Department of Fire Protection Engineering, University of Maryland, July 31, 1978. 
Bryan, John L. and Philip J. DiNenno, An Examination and Analysis of the Dynamics of the Human Behavior in the Fire Incident at the Sacred Heart Home on March 19, 1978. College Park: Department of Fire Protection Engineering, University of Maryland, July 31 , 1978.

Bryan, John L. and Philip J. DiNenno, An Examination and Analysis of the Dynamics of the Human Behavior in the Fire Incident at the Magnolia Gardens Nursing Home on April 2, 1978. College Park: Department of Fire Protection Engineering, University of Maryland, July 31 , 1978.

Bryan, John L. and Philip J. DiNenno, An Examination and Analysis of the Dynamics of the Human Behavior in the Fire Incident at the Lorien Nursing Home on May 7, 1978. College Park: Department of Fire Protection Engineering, University of Maryland, August 31, 1978.

Bryan, John L. and Philip J. DiNenno, An Examination and Analysis of the Dynamics of the Human Behavior in the Fire Incident at the Allegany County Infirmary on May 16, 1978. College Park: Department of Fire Protection Engineering, University of Maryland, August 31, 1978.

Bryan, John L. and Philip J. DiNenno, An Examination and Analysis of the Dynamics of the Human Behavior in the Fire Incident at the American Nursing Home on May 11, 1978. College Park: Department of Fire Protection Engineering, University of Maryland, August $31,1978$.

Bryan, John L. and Philip J. DiNenno, An Examination and Analysis of the Dynamics of the Human Behavior in the Fire Incident at the Sligo Gardens Nursing Home on June 10, 1978. College Park: Department of Fire Protection Engineering, University of Maryland, August 31, 1978.

Bryan, John L. and Philip J. DiNenno, An Examination and Analysis of the Dynamics of the Human Behavior in the Fire Incident at the Manor Care, Largo Nursing Home on May 9, 1978. College Park: Department of Fire Protection Engineering, University of Maryland, August 31, 1978.

Bryan, John L. and Philip J. DiNenno, An Examination and Analysis of the Dynamics of the Human Behavior in the Fire Incident at the St. Anne's Infant Home on June 20, 1978. College Park: Department of Fire Protection Engineering, University of Maryland, September 30,1978 .

Bryan, John L. and Philip J. DiNenno, An Examination and Analysis of the Human Behavior in the Fire Incident at the Manor Care, Largo Nursing Home on August 14, 1978. College Park: Department of 
Fire Protection Engineering, University of Maryland, September $30,1978$.

Bryan, John L. and Philip J. DiNenno, An Examination and Analysis of the Dynamics of the Human Behavior in the Fire Incident at the Avalon Manor Nursing Home on June 16, 1978. College Park: Department of Fire Protection Engineering, University of Maryland, October 31 , 1978.

Bryan, John L. and Philip J. DiNenno, An Examination and Analysis of the Dynamics of the Human Behavior in the Fire Incident at the Anne Arundel General Hospital on May 1, 1978. College Park: Department of Fire Protection Engineering, University of Maryland, October 31, 1978.

Bryan, John L. and Philip J. DiNenno, An Examination and Analysis of the Dynamics of the Human Behavior in the Fire Incident at the North Arundel Hospital on September 4, 1978. College Park: Department of Fire Protection Engineering, University of Maryland, October 31, 1978.

Bryan, John L. and Philip J. DiNenno, An Examination and Analysis of the Dynamics of the Human Behavior in the Fire Incident at the University of Maryland Hospital on April 26 to May 8, 1978. College Park: Department of Fire Protection Engineering, University of Maryland, November 30, 1978.

Bryan, John L. and Philip J. DiNenno, An Examination and Analysis of the Dynamics of the Human Behavior in the Fiie Incident at the Anne Arundel General Hospital on May 11, 1978. College Park: Department of Fire Protection Engineering, University of Maryland, November 30,1978 .

Bryan, John L. and Philip J. DiNenno, An Examination and Analysis of the Dynamics of the Human Behavior in the Fire Incident at the Manor Care, Towson Nursing Home on October 18, 1978. College Park: Department of Fire Protection Engineering, University of Maryland, December 22, 1978.

Bryan, John L. and Philip J. DiNenno, An Examination and Analysis of the Dynamics of the Human Behavior in the Fire Incident at the Anne Arundel General Hospital on November 14, 1978. College Park: Department of Fire Protection Engineering, University of Maryland, December 22, 1978.

Bryan, John L. and Philip J. DiNenno, An Examination and Analysis of the Dynamics of the Human Behavior in the Fire Incident at the Shepphard Pratt Hospital on October 25 and 26, 1978. College Park: Department of Fire Protection Engineering, University of Maryland, January 31, 1979. 
Bryan, John L. and Philip J. DiNenno, An Examination and Analysis of the Dynamics of the Human Behavior in the Fire Incident at the Washington Adventist Hospital on December 22, 1978. College Park: Department of Fire Protection Engineering, University of Maryland, January $31,1979$.

Bryan, John L. and Philip J. DiNenno, An Examination and Analysis of the Dynamics of the Human Behavior in the Fire Incident at the Spring Grove Hospital on January 31, 1979. College Park: Department of Fire Protection Engineering, University of Maryland, January $31,1979$.

Bryan, John L. and Philip J. DiNenno, An Examination and Analysis of the Dynamics of the Human Behavior in the Fire Incident at the Southern Maryland Hospital on January 2, 1979. College Park: Department of. Fire Protection Engineering, University of Maryland, February 28, 1979.

Bryan, John L. and Philip J. DiNenno, An Examination and Analysis of the Dynamics of the Human Behavior in the Fire Incident at the Lafayette Square Nursing Home on October 24, 1978. College Park: Department of Fire Protection Engineering, University of Maryland, February 28, 1979.

Bryan, John L. and Philip J. DiNenno, An Examination and Analysis of the Dynamics of the Human Behavior in the Fire Incident at the Washington Adventist Hospital on December 9, 1978. College Park: Department of Fire Protection Engineering, University of Maryland, March 31, 1979.

Bryan, John L. and Philip J. DiNenno, An Examination and Analysis of the Dynamics of the Human Behavior in the Fire Incident at the Shepphard Pratt Hospital on February 7, 1979. College Park: Department of Fire Protection Engineering, University of Maryland, March 31, 1979.

Bryan, John L. and Philip J. DiNenno, An Examination and Analysis of the Dynamics of the Human Behavior in the Fire Incident at the E1licott City Middle School on February 14, 1979. College Park: Department of Fire Protection Engineering, University of Maryland, March 31, 1979.

Bryan, John L. and Philip J. DiNenno, An Examination and Analysis of the Dynamics of the Human Behavior in the Fire Incident at the University of Maryland Hospital on February 6, 1979. College Park: Department of Fire Protection, University of Maryland, March $31,1979$.

Bryan, John L. and Philip J. DiNenno, An Examination and Analysis of the Dynamics of the Human Behavior in the Fire Incident at the Georgian Towers on January 9, 1979. College Park: Department of Fire Protection Engineering, University of Maryland, April 30, 1979. 


\section{ANNUAL CONFERENCE ON FIRE RESEARCH \\ CENTER FOR FIRE RESEARCH \\ NATIONAL BUREAU OF STANDARDS \\ GAITHERSBURG, MARYLAND}

August 22-24, 1979

Institution: University of Massachusetts, Amherst

Grant/Contract No: G7-9010

Title: Flame Suppression by Chemical Inhibitors

Principal Investigators: Professor James C.W. Chien

Department of Polymer Science \& Engineering

Materials Research Laboratory

University of Massachusetts

Amherst, MA 01003

Professor Marcel Vanpee

Department of Chemical Engineering

University of Massachusetts

Amherst, MA 01003

Other Professional Personnel: J.K.Y. Kiang, Ph.D. Completed

J.L. Fan, Ph.D. Candidate

G. Riska, Ph.D. Candidate

J. Scagnelli, Ph.D. Candidate

C.Y. Leung, M.S. Candidate

\section{NBS Scientific Officer: W.G. Mallard}

Technical Abstract

Chemically bound chromium has been found to be extremely effective (at ca. $1 \%$ ) in suppressing oxidative pyrolys is of poly (propylene) by raising the self-ignition temperature by $\mathrm{ca} .150^{\circ} \mathrm{C}$ and the activation energy by ca. $10 \mathrm{kcal}$. mole $\mathrm{e}^{-1}$. From the product distribution with and without chromium, the mechanism of action appears to be one of catalyzing recombination of peroxy radicals, and of dehydrogenation and/or dehydration, the latter leading to the formation of crosslinks and char.

Synthetic procedures for the hydroxylation of poly(isoprene) and subsequent reaction to chemically incorporate various transition metal ions have been developed. This should enable the investigation of many other metal elements as solid phase chemical inhibitors for polymer combustion.

In the area of polymer combustion, extinction data has been obtained for poly(methylmethacrylate) ABS and flame retarded poly(propylene). The results showed that burning of the polymer in our equipment is the same as the conventional method. This gave us the confidence 
to carry out spectroscopic measurements. Spectra of polymer flames have been obtained and their electronic transitions assigned. Flame structure is important to the understanding of the combustion mechanism. We have purchased and set up a GC apparatus to probe the flame structure.

\section{Technical Report}

\section{Chemical Inhibition}

\section{A. Objective}

Current flame retardants are limited to a few elements and their efficiencies are low, thus requiring large levels of additives to impart flame retardancy to a polymer. It is the principal objective of this work to evaluate other elements which may offer new mechanisms for inhibition. The emphasis is on mechanistic study to obtain basic knowledge about chemical reactions involved in the inhibition.

\section{B. Results}

Poly(propylene) has been reacted with chromyl chloride (Etard reaction) to chemically bound chromium to the polymer. The thermal pyrolysis and oxidative pyrolysis of poly(propylene) with and without chromium have been compared using an interfaced pyrolysis GC peak dentification system. The effect of chromium on oxidative pyrolysis is the suppression of all major products; no new product was detected. Chromium increases the activation energy of oxidative pyrolysis by 10 $\mathrm{kcal}$. mole $\mathrm{e}^{-1}$ and promotes char formation. The behavior suggests possible catalysis by chromium in the termination processes. The combustion properties of poly(propylene) are significantly modified by the bound chromium. At only $1.5 \%$ level of chromium, the poly (propylene) has a limiting oxygen index of 26.4 and a self-ignition temperature of $400^{\circ} \mathrm{C}$ in air as compared to 17.4 and $250^{\circ} \mathrm{C}$, respectively, for normal poly(propylene). The results showed chemically bound chromium is very effective in retarding oxidative pyrolysis and flammability of poly(propylene).

One of the possible mechanisms of action for the chromium is the scavenging of $\mathrm{RO}_{2}{ }^{\circ}$ radicals.

$$
\begin{aligned}
& \mathrm{RO}_{2}{ }^{\circ}+\mathrm{Cr} \rightleftharpoons \mathrm{Cr}\left(\mathrm{RO}_{2}{ }^{\circ}\right) \\
& \mathrm{Cr}\left(\mathrm{RO}_{2}{ }^{\circ}\right)+\mathrm{RO}_{2}{ }^{\circ} \longrightarrow \mathrm{Cr}+\text { products }
\end{aligned}
$$

We are testing this mechanism by EPR technique. Firstly, one can compare the $\mathrm{RO}_{2}{ }^{\circ}$ radical concentration of poly(propylene) with chromylated poly (propylene) in $\mathrm{O}_{2}$ at $250^{\circ} \mathrm{C}$. If the hypothes is is correct there should be a small $\mathrm{RO}_{2}$. signal in the latter material. Furthermore, we would find out the oxidation state of the chromium from EPR, and maybe even detach the $\mathrm{Cr}\left(\mathrm{RO}_{2}{ }^{\circ}\right)$ species. We expected the EPR signals from $\mathrm{RO}_{2}{ }^{\circ}$, $\mathrm{Cr}, \mathrm{Cr}\left(\mathrm{RO}_{2}{ }^{\circ}\right)$ to all have different g-values. 
i.e.

Another possible mechanism if the decomposition of hydroperoxide,

$$
\mathrm{Cr}+\mathrm{ROOH} \longrightarrow \mathrm{CrO}+\mathrm{ROH}
$$

We are in the process of studying the reaction of chromylated poly(propylene) with t-butyl hydroperoxide and followed the [t-BuOOH] by iodometric titration.

We have used both EPR and hydroperoxide determination in many of our previous research projects.

The Etard reaction is inapplicable to metal ions other than $\mathrm{Cr}$. We thought a general substrate would be hydroxylated polyisoprene. 'lhe relevant reactions are:

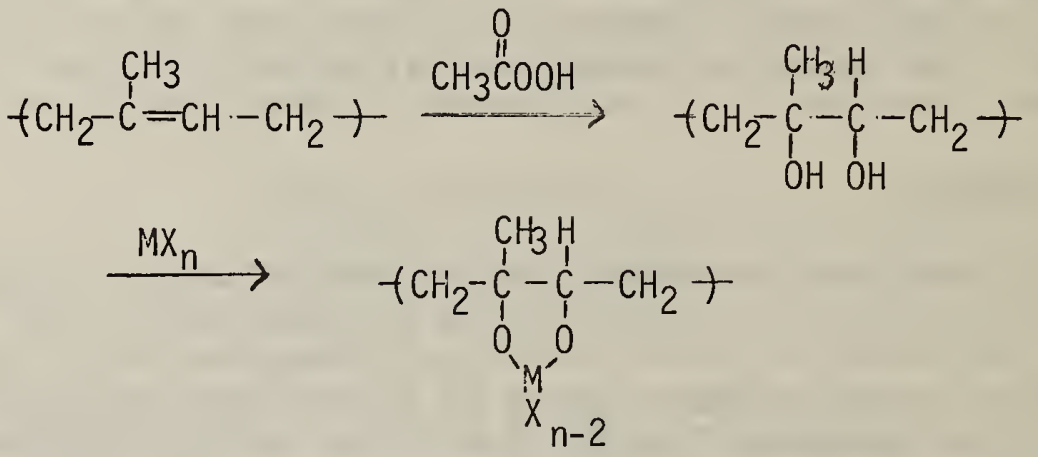

The synthetic procedure has been worked out for the incorporation of $\mathrm{Ti}, \mathrm{Cr}, \mathrm{V}$, Co and $\mathrm{Fe}$ in poly(isoprene).

Meanwhile, we need to know the mechanism and kinetics of pyrolysis and oxidative pyrolysis. Oxidative pyrolysis of poly(isoprene) has been carried out in a carrier stream of helium gas from 315 to $384^{\circ} \mathrm{C}$. The products were on-line identified and quantitatively analyzed by an interfaced pyrolysis GC peak identification system. The first order rate constant for pyrolysis is $1.1 \times 10^{-2} \mathrm{sec}^{-1}$ at $384^{\circ} \mathrm{C}$ with an overa 11 activation energy of $41 \mathrm{kcal}$. mole $\mathrm{e}^{-1}$. The main products are isoprene and 1-methy 1-4-isopropenyl cyclohexene. The dominant initiation process has been shown to be a chain scission leading to two allylic radicals. The former product is derived from their unzipping reaction, the latter together with 1,5-dimethyl-5-vinylcyclohexene are the main $\mathrm{C}_{10}$ products from the allylic radicals. All the other minor products can be accounted for by simple chain propagation reactions with or without intramolecular hydrogen transfers.

\section{Polymer Combustion Studies}

\section{A. Objective}

This program's objective is to develop a better understanding of the mechanism of polymer combustion and of its inhibition by selected additives. The principal combustion configuration used in these 
studies is the counter-flow diffusion flame produced by directing an oxidizer gas stream downward onto the surface of a burning polymer. Two types of data are or will be obtained. I. Flame extinction data: These are used as the main criterion to characterize flammability as by plots of oxygen mass fraction at extinction versus oxidizer velocity at extinction. The higher the oxygen mass fraction at a particular velocity, the less flammability. The same criterion will be used to assess inhibition effectiveness of retardant formulations, i.e. the molar merit number and mass merit number will be determined. An attempt will be made to extract from these data overall kinetic parameters; that is the frequency factors and energies of activation of the combustion process, in the presence and absence of inhibitors. II. The microstructure of the flame will be investigated. Concentration profiles obtained by gas chromatography will include stable molecular species: $\mathrm{CO}_{2}, \mathrm{~N}_{2}, \mathrm{H}_{2} \mathrm{O}, \mathrm{O}_{2}, \mathrm{C}_{x} \mathrm{H}_{y}$, up to $x=5$ and $y=8$. As the $\mathrm{fl}$ ames obtained with the counterflow diffusion burner are flat, they are also well suited for a spectroscopic analysis of the reaction intermediates and excitation mechanisms.

\section{B. Results}

Progress on various parts of this program has been accomplished. These include: 1) extinction data on a variety of polymers, 2) a spectroscopic survey of polymer combustion, 3) construction of the combustion apparatus and of the sampling device for the study of the microstructure of polymer flames.

\section{Extinction Data}

The following polymers were investigated: polymethylmethacrylate, polypropylene with flame retardant (SA595 Profax), and T-1000 cycolac. The last two polymers were furnished by Borg-Warner Chemical and were tested to obtain base data for our combustion apparatus. These samples were compression molded into cylindrical specimens $5 \mathrm{~cm}$ in diameter and $1.5 \mathrm{~cm}$ in height. These samples were used in the countercurrent diffusion burner. The oxidizer gas $\left(\mathrm{O}_{2}+\mathrm{N}_{2}\right)$ is passed through a gas duct, containing wire screens, so that a flat velocity profile is obtained. The gas duct is placed above the polymer surface at a distance of about $15 \mathrm{~mm}$. A flat flame is obtained between the gas duct and the polymer surface. The flow rates of oxygen-nitrogen are measured at extinction. Based on this data, a plot of oxygen mole fraction against oxidizer velocity can be obtained. The plot is linear from oxygen mole fraction of 0.153 to 0.195 and oxidizer velocity from 0.4 to $1.3 \mathrm{~m} \mathrm{sec}^{-1}$.

\section{Spectroscopy of Polymer Flames}

The data reported herein constitute a first survey of the spectra emitted by burning polymers. Two types of flame configurations were used: a) candle flames and b) counter-flow diffusion flames.

\section{a. Candle Flames}


To obtain controllable and easily reproducible polymer flames, a modified candle method was first used. Sticks of the polymers ( $5^{\prime \prime} \times$ $\left.1 / 2^{\prime \prime} \times 1 / 4^{\prime \prime}\right)$ were positioned horizontally and ignited at one end. The flame from the burning polymer was focused onto a $50 \mu$ entrance slit of a McPhearson Spectrometer, Model 760 . The spectrometer utilized a plane reflection grating of 12,000 lines $\mathrm{cm}^{-1}$. A filter (Corning 3060) was used in the region of $5000 \AA-6500 \AA$ to cut off the second order light from the U.V. region. The spectral region investigated included the ultra-violet, the visible and some of the near infrared. The spectra were recorded on $35 \mathrm{~mm}$ Kodak film. The polymers investigated by this method were: 1) polystyrene (100\% polystyrene), 2) blendex 565 (70\% styrene, $30 \%$ acrylonitrile), 3) blendex 211 (55\% styrene, $24 \%$ acrylonitrile, $21 \%$ butadiene).

Polystyrene gives a spectrum similar to the conventional hydrocarbon air flames with predominantly $\mathrm{C}_{2}, \mathrm{CH}$ and $\mathrm{OH}$ bands. To be noted is the occurence of $\mathrm{CN}$ and $\mathrm{NH}$ bands in the blended polymers due to the presence of bound nitrogen in the original polymer. In addition to the assignable electronic transitions, all three blends gave a continua in the region of $5000 \AA-6500 \AA$ due to incandescent carbon and a continua in the $3000 \AA-5000 \AA$ region due to the $\mathrm{CO}+\mathrm{C}$ recombination reaction.

\section{b. Counterflow Diffusion Flames}

Three polymers were investigated with the counterflow diffusion flame apparatus: 1) polypropylene, 2) polypropylene with flame retardant (SA 595 Profax) and 3) polymethyl methacrylate. The spectra were recorded either photographically or spectrophotometrically using an R IP28 photo multiplier tube and amplifier, connected to a strip chart recorder.

At low oxygen concentration the flame is blue-colored with little or no soot formation. The prominent emissions are again those of $\mathrm{OH}$, $\mathrm{CH}$ and $\mathrm{C}_{2}$. The spectra of polypropylene with flame retardant addition showed the appearance of the Sb atomic lines. No SbO bands could be observed. These observations tend to indicate that most of the antimony in the flame is present in the atomic state.

\section{Flame Structure}

In an attempt to obtain more information concerning the chemical kinetic mechanisms underlying the combustion process, temperature profiles and concentration profiles will be measured as a function of distance above the burning surface. To perform these measurements, a Varian 3700 gas chromatograph was acquired with funds from the NBS grant and University matching funds. This instrument was received in January.

A new combustion apparatus similar to the one used for the extinction measurements has since been constructed. The microprobe and 
assembly for sampling with drawing is now nearly completed. Our first experiments will concentrate on polymethyl mechacrylate.

Reports and Papers

Chien, J.C.W. and Kiang, J.K.Y., "Pyrolysis and Oxidative Pryolysis of PoTypropylene", in "Stabilization and Degradation of Polymers", Eds. D.L. Allara and W.L. Hawkins, Adv. in Chem., Vol. 169 (1978).

Kiang, J.K.Y., Uden, P.C. and Chien, J.C.W., "Polymer Reactions VII. Thermal Pyrolys is of Polypropylene", J.Polym. Degrad. Stab., accepted for publication.

Chien, J.C.W. and Kiang, J.K.Y., "Polymer Reactions VIII. Oxidation Pyrolysis of Polypropylene", Makromol. Chem., submitted.

Chien, J.C.W. and Kiang, J.K.Y., "Polymer Reactions IX. Effect of Polymer-Bound Chromium on Oxidative Pyrolys is of Polypropylene", Macromolecules, submitted.

Chien, J.C.W. and Kiang, J.K.Y., "Polymer Reactions X. Thermal Pryolysis of Polyisoprene", Eur. Polym. J., accepted for publication.

Chien, J.C.W. and Kiang, J.K.Y., "Polymer Reactions XI. Oxidative Pyrolysis of Polyisoprene", Macromolecules, submitted. 
ANNUAL CONFERENCE ON FIRE RESEARCH

CENTER FOR FIRE RESEARCH

NATIONAL BUREAU OF STANDARDS

GAITHERSBURG, MARYLAND

August 22-24, 1979

Institution: University of Massachusetts

Grant No: DA 0001

Title: Waking Effectiveness of Household Smoke and Fire Alert Detector Devices

Principal Investigator: E. Harris Nober

Other Professional Personnel: Henry Pierce, Arnold Well, Charles Clifton, Charles Johnson

NBS Scientific Officer: Richard Bright

Technical Abstract

This investigation has three major goals:

Goal 1 asseses intensity-frequency characteristics of several smoke alert detector signals (Experiment A). Overall dBA levels of detector acoustic signals will be obtained at 10 feet from the source in an anechoic chamber and at other sample locations equivalent to typical household placement sites. Smoke alarm signals will be analyzed at nine octave bands with central frequencies $63,125,250,1000,2000,4000$, $8000,-16000 \mathrm{~Hz}$; refined analyses will include $1 / 3$ octave bands. Also Fast Fourier Transformation analyses will be conducted to determine peak values in select frequency bands.

Goal 2 is achieved using two experiments (B, C) that will profile and quantify sleep-waking behavioral performance relative to the alarm signals and extraneous environmental noise background. Experiment B employs a young college age population programmed to receive electronically controlled stimuli while Experiment $C$ is the field study of actual smoke alarm units in sampled family constellations and households. In both, Experiment $B$ and $\underline{C}$ subject responses are the waking-time trial duration latencies from "signal-on" presentation (electronically programmed) to the subject-initiated "signal-off" response. Furthermore, Experiment B includes a number of variables, i.e., three alarm sound pressure levels $(85,70,55 \mathrm{dBA})$, air-conditioner noise, hours into sleep, night of the week, etc. The three SPL values equate to alarm means calculated earlier from a ten-foot radius ( $85 \mathrm{dBA}$ ), at pillow site, 
bedroom door open ( $70 \mathrm{dBA})$ and at pillow site, bedroom door closed (55 dBA). SPL is controlled by using a tape recorded smoke detector alarm signal of a current Kobishi-type electromechanical horn, similar to those used in most household dwellings. One dwelling member serves as respondent and performs two tasks when (or if) awakened by the alarm, (1) deactivate the automated apparatus and (2) phone the Amherst Fire Department. Both responses will be recorded and quantified (second units) as S-R latency values. The same person also fills out a pre-alarm and a post-alarm questionnaire that contains pertinent behavioral and other supplemental environmental data.

Experiment $C$ is the direct household test efficiency component that will also compare the waking effectiveness of two prevalent alarm types, the electromechanical horn used in Experiment B and the newer piezoelectric alarms that are gaining in usage. The piezoelectric alarm has a distinctively different audible sound than the electromechanical and the two clearly differ in acoustic characteristics. Piezoelectric alarms will also be laboratory analyzed, as outlined in Experiment A. Thus, Experiment $C$ serves as the extended field-test of current detector alarms, actually installed in representative dwellings and sample families.

Goal 3 explores the most efficacious acoustic auditory stimuli for different household sleeping conditions and different population types. Further tests will examine different signal temporal patterns re maximum arousal (Experiment D). Other signal variations will consider a speech signal or combination of speech and tone, etc.

\section{Progress Report}

Since the study commenced recently, progress is limited to administrative and experimental preparations. The only hard data still available at this moment are the original SPL measures of several household alert units obtained in the pilot studies. Pilot data showed acoustic energy of electromechanical alarms concentrated between $500-4000 \mathrm{~Hz}$. In a second pilot study, alarms were installed in household hallway areas and SPL measures were taken from three sites: (1) the hallway installation area (10 feet), (2) in bedrooms with bedroom door open and (3) same bedrooms, door closed. Mean dBA values were 87,71 , and $56 \mathrm{dBA}$, respectively at the three pillow (ear level) sites; ranges rarely exceeded \pm five decibels. Hence, if a room air conditioner, radio or TV were producing 65-70 dBA, there could be formidable masking to auditory perception, particularly with sleeping subjects.

Experiment A should be completed by late August or conference time.

Accomplishments

Administrative and experimental preparation. 


\section{Potential Applications}

Latency response measures and the other behavioral and statistical data gleaned from the two questionnaires should collectively provide an index of anticipated and expected behavior to the current and future alarms employed in household detectors. Data should profile stressreaction patterns of individuals and families when suddenly awakened from nighttime sleep re: different living conditions, day(s) of the week, alarm levels, alarm modes, alarm installation sites, environmental noise masking conditions, age. Clearly these data are pertinent for local fire departments and other agencies. Several manufacturers have articulated intentions to consider the data for future changes and improvements.

Future Milestones

Organize and implement the research program.

Reports and Papers

None. 
Goals

Goal 1

Assess

Spectral

Characteristics of Alarm

Signals
Objectives

\section{Objective 1}

Intensity level at

various placements

\section{Objective 2 \\ Intensity/Frequency \\ Spectral Composition}

Experiments

Experiment A

5 months
Goal 2

Sleep-Waking

Responses to

Alarm Signal

\section{Objective 1}

Waking Responses 55,

70,85 , JBA, taped signal

$B^{\prime}$ adds background

AC/VCR 55/70/85 20-30

\section{Objective 2}

Validate Response

Protocol and

Questionnaire $\frac{\text { Experiment B }}{45 \mathrm{Ss}}$

7 months

$B^{\prime}$

$A C$ noise $=10-15 \mathrm{Ss}$

VCR

$=10-15 \mathrm{~s} \mathrm{~s}$
Goal 3

Explore New

Innovative

Alarm

Signals

\section{Objective 3}

Field Test Actual

Alarm Units
Experiment C

$91 \mathrm{Ss}$

12 months
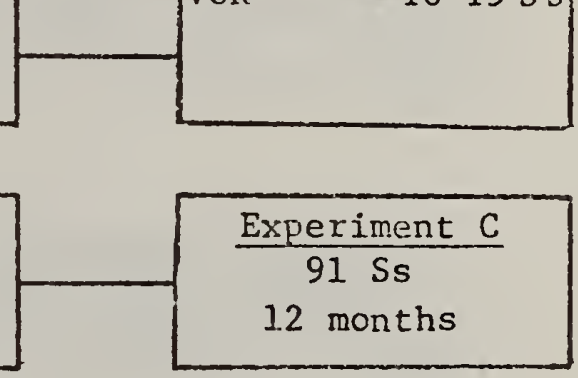


\section{ANNUAL CONFERENCE ON FIRE RESEARCH \\ CENTER FOR FIRE RESEARCH \\ NATIONAL BUREAU OF STANDARDS \\ GAITHERSBURG, MARYLAND}

August 22-24, 1979

Institution: University of Montana, Missoula, MT 59812

Grant No.: NBS Grant G8-9011

Grant Title: Ignition and Fire Spread of Cellulosic Materials

Principal Investigator: Professor Fred Shafizadeh

Wood Chemistry Laboratory

University of Montana

Missoula, MT 59812

406-243-6212

Other Professional Personnel: Dr. Allan G. W. Bradbury

Thomas W. Aanerud

NBS Scientific Officer: Dr. Richard Gann

Technical Abstract

Objectives

The current objective of this project is to investigate the chemical mechanism and kinetics of the smoldering combustion and the related inhibitors in order to provide a chemical description of the processes involved in the ignition and fire spread of cellulosic materials.

\section{Experimental Approach}

Detailed studies have been made on the mechanism and kinetics of the oxidation and thermal degradation of cellulose at temperatures below and above $300^{\circ} \mathrm{C}$; the effect of various smolder inhibitors or promoters on the combustion characteristics of cellulose, including thermal analysis, charring and heat release; the reactivity and combustion characteristics of the char produced at different temperatures, including the free radicals (unpaired electrons), the surface area, oxygen chemisorption and ignition temperature; and the effect of smolder inhibitors or promoters on the combustion of the char including the ignition temperature, ratio of $\mathrm{CO} / \mathrm{CO}_{2}$, and the heat of combustion.

\section{Results}

The resulting data show that the heat flux required for propagation of smoldering combustion is derived mainly from oxidation of the char. Chars containing smolder inhibitors are harder to ignite. They provide 
a ratio of $\mathrm{CO} / \mathrm{CO}_{2}>1$, and lower rates of oxidation and heat release (see Table 1). The reverse is true for smolder promoters which also promote glowing ignition of the char.

Chars prepared by heating of cellulose in nitrogen irreversibly adsorbed oxygen. Maximum surface area and chemisorption was observed for chars prepared by pyrolys is of cellulose for 1.5 minutes at $550^{\circ} \mathrm{C}$ (Figure 1), which corresponds to the temperature of smoldering combustion. The rate of chemisorption increased with temperature and followed the Elovich equation for activated chemisorption over the temperature range of $70-230^{\circ} \mathrm{C}$. The activation energy for oxygen chemisorption on a typical char varied linearly from 13 to $22 \mathrm{kcal} / \mathrm{mole}$ with surface coverage of 0 to $0.06 \mathrm{mmole} 0_{2} / \mathrm{gm}$ char (Figure 2). The rate of chemisorption at a given surface coverage was also related to the oxygen concentration (Figure 3). Differential scanning calorimetry and thermogravimetry indicated an initial heat of chemisorption of $\mathrm{ca} .120 \mathrm{kcal} / \mathrm{mole} 0_{2}$, leveling off to ca. $75 \mathrm{kcal} / \mathrm{mole}$ at a higher surface coverage. The concurrent carbonyl and hydroxyl formation on chemisorption was shown by infrared analysis.

It was found that the heat released by the exothermic chemisorption process could ignite cellulose chars at temperatures as $10 \mathrm{w}$ as $270^{\circ} \mathrm{C}$ in oxygen, or in the presence of a suitable inorganic catalyst, at $250^{\circ} \mathrm{C}$ in air. However, the temperature of char ignition could be raised to over $400^{\circ} \mathrm{C}$ in oxygen if the chemisorption was allowed to take place at lower temperatures.

\section{Conclusion}

Incomplete pyrolysis of cellulosic materials produces a pyrophoric char that is characterized by its high affinity for chemisorption of oxygen, and capability to ignite at relatively low temperatures. In low density cellulosic batting and insulation, where oxygen could penetrate by diffusion and the heat loss is restricted, the heat of chemisorption is intense enough to induce ignition and the subsequent combustion of the reactive char at low temperatures provides sufficient heat flux for propagation of the smoldering combustion.

The flame retardants and inorganic materials could inhibit or promote the smoldering, although they generally lower the pyrolysis temperature and enhance the char production. This is because some cationic compounds such as boron, phosphorus, and sulfur oxides could react with the oxidized groups (hydroxyl) and the active sites. Consequently, oxidation of the char produces more $\mathrm{CO}$ and less heat, thus hindering the smoldering process. On the other hand metallic anions could aid dissociation of the absorbed oxygen and produce rapid and more complete oxidation of the char which promote the smoldering process. The effectiveness of these materials should also be related to the surface area of the catalyst and its distribution.

Since suppression of the smoldering combustion is achieved by incomplete oxidation of the char, the concentration of $\mathrm{CO}$ in the 
combustion gases should be considered in evaluation of smolder inhibitors.

Reports and Papers

\section{Recent Publications}

Shafizadeh, F., Lai, Y. Z., and C. R. McIntyre, "Thermal Degradation of 6-Chlorocellulose and Cellulose-Zinc Chloride Mixture," ‥ Appl. Polym. Sci., 22, 1183-1193 (1978).

Shafizadeh, F., "Combustion, Combustibility, and Heat Release of Forest Fuels," AIChE Symposium Series No. 177, 74, (1978).

Shafizadeh, F. and Bradbury, A. G. W., "Thermal Degradation of Cellulose

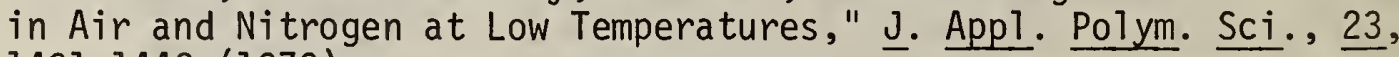
$1431-1442$ (1979).

Susott, R. A., Shafizadeh, F., and Aanerud, T. W., "A Quantitative Thermal Analysis Technique for Combustible Gas Detection," J. Fire/Flamm 10, 94-104 (1979).

\section{Recent Manuscripts}

Bradbury, A. G. W. and Shafizadeh, F., "The Role of Oxygen Chemisorption in Low Temperature Ignition of Cellulose," submitted to Combustion and Flame.

Bradbury, A. G. W. and Shafizadeh, F., "Chemisorption of Oxygen on Cellulose Char," submitted to Carbon. 
Table III. Effect of Pre-Pyrolysis Additives on Heat and Rate of Char Oxidation and $\mathrm{CO} / \mathrm{CO}_{2}$ Ratio at $450^{\circ} \mathrm{C}$ in Air.

\begin{tabular}{|c|c|c|c|c|}
\hline Additive. & $\begin{array}{l}1 \mathrm{~mole}^{\mathrm{a}} / \\
162 \mathrm{gm}\end{array}$ & $\begin{array}{l}d\left(\frac{\left.\mathrm{CO}+\mathrm{CO}_{2}\right)}{d t \mathrm{max}} \text { at } 450^{\circ} \mathrm{C}\right. \\
\text { mole } \mathrm{g} \mathrm{char}{ }^{-1} \text { min. }^{-1}\end{array}$ & $\begin{array}{l}\mathrm{CO}_{\mathrm{CO}_{2}} \text { yield } \\
\text { at } 450^{\circ} \mathrm{C}\end{array}$ & kcal. $\stackrel{\Delta \mathrm{H}_{\mathrm{Ox}}}{\mathrm{C} \text { char }}{ }^{-1}$ \\
\hline & - & 5.7 & 1.01 & 5.1 \\
\hline $\mathrm{HBO}_{3}$ & B & 4.6 & 1.69 & 3.1 \\
\hline $\mathrm{Na}_{2} \mathrm{~B}_{4} \mathrm{O}_{7}$ & 8 & 6.1 & 1.03 & 3.8 \\
\hline$\left(\mathrm{NH}_{4}\right)_{2} \mathrm{HPO}_{4}$ & $\mathbf{p}$ & 2.9 & 1.71 & 3.6 \\
\hline$\left(\mathrm{NH}_{4}\right)_{2} \mathrm{SO}_{4}$ & $\mathrm{~s}$ & 3.9 & 1.43 & \\
\hline $\mathrm{ZnCl}_{2}$ & $2 n$ & 5.1 & 0.90 & 4.1 \\
\hline $\mathrm{AlCl}_{3}$ & Al & 5.3 & 0.95 & 3.9 \\
\hline $\mathrm{NaCl}{ }^{\mathrm{B}}$ & $\mathrm{Na}$ & 13.9 & 0.70 & - \\
\hline $\mathrm{Na}_{2} \mathrm{SO}_{4}{ }^{\mathrm{b}}$ & $\mathrm{Na}$ & 15.2 & 0.86 & - \\
\hline
\end{tabular}

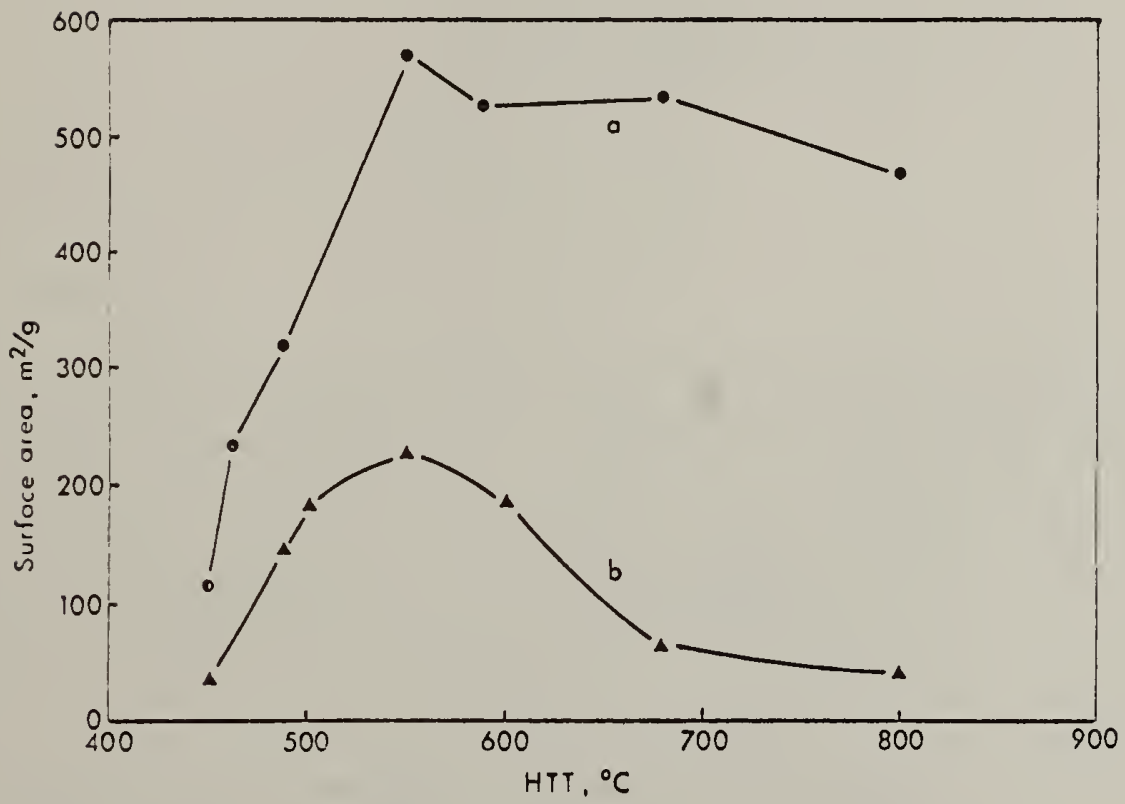

Fig. I Comparison between total surface area calculated from $\mathrm{CO}_{2}$ adsorption at $25^{\circ} \mathrm{C}$ (curve a) and that occupied by surface oxides calculated from oxygen chemisorption at $230^{\circ} \mathrm{C}$ (curve b). 


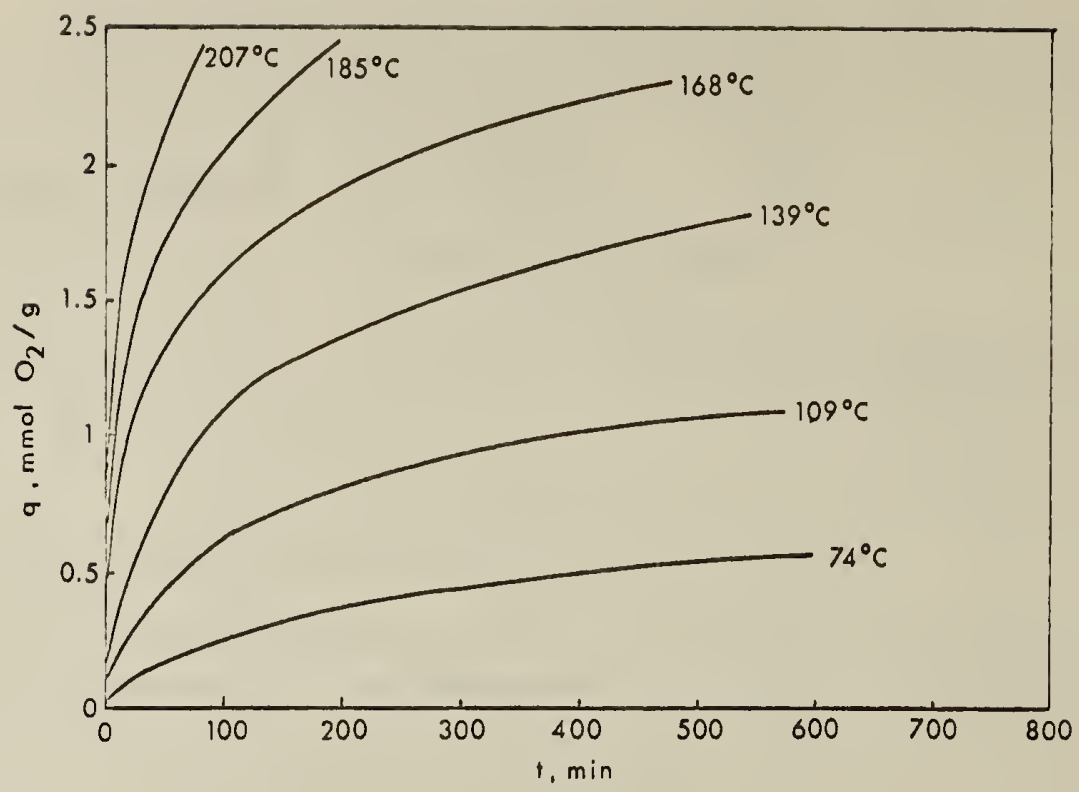

Fig. 2 Chemisorption of oxygen on cellulose chars (HTT $550^{\circ} \mathrm{C}$ ).

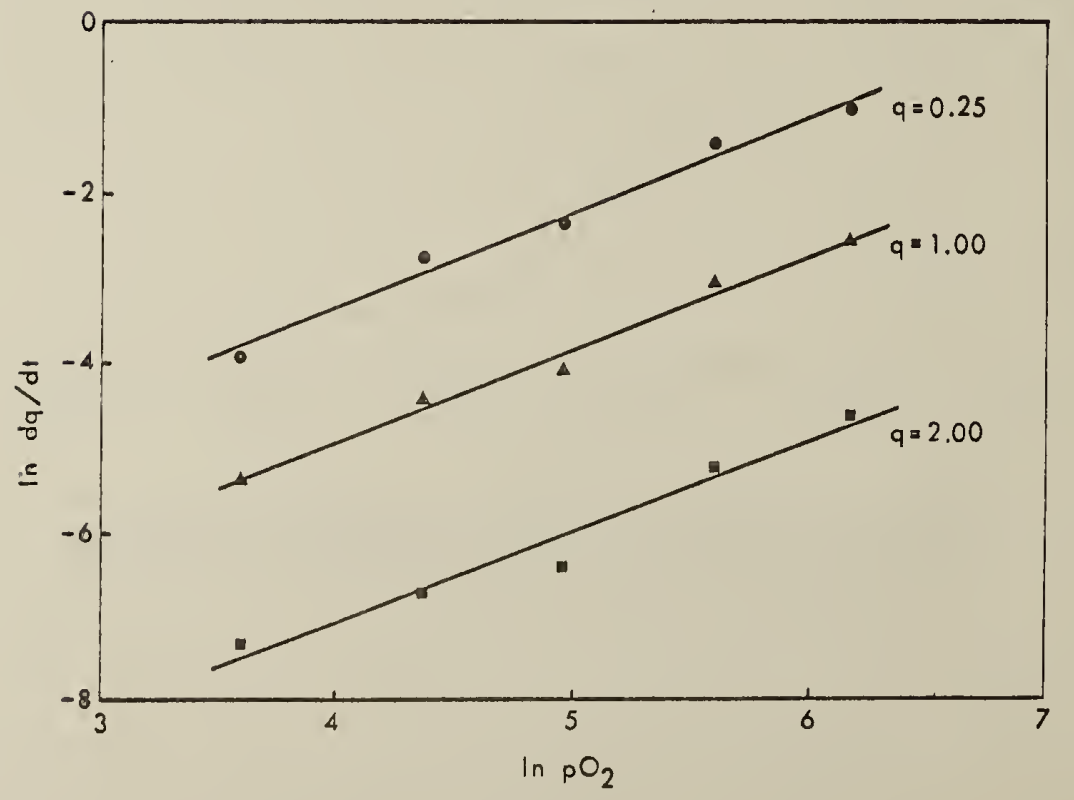

Fig. 3 Effect of oxygen concentration on instantaneous rates of chemisorption. 


\section{ANNUAL CONFERENCE ON FIRE RESEARCH CENTER FOR FIRE RESEARCH \\ NATIONAL BUREAU OF STANDARDS GAITHERSBURG, MARYLAND}

August $22-24,1979$

\section{Institution: University of North Carolina at Chapel Hill}

Grant No.: NBS Grant G7-9021

Grant Title: The Psychology of Arson: Theoretical Analyses with Suggestions for Application

Principal Investigator: Marcus B. Waller, Ph.D. Department of Psychology University of North Carolina Chapel Hill, N.C. 27514

Other Professional Personnel: Robert G. Vreeland, Ph.D. Research Associate and Project Director E. Earl Baughman, Ph.D. Associate in Personality Theory

NBS Scientific Officer: Bernard Levin, Ph.D.

\section{Technical Abstract}

The major purpose of the project has been to gain some systematic knowledge about the psychology of arson: the type of person likely to set a fire and the circumstances surrounding the firesetting act. In the first year of the project, we reviewed and systematically organized current knowledge about firesetting in children, adolescents, and adults. Although much of our information came from the literature, we also reported information obtained from meetings and conferences, and from personal contact with researchers, clinicians, and investigators.

In the second year of the project, we have been concerned with interpreting what is known about firesetting in a context of current psychological theory. The most important objectives are an improvement in existing classification and diagnostic schemes, an evaluation of the potential contributions of various personality and behavior theories to our understanding of firesetting, and specific suggestions for the application of our findings to the clinical treatment and management of firesetting. We also plan to suggest fruitful directions for future research.

Our review of the literature concentrated on common factors which appear to be characteristic of a wide range of types of firesetters. 
The traditional psychoanalytic view has emphasized the sexual roots of firesetting, and a great deal of attention has been paid to the relationship between firesetting and sexual problems. However, we have found firesetters' problems to be considerably more extensive. Among adult firesetters of all types (arson-for-profit excluded), marital, occupational, and drinking problems, as well as other criminal activity, have been prevalent. Children and adolescents who set fires have also typically shown a variety of other types of problem behaviors, including running away from home, truancy, stealing, hyperkinesis, and aggression. The "typical" firesetter in many ways appears to be similar to other types of criminals and delinquents. One major difference, however, has been the general finding that adult arsonists commit more offenses against property (firesetting excluded) and fewer offenses against persons than do other types of criminals. The extent to which these findings apply to arson-for-profit firesetters is open to question, since we know very little about this type of firesetter.

Taken together, the findings reviewed thus far have led us to emphasize a social learning model of firesetting behavior, in which firesetters are viewed as deficient in the skills, particularly social skills, necessary to obtain rewards from the environment. Having failed to gain sufficient control over his environment through appropriate interpersonal skills, the individual may turn to interpersonally less direct means for gaining a great deal of control over his environment, firesetting being one such way. Thus, the social learning model emphasizes the interaction between the person and the environmental factors which control his deviant behavior. The processes involved in the social learning model were briefly explained in our earlier review of the literature (Vreeland \& Waller, 1978). In the second year of the project we are examining these processes more fully and formally.

While we have thus far concentrated mainly on factors common to most groups of firesetters, there are also important differences. The first year's report (Vreeland \& Waller, 1978) proposed the development of a functional classification system for firesetting. The development of such a system and the interpretation of different types of firesetting within that system may aid in suggesting optimal treatment and case management strategies for different types of firesetters. It is also important that future research strategies to fill gaps in current knowledge be identified.

\section{Reports and Papers}

Vreeland, R. G. and Waller, M. B., "The Psychology of Firesetting: A Review and Appraisal," prepared for the National Bureau of Standards, U.S. Department of Commerce, NBS-GCR-79-157, 1978. 


\section{ANNUAL CONFERENCE ON FIRE RESEARCH CENTER FOR FIRE RESEARCH \\ NATIONAL BUREAU OF STANDARDS \\ GAITHERSBURG, MARYLAND}

August $22-24,1979$

Institution: University of Notre Dame

Grant No.: NBS Grant 7-9002

Grant Title: Fire and Smoke Spread

Principal Investigators: Professor K. T. Yang

Professor J. R. Lloyd

Professor A. A. Szewczyk

Department of Aerospace and Mechanical

Engineering

University of Notre Dame

Notre Dame, IN 46556

Other Professional Personnel: H. C. Chiou, Ph.D. Candidate

C. J. Huang, M.S. Candidate

NBS Scientific Officer: J. Quintiere

$\underline{\text { Technical Abstract }}$

The development of the three-dimensional UNDSAFE (University of Notre Dame Smoke and Fire in Enclosure) code for predicting smoke and fire spread in compartments is now continuing. This code represents a direct extension of the two-dimensional code (UNDSAFE-II) based on finite-difference differential-field calculations employing primitive variables and taking into account turbulence, compressibility, buoyancy and one dimensional thermal soot and gaseous radiation. However, the algebraic turbulence model for UNDSAFE-II has now been replaced by three transport differential equations for the turbulence kinetic energy, the dissipation function, and the mean-square temperature fluctuation, together with appropriate algebraic formulae for the Reynolds stresses and the components of the turbulent heat flux. The current progress may be summarized as follows:

1. The complete three-dimensional code has been written in a modularized form to provide flexibility for future updating and refinement. A variety of commonly encountered boundary conditions have been incorporated.

2. A series of debugging computer runs have been carried out. For the case of zero velocities, the code reduces to that for threedimensional unsteady conduction, and has been successfully tested for 
the case of unsteady heat conduction in a long bar of square cross section with combinations of constant surface temperatures and insulated surfaces. The momentum equations have also been tested successfully in terms of the code structure by means of physically trivial cases of unsteady channel flow. Also, the tridiagonal matrix algorithm which forms the basis for all transport equation calculations in the code, has been verified with test cases available in the literature. Test runs have also been initiated on a complete three-dimensional laminar internal flow case for the specific purpose of debugging the pressure-correction algorithm in the code.

3. Considerable effort in the recent past has been placed on the development of the turbulence model to be used in the 3-D UNDSAFE code. While the differential transport field equations for the turbulence kinetic energy $(k)$, the dissipation function $(\varepsilon)$, and the mean-square temperature fluctuation ( $g$ ) represent one of the most general turbulence field models currently available, there are several difficulties in using such a model in the field calculations for three-dimensional flows. Both the boundary conditions or wall functions and the initial conditions for $k, \varepsilon$, and $g$ are not adequately known. Also, it is difficult to find a rational basis for adjusting the large number of constants in the turbulence model for the three-dimensional problem. A major effort has been placed in the recent past on an extensive search of the experimental literature for meaningful representation of these functionals $k, \varepsilon$ and g. Several sets of data are available only for two-dimensional channel flows, but the corresponding wall functions are quite sketchy. It is decided that these data, together with available experimental data for the wall region for external flows will form the basis for the development of our analytical representations. Initial efforts on computer runs will address the simpler three-dimensional channel-flow problem. Efforts on the three-dimensional enclosure problem will then follow.

It is generally recognized that fire losses can be reduced in instances where the physical phenomena of fire and smoke spread are better understood and can be adequately predicted in advance. Research efforts in the area of mathematical fire modeling specifically address this problem by the development of zone models as well as field models, of which the present study is one example. Despite early controversies, there is a general agreement now that both the zone and field models should be developed simultaneously and complementary to one another. While field models are not yet ready for general application, they nevertheless can serve the good purpose of providing needed additional detailed information to the development of the zone model which are easier to use and are now on the verge of being applied to realistic fire problems.

\section{Reports and Papers}

N. P. Lynch, "An Experimental Study of Fire and Smoke Spread in RoomCorridor Geometries," M.S. Thesis, Department of Aerospace and Mechanical Engineering, University of Notre Dame, Notre Dame, IN., July 1979. 
ANNUAL CONFERENCE ON FIRE RESEARCH

CENTER FOR FIRE RESEARCH

NATIONAL BUREAU OF STANDARDS

GAITHERSBURG, MARYLAND

AUGUST 22-24, 1979

Institution: University of Pittsburgh

Grant No: NBS Grant NB79NADA0009 (formely NBS Grant 5-9005)

Grant Title: Toxicity of Plastic Combustion Products

Principal Investigator: Professor Yves Alarie

Department of Industrial

Environmental Health Sciences

Graduate School of Public Health

University of Pittsburgh

Pittsburgh, PA 15261

Other Professional Personnel: Rosalind C. Anderson, Ph.D.

NBS Scientific Officer: M.M. Birky, Ph.D.

Technical Abstract:

Methodologies are being developed to investigate the toxicological effects of thermal decomposition products from polymers; the end-points selected, which are of relevance in preventing escape from a fire as well as recovery following exposure to smoke are:

i) sensory irritation of the eyes, nose, and throat.

ii) physiological stress due to smoke exposure

iii) development of asphyxiation due to smoke inhalation.

iv) acute lethality due to smoke inhalation

v) pulmonary irritation during and following smoke inhalation. 
Summary:

The results obtained with the methodologies developed have permitted us to rank the potency of smoke from polymers and to make comparisons with either a reference material such as wood or to compare among materials as given in Table 1. Also, we have started the development of an Acute Lethal Hazard (ALH) index to compare materials used for the same function, i.e. insulation. These results are presented in Table 2. This information should provide good guidelines for better material used in reducing fire facilities due to smoke inhalation. 
Classification of thermal decomposition products from tested materials in comparison to wood*

\begin{tabular}{|c|c|c|c|c|}
\hline \multirow{2}{*}{$\begin{array}{l}\text { TOXICITY } \\
\text { INDICES } \\
\text { MEASURED AS }\end{array}$} & \multicolumn{4}{|c|}{ CLASSIFICATIONS } \\
\hline & $\begin{array}{l}\text { MUCH MORE } \\
\text { THAN WOOD }\end{array}$ & $\begin{array}{l}\text { MORE } \\
\text { THAN WOOD }\end{array}$ & $\begin{array}{l}\text { SIMILAR } \\
\text { TO WOOD }\end{array}$ & $\begin{array}{l}\text { LESS } \\
\text { THAN WOOD }\end{array}$ \\
\hline $\begin{array}{l}\text { ACUTE } \\
\text { MORTALITY } \\
\left(L_{50}\right)\end{array}$ & $\begin{array}{c}\mathrm{LC}_{50}=0.2-2.0 \mathrm{~g} \\
\text { PTFE }\end{array}$ & $\begin{array}{l}\mathrm{LC}_{50}=2-20 \mathrm{~g} \\
\text { A1 } 1 \text { Materials } \\
\text { except } \\
\text { PTFE and Wood }\end{array}$ & $\begin{array}{l}C_{50}=20-200 \mathrm{~g} \\
\text { Wood }\end{array}$ & $\begin{array}{l}L C_{50}>200 \mathrm{~g} \\
\text { None found }\end{array}$ \\
\hline $\begin{array}{c}\text { PHYSIOLOGICAL } \\
\text { STRESS } \\
\left(\text { SI }_{100}\right)\end{array}$ & $\begin{array}{l}S_{100}=.012-.12 g \\
\text { None Found }\end{array}$ & $\begin{array}{l}\text { SI } 100=.12-1.29 \\
\text { GM } 29, \text { GM } 31, \\
\text { GM 35, GM } 37, \\
\text { GM 41, GM 43, } \\
\text { UF, PVC-A }\end{array}$ & $\begin{array}{l}\text { SI } 100=1.2-12 \mathrm{~g} \\
\text { GM 21, GM 23, } \\
\text { GM 25, GM 27, } \\
\text { GM 47, Wood }\end{array}$ & $\begin{array}{l}\mathrm{SI}_{100}>12 \mathrm{~g} \\
\text { GM } 49\end{array}$ \\
\hline $\begin{array}{l}\text { SENSORY } \\
\text { IRRITATION } \\
\text { (RD50) }\end{array}$ & $\begin{array}{l}R D_{50}=.1-1 \mathrm{mg} \\
\text { None found }\end{array}$ & $\begin{array}{l}\text { RD } 50=1-10 \mathrm{mg} \\
\text { GM 21, GM 23, } \\
\text { GM 25, GM 27 }\end{array}$ & $\begin{array}{l}\mathrm{RD}_{50}=10-100 \mathrm{mg} \\
\text { GM } 31, \mathrm{GM} 35, \\
\text { GM } 37, \mathrm{GM} 47 \\
\text { GM 49, UF, } \\
\text { PTFE, PVC-A }\end{array}$ & $\begin{array}{l}\mathrm{RD}_{50}>100 \mathrm{mg} \\
\text { GM } 29, \text { GM4 } 1 \\
\text { GM } 43, \text { GM } 57\end{array}$ \\
\hline
\end{tabular}

* Wood taken as Douglas Fir. Basis for the classification as given in Anderson, R.C., and Alarie, Y., - Approaches to the Evaluation of the toxicity of decomposition products of polymeric materials under thermal stress. J. Comb, Toxicol. $\underline{5}$, 214-221, 1978. 
Table 2

Classification of materials for acute lethal hazard (ALH)* in comparison to fiberglass, when used for insulation purposes.

\section{CLASSIFICATIONS}

\begin{tabular}{|c|c|c|c|}
\hline $\begin{array}{l}\text { MUCH } \\
\text { MORE THAN } \\
\text { FIBERGLASS }\end{array}$ & $\begin{array}{l}\text { MORE THAN } \\
\text { FIBERGLASS }\end{array}$ & $\begin{array}{l}\text { SIMILAR TO } \\
\text { FIBERGLASS }\end{array}$ & $\begin{array}{l}\text { LESS THAN } \\
\text { FIBERGLASS }\end{array}$ \\
\hline$A L H>240$ & $A L H=24-240$ & $A L H=2.4-24$ & $A L H<2.4$ \\
\hline PTFE & $\begin{array}{l}\text { D. Fir, Cellulose } \\
\text { UF, GM } 25, \text { GM } 35 \text {, } \\
\text { GM } 37, \text { GM } 57\end{array}$ & $\begin{array}{l}\text { GM } 21, \text { GM } 23, \\
\text { GM 27, GM } 29, \\
\text { GM } 31, \text { GM } 41, \\
\text { GM } 43, \text { GM } 47, \\
\text { GM } 49\end{array}$ & None found \\
\hline
\end{tabular}

* Calculated as given in Alarie, Y., and Anderson, R.C., Toxicologic and acute lethal hazard evaluation of thermal decomposition products of synthetic and natural polymers. Toxicol. App1. Pharmacol., Submitted, May 1979 and NBS third quarterly progress report for 1979. 


\section{PUBLICATIONS \\ (since last report)}

Anderson, R.C., and Alarie, Y. - Approaches to the evaluation of the toxicity of decomposition products of polymeric materials under thermal stress, J. Comb. Toxicol. 5, 214-221, 1978.

Anderson, R.C., Dierdorf, J., Stock, M.F., Matijak, M., Sawin, R., and Alarie, Y. - Use of experimental materials to assess the ability of toxicological testing schemes in rating the hazards of polymeric materials under thermal stress. Fire and Materials, 2, 136-140, 1978.

Anderson, R.C., and Alarie, Y. - An attempt to translate toxicity of polymer thermal decomposition products into a toxicological hazard index and discussion of the approaches selected, J. Comb, Toxicol. $\underline{5}$, 476-484, 1978.

Barrow, C.S., Lucia, H., Stock, M.F., and Alarie, Y - Development of methodologies to assess the relative hazards from thermal decomposition products of polymeric materials, Am. Ind. Hyg. Assoc. J., 40, 408-423, 1979.

Barrow, C.S., Lucia, H., and Alarie, Y. - A comparison of the acute inhalation toxicity of hydrogen chloride versus the thermal decomposition products of polyvinylchloride. J. Comb, Toxicol. 6 , 3-12, 1979.

Anderson, R.C., Stock, M.F., Sawin, R., and Alarie, Y. - Toxicity of thermal decomposition products of urea formaldehyde and phenol formaldehyde foams. Toxicol. Appl. Pharmacol., in press.

Alarie, Y. and Anderson, R.C. - Toxicologic and acute lethal hazard evaluation of thermal decomposition products of synthetic and natural polymers. Toxicol. Appl. Pharmacol. - Submitted, May 1979. 
ANNUAL CONFERENCE OF FIRE RESEARCH

CENTER FOR FIRE RESEARCH

NATIONAL BUREAU OF STANDARDS

GAITHERSBURG, MARYLAND

August 22-24, 1979

Institution: Flammability Research Center, University of Utah

Grant No: NBS Grant G8-9012

Grant Title: Indepth Considerations of the Toxicological Effects of Combustion Products

Principal Investigator: Professor J. H. Futrell

Flammability Research Center

University of Utah

391 South Chipeta Way

P. O. Box 8089

Salt Lake City, Utah 84108

Other Professional Personnel: D. G. Farrar, B.Pharm.

F. D. Hileman, Ph.D.

NBS Scientific Officer: Dr. M. M. Birky

$\underline{\text { Technical Abstract }}$

The objectives of the current work fall into three basic research areas. These are:

a) the study of certain practical aspects of the proposed NBS combustion toxicity test method;

b) the study of the potential contribution of sensory irritants to incapacitation; and

c) the study of the contribution of the particulate phase of combustion product atmospheres to observed toxicity in the rat.

a) NBS Protocol

1) the effect of chamber configuration on combustion product distribution

Differences in the toxicological potency of combustion product atmospheres have been identified with certain materials when tested using similar protocols. The two protocols included the same furnace and the same toxicological endpoints, but employed exposure chambers of differing volume and configuration. Experiments are underway to 
determine whether these differences were due to variations in product distribution within the chambers.

The vertical distribution of both $\mathrm{CO}_{2}$ and $\mathrm{HCl}$ in the 200-1iter chamber has been examined by various laboratories. These studies showed minimal stratification within the chamber. These observations have been extended to include the horizontal distribution with time of selected components of the combustion product atmosphere from nonflaming Douglas fir (molecular weights of methane $\rightarrow$ acetaldehyde). The conclusion from the initial study was that the product distribution in the 200-1iter "NBS" rectangular chamber was good, especially in relation to low molecular weight compounds (b.pt. $<30^{\circ} \mathrm{C}$ ). The early distribution of higher molecular weight compounds (e.g., acrolein) tended to show greater runto-run variability. However, the products were not consistently higher or lower at any given position within the chamber. Thus the problem may not be one of mixing, but of the reproducible combustion of materials in the test furnace.

2) the effect of the variation of the intensity of the electrical stimulus on the sensitivity of the leg-flexion avoidance response to combustion products

Differences in the sensitivity of the leg-flexion avoidance response to certain combustion product atmospheres have been reported from different laboratories using the paradigm in similar protocols. The possibility that these differences may be due to variations in the practical use of the paradigm is being studied. The most variable aspect of the use of the response may lie in the degree of incentive (electrical shock) used to train rats to perform the response. In practice in our laboratory, this is controlled by the voltage output from the stimulus source. The degree of shock received by the animal is more a function of the current applied between the stimulating electrodes. Measurements in-house have shown that the routine intensity of the shock employed is between 3.5 to $8.5 \mathrm{mV}$.

Using this shock intensity, it has been shown that the leg-flexion response is sensitive to the sensory irritant component of certain combustion product atmospheres. Further experiments are planned to determine the relationship between the shock intensity and the sensitivity of the model to experimental atmospheres of acrolein and the nonflaming combustion products of Douglas fir. It is anticipated that the study will provide adequate data to allow a more precise definition of the conditions required to train rats to perform this response. Hopefully, this will lead to improved repeatability between laboratories in the use of this endpoint in the determination of the incapacitating effects of combustion products.

\section{3) materials evaluation}

As the "NBS" protocol approaches the status of inter-laboratory review, the role of "trouble-shooting" becomes imperative. Problems with any given.system will only come to light when the protocol is stretched to the limits of its proposed application by a variety of laboratories. In an attempt to preempt some of these problems, the 
laboratory has continued to expand the range of types (both physical and chemical) of material tested for combustion toxicity. Currently under consideration are PTFE resin, wool fiber and modacrylic fabric.

Differences in potency obtained with PTFE (Table 1), when compared to comparable data from NBS, have highlighted a potential problem with the protocol, i.e., the determination of the autoignition point. The autoignition point determined at FRC was $700^{\circ} \mathrm{C}$, whereas that at NBS was

Table 1

Inter-1aboratory Comparison of Combustion Toxicity Data Obtained for PTFE Using the "NBS" Protocol

Nonflaming

Flaming

Utah Data

Temperature ${ }^{\circ} \mathrm{C}$

\begin{tabular}{llll}
\multicolumn{2}{c}{680} & \multicolumn{2}{c}{720} \\
$0.53^{620}$ & 0.12 & $0.37^{2}$ & 0.01 \\
0.25 & 0.05 & 0.21 & 0.05
\end{tabular}

$\mathrm{EC}_{50}\left(\mathrm{gm} / \mathrm{m}^{3}\right)$

LC50 $\left(\mathrm{gm} / \mathrm{m}^{3}\right)$

0.250 .05

0.21

0.05

NBS Data

Temperature ${ }^{\circ} \mathrm{C}$

EC50 $\left(\mathrm{gm} / \mathrm{m}^{3}\right)$

$\mathrm{LC}_{50}\left(\mathrm{gm} / \mathrm{m}^{3}\right)$

0.004

0.004

$620^{\circ} \mathrm{C}$. This resulted in the fact that the experiments with PTFE were conducted at the two institutions at different temperatures. Additional preliminary experiments with PTFE using the same furnace have shown that the potency of its combustion products is highly dependent on the temperature of combustion used, and that small differences in temperature (of the order of $25-50^{\circ} \mathrm{C}$ ) may lead to large differences in potency. Therefore, the criteria by which the autoignition temperature is determined becomes a highly significant component in materials evaluation using this system. This problem needs to be resolved.

\section{b) Sensory Irritants as Incapacitating Agents}

In the context of combustion toxicology, a model of incapacitation should detect those combustion products likely to delay the egress of man from a fire scenario. The exact role of sensory frritants in this context is unclear, but it is acknowledged that those irritants having profound effects in the eye could be classified as incapacitating agents. A current animal model showing extreme sensitivity to sensory irritants (reduction in the respiratory rate of the mouse) may not rationally discriminate between irritants that have profound effects in the eye and others that have less profound effects. A second animal model that may be sensitive to the effects of sensory irritants (i.e., leg-flexion response) may also show the same lack of discrimination.

To explore this possibility, the effects of four sensory irritants of relevance to combustion atmospheres (acrolein, acetaldehyde, formaldehyde and hydrogen chloride) on a range of endpoints in the rat will be 
studied. The endpoints selected include objective and subjective measurements of eye irritation, leg-flexion response, acute changes in lung function, post-exposure changes in lung function, pulmonary edema and 14-day mortality. The relative sensitivities of these endpoints to the different irritants may lead to a more complete understanding of the role of sensory irritants as incapacitating agents.

\section{c) Contribution of Particulates to Combustion Product Toxicities}

The particulate phase of combustion product atmospheres has two potential functions of toxicological significance. Firstly, the particles may in themselves have intrinsic toxicity. Secondly, they may act as carriers of absorped toxicants that are normally found in the gas phase of combustion atmospheres. Toxicological observations have been made recently with the combustion products of certain materials that may be related to the particulate component of the atmosphere. Generally the involvement is observed during the post-exposure period and is manifested as profound and prolonged losses in body weight, significant post-exposure mortality and the occurrence of inflammatory lung lesions in surviving rats. One such material to cause these effects is GM-21 (a flexible polyurethane foam).

An empirical experiment will be conducted to determine the role of the particulate component of this atmosphere in causing these responses. In this experiment, the particles will be filtered out of the atmosphere, whilst maintaining the levels of the individual components of the gas phase. The effect of this modification of the atmosphere on the resulting toxicological profile will be established. If a caúsal relationship can be established between the particulate and the responses it is anticipated that the study will be expanded to consider the overall contribution of the particulate entity involved.

Reports and Publications

Farrar, D.G., "The effect of the sensory irritant component of a combustion atmosphere derived from Douglas fir on the leg-flexion avoidance response of the rat," Proc. IVth Int. Conf. on Fire Safety, San Francisco, January 1979, pp. 139-141 (to be published in J. Comb. Tox.).

Farrar, D.G. and Galster, W.A., "Biological endpoints for the assessment of the toxicity of products of combustion of materials," Proc. Interflam '79, Guildford, U.K., March 1979, pp. 63-65 (to be published in Fire and Materials).

Farrar, D.G., Blank, T.L. and Galster W.A., "Toxicity of the combustion products of a phenolic foam and a urea-formaldehyde foam," presented at VIIth Int. Congress of Pharmacology, Paris France, 1978.

Farrar, D.G., Galster, W.A. and Hughes, B.M., "Toxicological evaluation of material combustion products," Final Report to National Bureau of Standards, 1979. 

NBS-114A (REV. 0-78)

U.S. DEPT. OF COMM.

BIBLIOGRAPHIC DATA SHEET

1. PUBLICATION OR REPORT NO.

NBSIR 79-1916

4. TITLE AND SUBTITLE

Third Annual Conference on Fire Research

7. $A U T H O R(S)$

Ileana M. Martinez, Editor

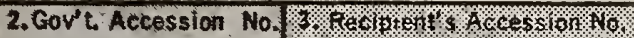

5. Publication Date

October 1979

9. PERFORMING ORGANIZATION NAME AND ADDRESS

10. Project/Task/Work Unit No.

NATIONAL BUREAU OF STANDARDS

DEPARTMENT OF COMMERCE

11. Contract/Grant No.

WASHINGTON, DC 20234

12. SPONSORING ORGANIZATION NAME AND COMPLETE ADDRESS (Street, City, State, ZIP)

13. Type of Report \& Period Covered same as No. 9

Final Report

14. Sponsoring Agency Code

15. SUPPLEMENTARY NOTES

none

$\square$ Document describes a computer program; SF-185, FIPS Software Summary, is attached.

16. ABSTRACT (A 200-word or less factual summary of most sigrificant information. If document includes a significant bibliography or literature survey, mention it here.)

This report contains extended abstracts of grants and contracts for fire research sponsored by the Center for Fire Research, National Bureau of Standards, as well as descriptions of the internal programs of the Center for Fire Research.

17. KEY WORDS (six to twelve entries; alphabetical order; capitalize only the first letter of the first key word unless a proper name; separated by semicolons)

Chemistry of fire; combustion products; fire hazards; fire modeling; fire research; human behavior in fires; physics of fire; toxicity of combustion products.

18. AVAILABILITY [x] Unlimited

For Official Distribution. Do Ilot Release to NTIS

Order From Sup. of Doc., U.S. Government Printing Office, Washington, DC 20402, SD Stock No. SNO03-003-

$\sqrt{\mathrm{Kx}}$ Order From National Technical Information Service (NTIS), Springfield, VA. 22161

\begin{tabular}{|l|c|}
\hline $\begin{array}{l}\text { 19. SECURITY CLASS } \\
\text { (THIS REPORT) }\end{array}$ & $\begin{array}{c}\text { 21. NO. OF } \\
\text { PRINTED PAGES } \\
\text { UNCLASSIFIED }\end{array}$ \\
\hline $\begin{array}{l}\text { 20. SECURITY CLASS } \\
\text { (THIS PAGE) }\end{array}$ & 22. Price \\
UNCLASSIFIED & $\$ 9.00$ \\
\hline
\end{tabular}

USCOMM-DC 






